Universidad de Lima

Facultad de Ciencia Empresariales y Económicas

Carrera de Negocios Internacionales

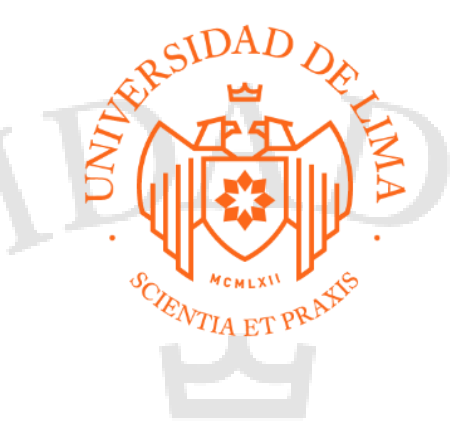

\title{
PLAN COMERCIAL DE EXPORTACIÓN DE VINO NO ALCOHÓLICO DE FRUTAS EXÓTICAS AL MERCADO DE ALEMANIA
}

Trabajo de suficiencia profesional para optar el Título Profesional de Licenciado en

Negocios Internacionales

\section{Paul Juniors Rios Meza}

Código 20082472

Asesor

Arturo Alberto Zevallos Pérez

Lima - Perú

Abril del 2019 


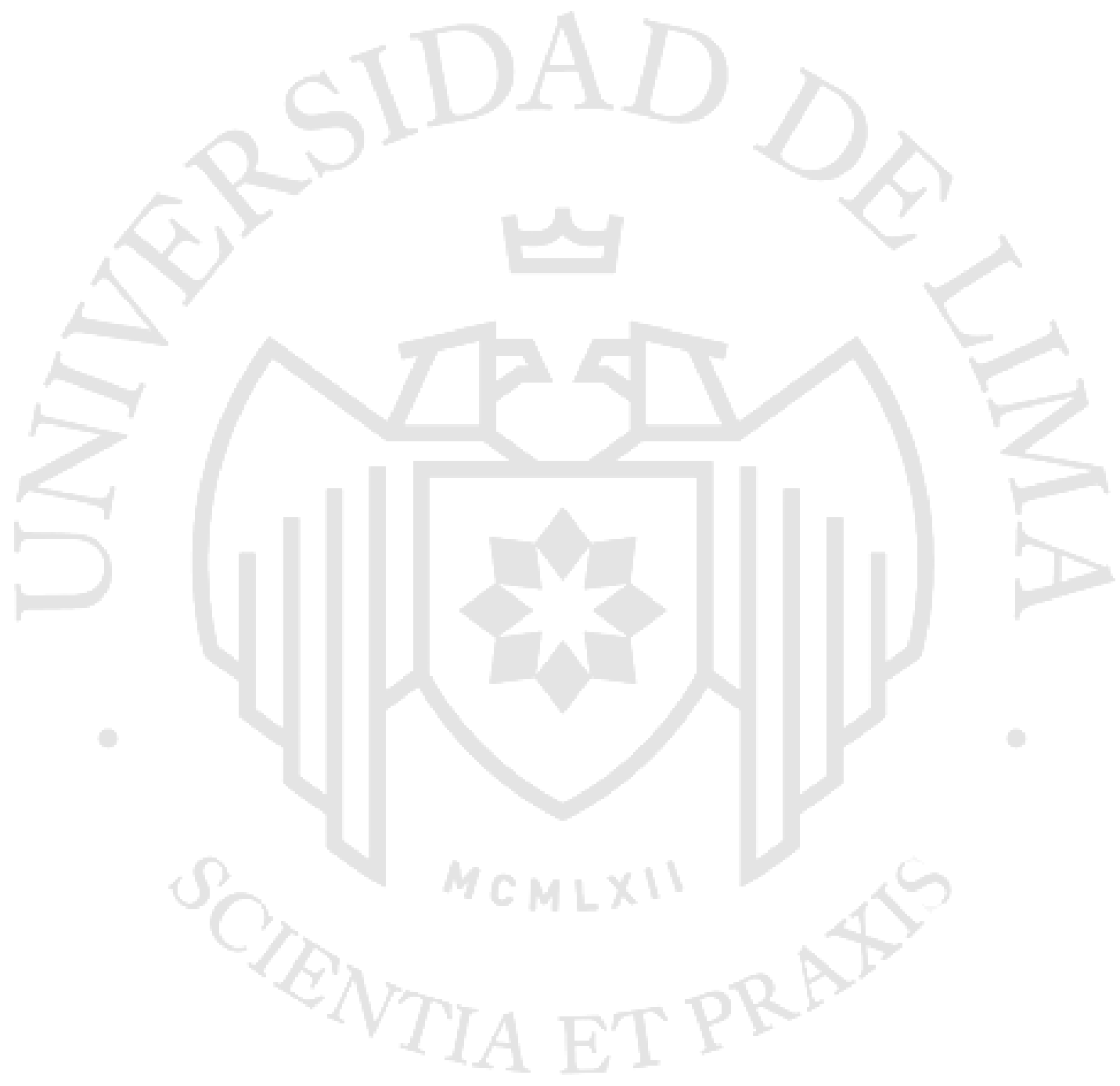




\section{PLAN COMERCIAL DE EXPORTACIÓN DE VINO NO ALCOHÓLICO DE FRUTAS EXÓTICAS AL MERCADO DE ALEMANIA}




\section{TABLA DE CONTENIDO}

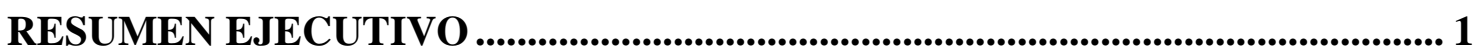

CAPÍTULO I: ASPECTOS GENERALES DEL PROYECTO................................ 3

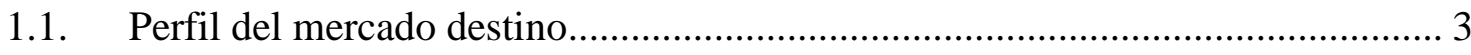

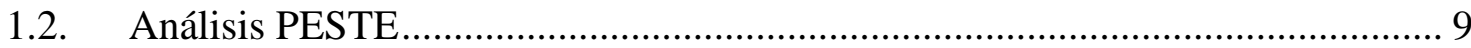

1.2.1. Análisis Político, Gubernamental y Legal ...................................................... 9

1.2.2. Análisis Económico y Financiero ........................................................................... 10

1.2.3. Análisis Social, Cultural y Demográfico ...................................................... 11

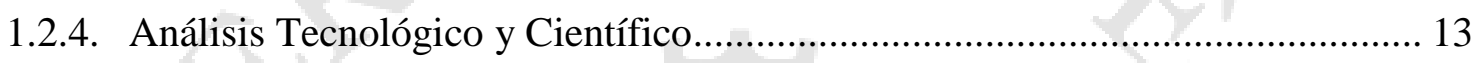

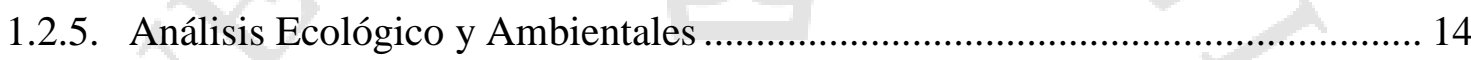

1.3. Comportamiento del Consumidor / Comprador........................................... 15

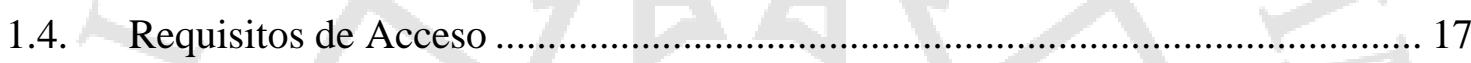

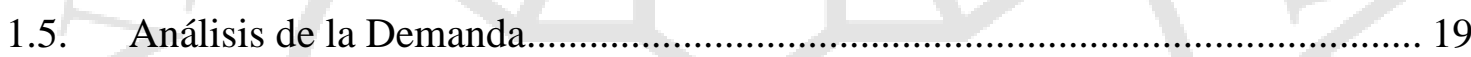

1.5.1. Distribución geográfica del mercado consumo............................................. 20

1.5.2. Proyección de la demanda internacional....................................................... 24

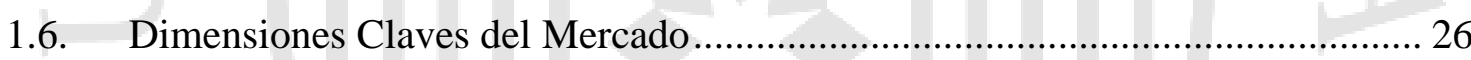

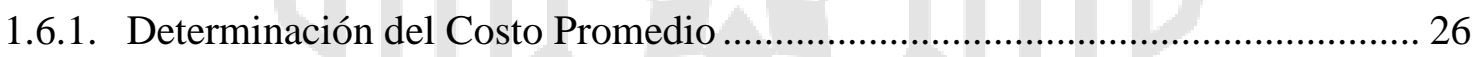

1.6.2. Canales de comercialización y distribución del producto.................................. 27

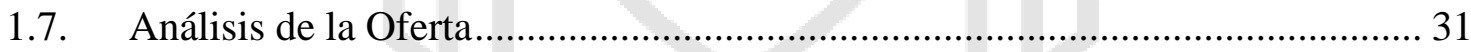

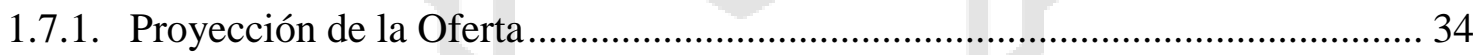

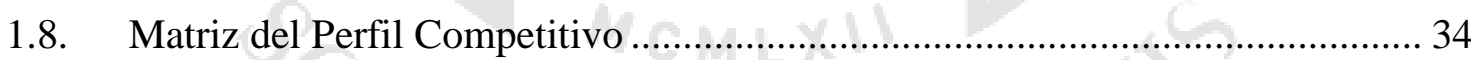

\section{CAPÍTULO II: PLAN DE MARKETING Y COMERCIALIZACIÓN}

INTERNACIONAL ............................................................................................... 36

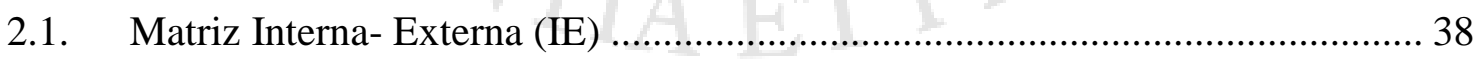

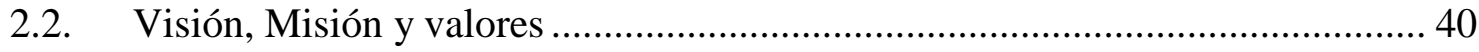

2.3. Objetivos específicos - Generales del Plan de Marketing ................................. 41

2.4. Mercado Potencial y Objetivo........................................................................ 42

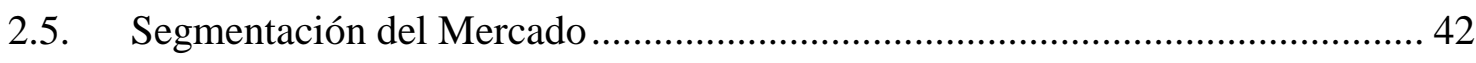

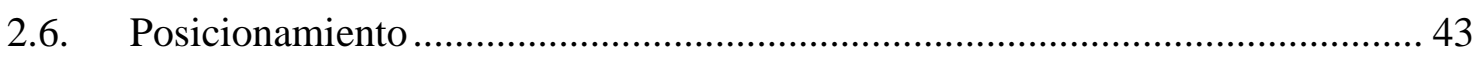

2.7. Estrategias comerciales de entrada al mercado........................................... 43

2.8. Estrategias de producto, plaza, precio y promoción internacional .................... 44 


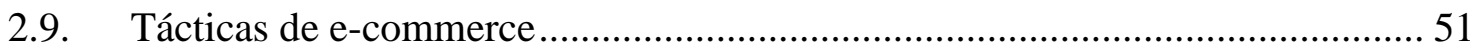

2.10. Balance del plan de Marketing y Comercialización Internacional .....................52

2.11. Factores críticos de éxito de la planificación comercial y de marketing

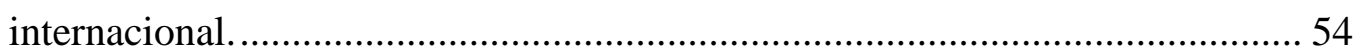

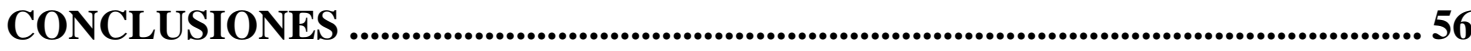

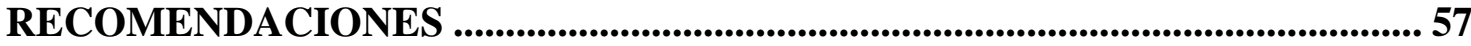

REFERENCIAS ............................................................................................................................... 58

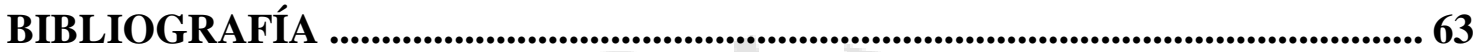

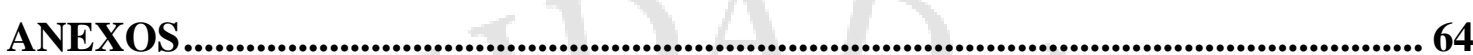




\section{ÍNDICE DE TABLAS}

Tabla 1.1 Factores de evaluación para la selección del mercado ................................ 5

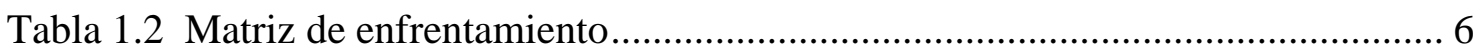

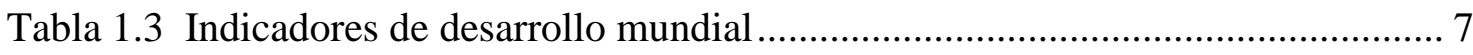

Tabla 1.4 Ranking de factores para selección del mercado destino .............................. 8

Tabla 1.5 Indicadores macroeconómicos de crecimiento de Alemania........................ 11

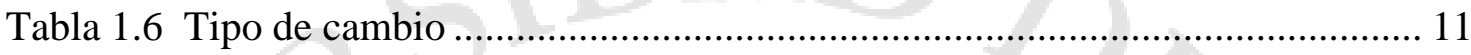

Tabla 1.7 Población áreas metropolitanas de Alemania .............................................. 12

Tabla 1.8 Certificaciones de entrada al mercado alemán ......................................... 18

Tabla 1.9 Principales puertos y aeropuertos de Alemania......................................... 19

Tabla 1.10 Volumen de países importadores de bebidas no alcohólicas (Valores)...... 19

Tabla 1.11 Volumen de países importadores de vino (Valores) ................................. 20

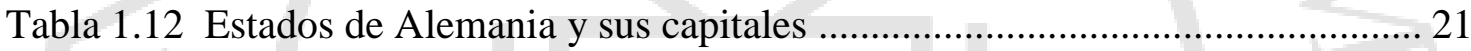

Tabla 1.13 Población segmentada de Alemania …...................................................... 25

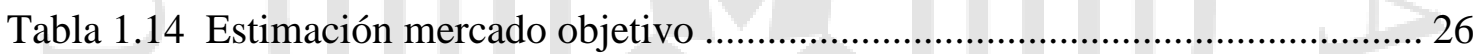

Tabla 1.15 Determinación del precio promedio al consumidor final ......................... 26

Tabla 1.16 Evolución de precios estimados del vino premium en Alemania (Millones -

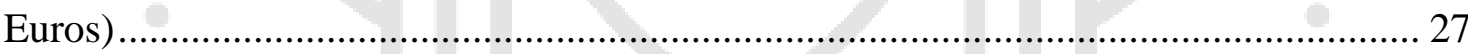

Tabla 1.17 Tiendas de descuento \& tiendas especializadas en Berlín, Alemania ........ 28

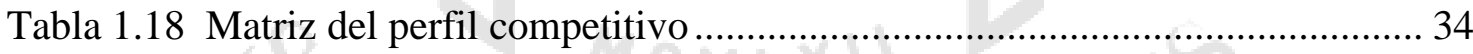

Tabla 2.1 Matriz de Fortalezas, Oportunidades, Debilidades y Amenazas (DAFO).... 37

Tabla 2.2 Matriz de Evaluación de Factores Externos (EFE)....................................... 38

Tabla 2.3 Matriz de Evaluación de Factores Internos (EFI) ....................................... 39

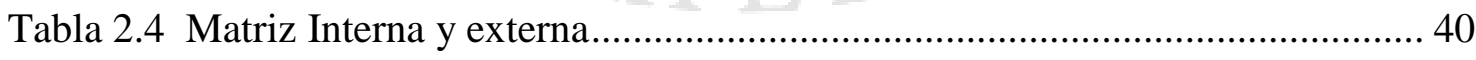

Tabla 2.5 Balance Plan Anual de Marketing ............................................................. 52

Tabla 2.6 Cronograma de la Planificación.................................................................... 54 


\section{ÍNDICE DE FIGURAS}

Figura 1.1 Principales países importadores de bebidas no alcohólicas en el mundo

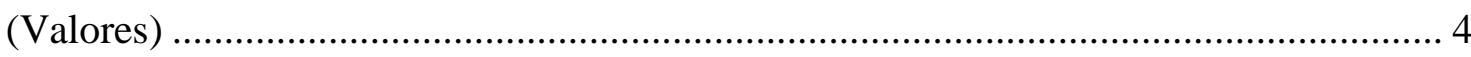

Figura 1.2 Principales países importadores de vinos en el mundo (Valores) .................. 4

Figura 1.3 Distribución por edades de la población en Alemania ................................ 13

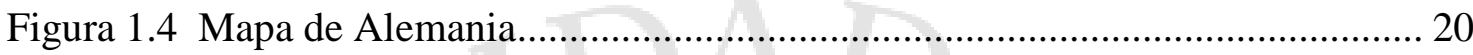

Figura 1.5 Evolución de importación de bebidas no alcohólicas en Alemania (Valores)

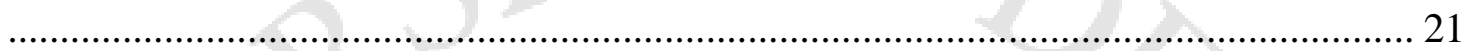

Figura 1.6 Volumen de ventas de bebidas no alcohólicas en Alemania (Valores)....... 22

Figura 1.7 Principales países importadores de Uva (Valores) .................................... 22

Figura 1.8 Principales países importadores de productos frescos y cítricos (Valores). 23

Figura 1.9 Principales países exportadores de vino a Alemania (Valores) .................. 23

Figura 1.10 Principales países Importadores de vino exportado por Perú.................... 24

Figura 1.11 Comercio Bilateral de vinos entre Perú y Alemania ................................. 24

Figura 1.12 Canales de vinos premium Off Trade - On Trade en Alemania................ 28

Figura 1.13 Empresas que comercializan Vinos Premium en Alemania...................... 29

Figura 1.14 Marcas que comercializan Vinos Premium en Alemania ......................... 29

Figura 1.15 Vino Tinto no alcohólico WIN ............................................................ 30

Figura 1.16 Vino No Alcohólico INVICTO …............................................................. 30

Figura 1.17 Productos alternativos de mayor consumo en Alemania........................... 31

Figura 1.18 Principales países exportadores de bebidas no alcohólicas en el Mundo (Valores)

Figura 1.19 Principales países exportadores de bebidas no alcohólicas por Alemania

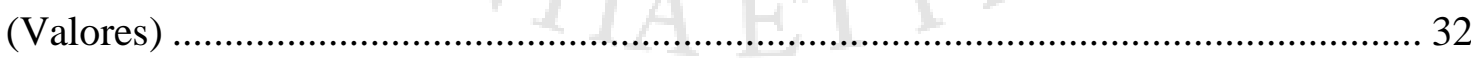

Figura 1.20 Principales países exportadores de vinos en el Mundo (Valores) ............. 33

Figura 1.21 Principales países exportadores de vinos importado por Alemania

(Valores) 33

Figura 1.22 Proyección de ventas de vinos Premium Alemania (Valores) ................... 34

Figura 2.1 Vino a base de frutos peruanos Elaboración propia .................................... 45

Figura 2.2 Logo y Slogan de la Marca en español Elaboración propia ........................ 46

Figura 2.3 Logo y Slogan de la Marca en inglés Elaboración propia............................ 46 
Figura 2.4 Logo y Slogan de la Marca en alemán Elaboración propia.......................... 47

Figura 2.5 Etiqueta Vino no alcohólico de Uvas ........................................................... 48

Figura 2.6 Etiqueta Vino no alcohólico de Camu Camu Elaboración propia............... 49

Figura 2.7 Etiqueta Vino no alcohólico de Aguaymanto Elaboración propia.............. 49

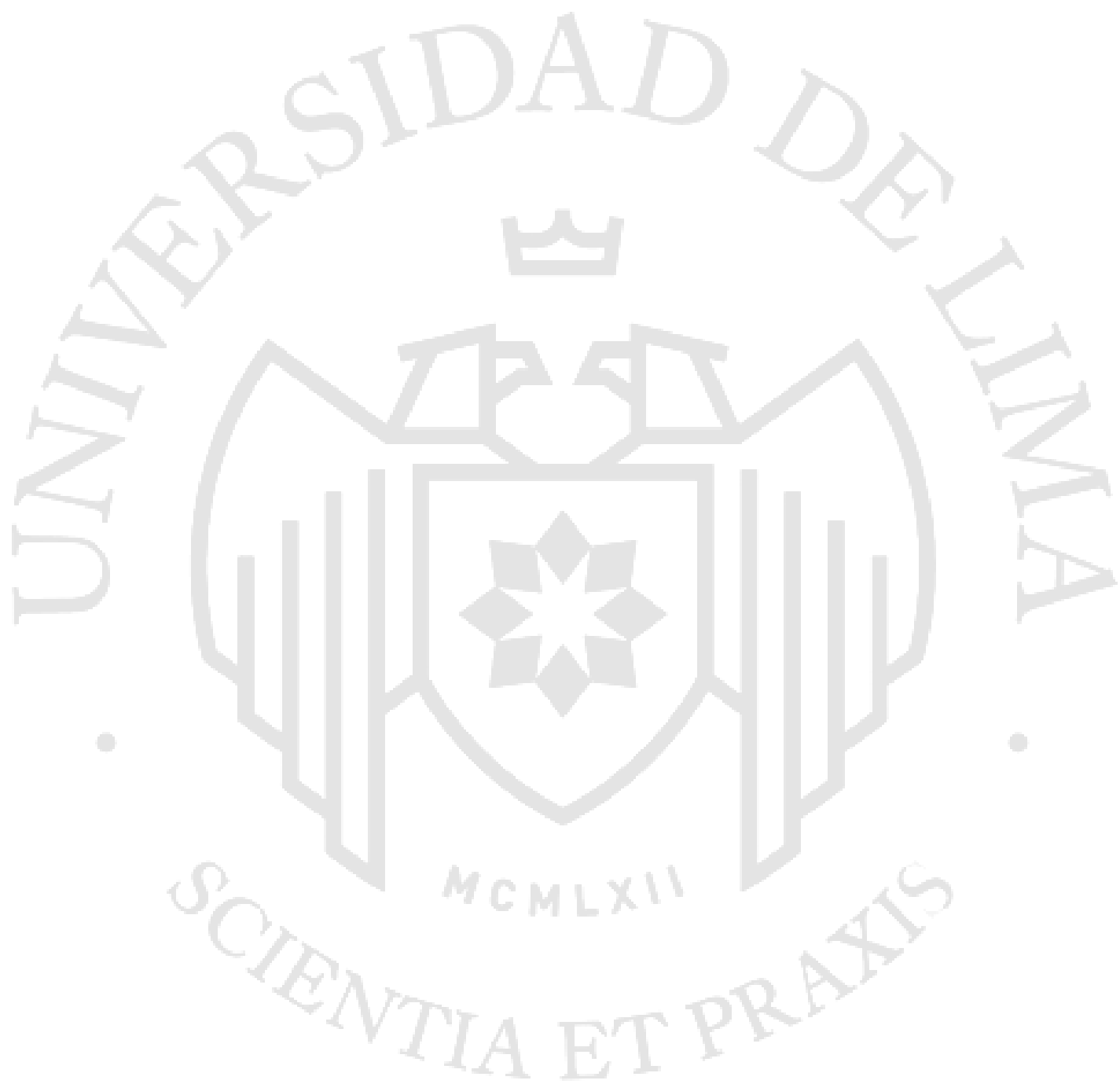




\section{ÍNDICE DE ANEXOS}

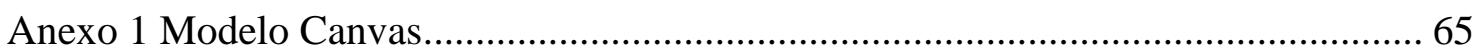

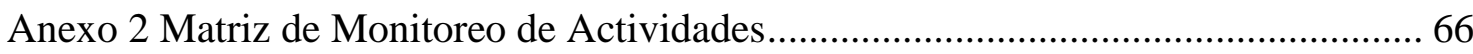

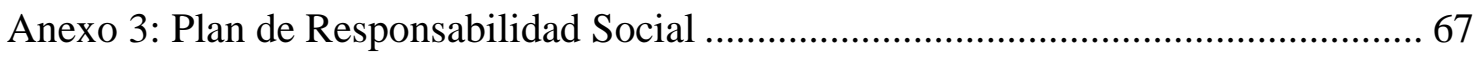

Anexo 4: Canales de Distribución de Vinos en Alemania................................................. 68

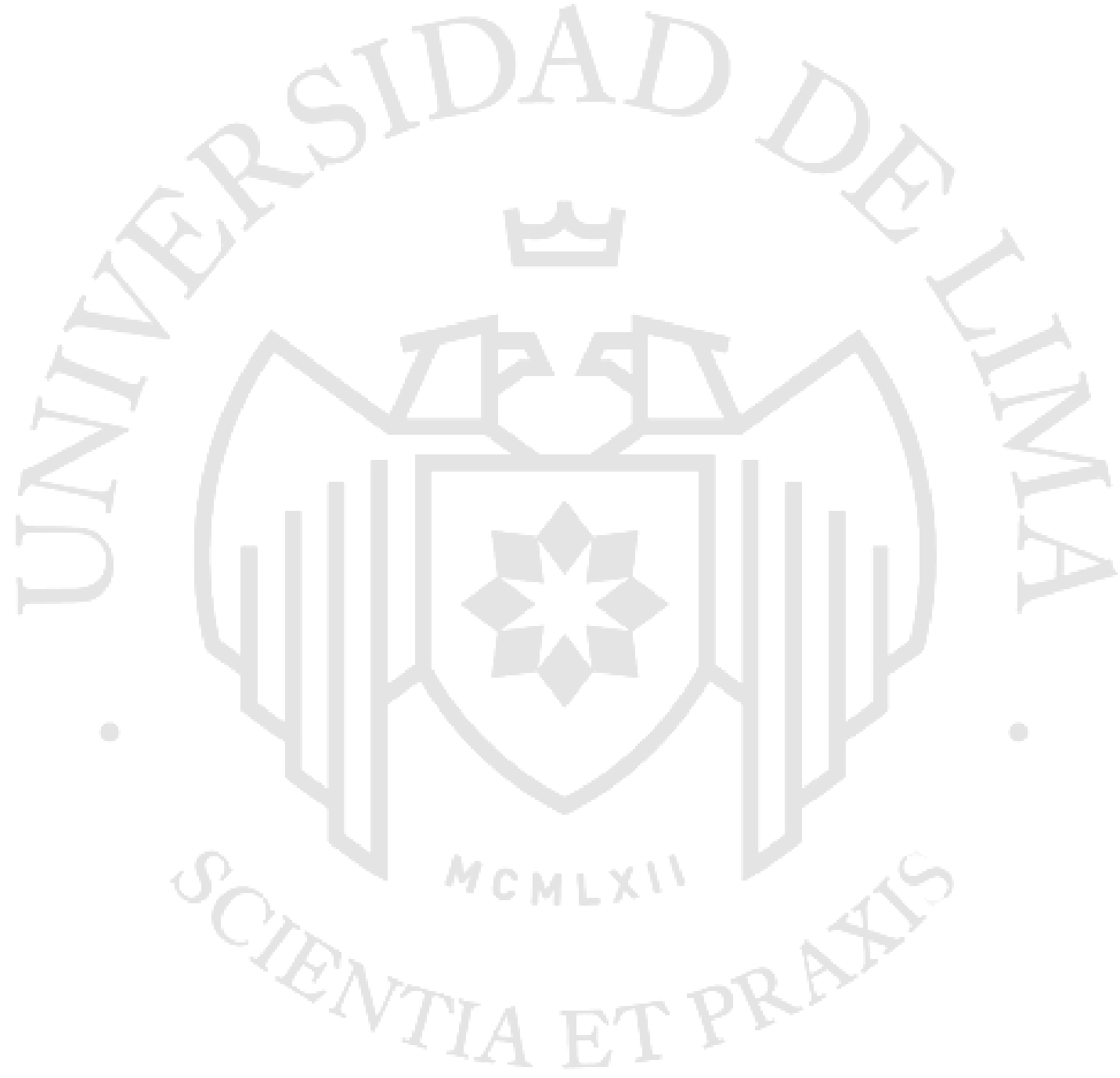




\section{RESUMEN EJECUTIVO}

El proyecto de investigación consiste en la elaboración de un plan comercial enfocado en una marca de vino no alcohólico con atributos benéficos para la salud, que sea sofisticada sin cambiar hábitos de consumo, pueda atender y desarrollar un mercado incipiente, identificado durante el presente documento, con mucho potencial en los próximos años. Los vinos no alcohólicos representan un buen producto para un público objetivo que busca alternativas de consumo sano, de agradable y diversificado sabor.

La creciente demanda de nuevos sabores de vinos y el surgimiento de nuevas tendencias globales enfocadas en el consumo responsable y saludable, así como la preferencia por las frutas cítricas procedentes del Perú identifican una oportunidad de negocio para la exportación de vinos desde otra y variada presentación; es decir, sin hacer uso de conservantes y libres de alcohol centrándose en un vino natural, de alta calidad y responsable con el medio ambiente.

La ventaja comparativa se centra en la diversificación de insumos durante la elaboración de los vinos; la uva, el camu camu y el aguaymanto, frutos peruanos de gran reconocimiento a nivel mundial. Así mismo, la creación de una marca propia es muestra de un valor agregado que se diferencia de la competencia.

El mercado elegido para la distribución del vino es Alemania, uno de los principales importadores de vino a nivel mundial, además de contar con una facilidad de hacer negocios y aspecto logístico, líder dentro del comercio internacional, por lo que se considera como el destino de mayor eficiencia y eficacia para la venta y comercialización de los vinos no alcohólicos. En adición a esta información, se encuentran beneficios arancelarios debido al tratado de libre comercio que el Perú firmó con la Unión Europea (Ministerio de Comercio Exterior y Turismo, 2013), ofrecen a la empresa una oportunidad de inserción al mercado alemán con el innovador producto.

Dentro de Alemania, se consideró dirigirse a la capital Berlín, el cual es una de las ciudades con más población urbana y con un mejor poder adquisitivo. La estrategia de entrada del mercado en mención será la estrategia "push” y la de posicionamiento, este último por ventaja diferencial en comparación a sus competidores. 
Así mismo, se ha determinado al segmento del mercado objetivo constituido por jóvenes adultos entre 30 y 54 años de nivel socio - económico alto, consumidores de vino. "VINKA", el nombre de la marca, se comercializará principalmente en los canales "off - trade" como tiendas especializadas y tiendas de descuento; además de ello, y como objetivo a largo plazo se distribuirá en los canales distinguidos de "on - trade" como hoteles y restaurantes con la finalidad de captar en mayor medida la lealtad de los consumidores finales.

Por otro lado, el producto cumplirá con los elevados estándares de calidad y trazabilidad. Los atributos intrínsecos únicos como el aroma, color y el buen sabor le otorgan una imagen de exclusividad, y la obtención de certificaciones de calidad como el de las buenas prácticas de manufactura (BPM) y el análisis de peligros y puntos críticos de control (HACCP), respaldarán a los productos finales por su elaboración y ética empresarial. También se va a trabajar de la mano con las comunidades y asociaciones productoras quienes proveerán de la materia prima para la elaboración de los vinos.

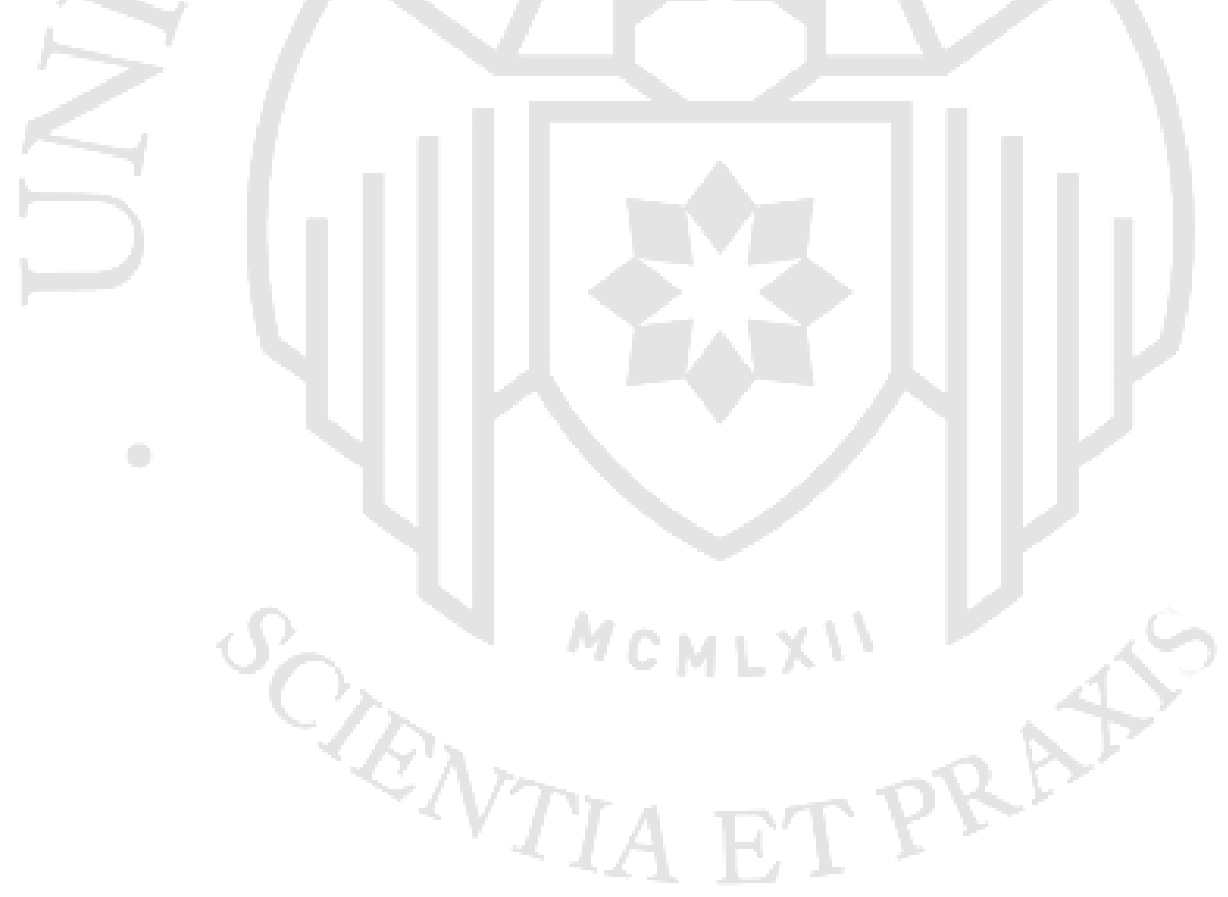




\section{CAPÍTULO I: ASPECTOS GENERALES DEL PROYECTO}

\subsection{Perfil del mercado destino}

En los últimos años, la globalización ha generado impactos positivos para el comercio internacional, nacen oportunidades de intercambio de bienes y servicios que satisfacen exigentes necesidades a nivel mundial.

Así mismo, existe una creciente preocupación por el cuidado de la salud, y el consumo de productos naturales que contribuyan al bienestar de cada persona, hábitos de consumo saludable que se ha desarrollado de manera creciente hoy en día.

Al respecto, Danty et. al. (2018) las economías más desarrolladas en el mundo han incrementado el consumo de productos saludables y naturales, aunque incurran a veces en mayor gasto por ellos (p. 2).

El principal propósito de la internacionalización de la marca Vinka, es dirigirse y posicionarse en un mercado atractivo y de mucho potencial que le brinde oportunidades comerciales a corto, mediano y largo plazo; el vino desarrolla una presentación diferente a los vinos convencionales, dicha presentación es como bebida no alcohólica que tendrá valor agregado de la marca propia y la diversificación del producto además de ser competitivo y con la capacidad de atender a las exigentes tendencias globales en los próximos años (Euromonitor International, 2018).

Leandro Arnaldo Araya (2009), atendiendo el significado de internacionalización, define tal concepto como:

La internacionalización, proceso por el cual una empresa participa de la realidad de la globalización; es decir, la forma en que proyecta sus actividades, total o parcialmente, a un entorno internacional y genera flujos de diversos tipos (comerciales, financieros y de conocimiento) entre distintos países. (p. 18)

El perfil del mercado destino que se espera atender deberá cumplir con ciertas expectativas a considerar al momento de la elección, entre los principales se encuentran el alto poder adquisitivo del público objetivo, los niveles de importación del producto, la 
facilidad de hacer negocios, entre otros, ya que el producto a internacionalizar está presentado como "Premium".

De acuerdo a Trade Map (2018), los 5 principales países importadores de bebidas no alcohólicas, de mayor a menor en lo que respecta al volumen, son: Estados Unidos de América, Canadá, Reino Unido, Alemania y China. Cabe señalar que, al mencionar bebidas no alcohólicas incluye agua embotellada, jugos, café, té, cerveza sin alcohol, y también se introduciría el vino no alcohólico. Los 5 países representan más del $25 \%$ del volumen de las importaciones totales. Alemania se encuentra en la cuarta posición y representa el $6.60 \%$ de las importaciones mundiales de bebidas no alcohólicas.

Figura 1.1

Principales países importadores de bebidas no alcohólicas en el mundo (Valores)

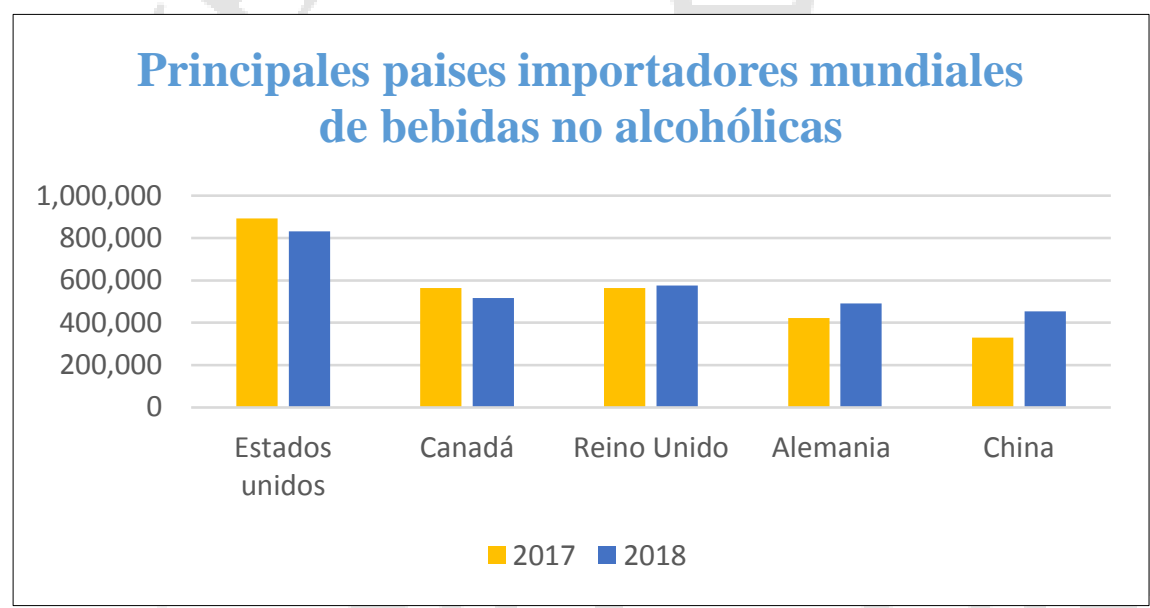

Fuente: Trade Map (2018)

Figura 1.2

Principales países importadores de vinos en el mundo (Valores)

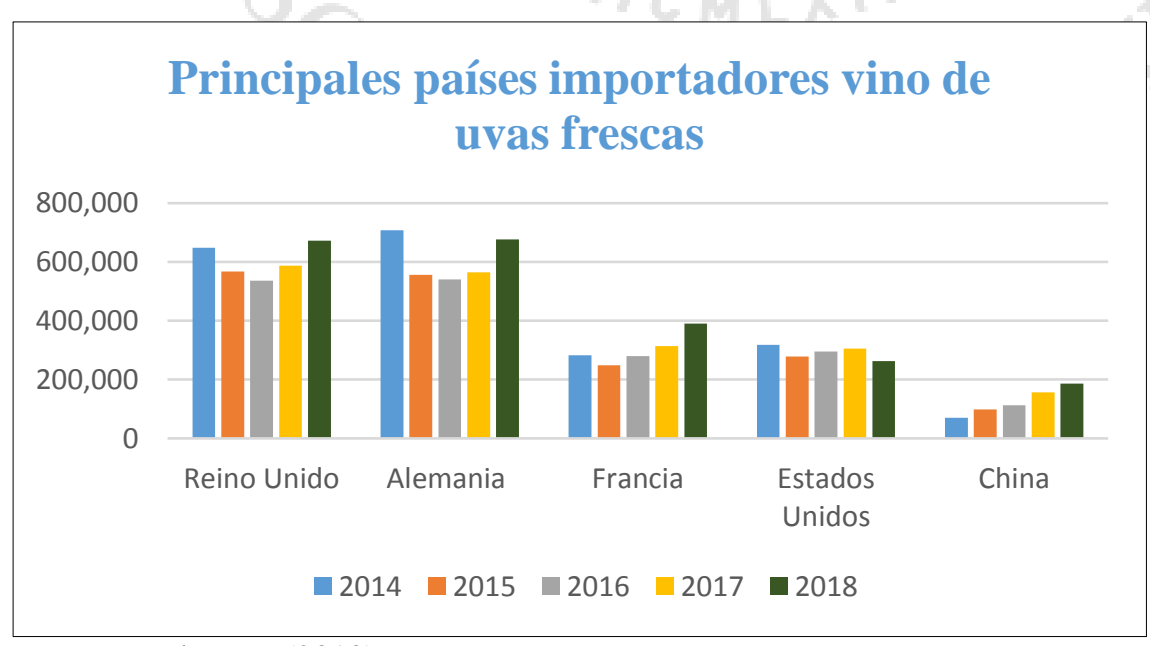

Fuente: Trade Map (2018) 
Por otro lado, los 5 principales países importadores de vinos a nivel mundial, de mayor a menor en lo que respecta el volumen, son: Reino Unido, Alemania, Francia, Estados Unidos de América y China que representan más del $50 \%$ del volumen de las importaciones totales siendo destacados Reino Unido y Alemania, ocupando el primer y segundo lugar respectivamente. Alemania obtuvo un crecimiento del 7\% entre el $2017 \mathrm{y}$ 2018 .

Para proceder con la elección del mercado destino se ha considerado factores indispensables que ayudarán a realizar un estudio para conocer la situación actual de la economía a la cual se quiere internacionalizar. Dichos factores de evaluación fueron obtenidos de los datos del Banco Mundial (2018). Por ello, se identificaron 8 factores para la elección, los cuales están detallados en la siguiente tabla.

Tabla 1.1

Factores de evaluación para la selección del mercado

\begin{tabular}{c|l}
\hline Código & \multicolumn{1}{|c}{ Factor } \\
\hline F1 & Índice de facilidad de hacer negocio (1= reglamentaciones más favorables para los negocios) \\
F2 & Crecimiento del PBI per Cápita (\% Anual) \\
F3 & Índice Desempeño Logístico: facilidad para coordinar embarques a precios competitivos \\
F4 & Costo para Importar (US\$ por Contenedor) \\
F5 & Tiempo de Importación (Días) \\
F6 & Consumo de alcohol Total per cápita (Litros de alcohol puro, mayores de 15 años) \\
F7 & Precios Actuales - Importación bienes y servicios \\
F8 & Índice Volumen Importaciones (2000=100) \\
\hline Fuente: Banco Mundial (2018)
\end{tabular}
Fuente: Banco Mundial (2018)

Una vez elegidos e identificados, se elabora la matriz de enfrentamientos que se muestra a continuación. 
Tabla 1.2

Matriz de enfrentamiento

\begin{tabular}{|c|c|c|c|c|c|c|c|c|c|c|}
\hline Factor & F1 & F2 & F3 & F4 & F5 & F6 & F7 & F8 & Conteo & $\begin{array}{c}\text { Ponderación } \\
\text { (Peso) }\end{array}$ \\
\hline F1 & & $\mathbf{0}$ & $\mathbf{0}$ & $\mathbf{1}$ & $\mathbf{0}$ & $\mathbf{0}$ & $\mathbf{1}$ & $\mathbf{0}$ & $\mathbf{2}$ & $\mathbf{7 \%}$ \\
\hline F2 & $\mathbf{1}$ & & $\mathbf{1}$ & $\mathbf{1}$ & $\mathbf{0}$ & $\mathbf{1}$ & $\mathbf{0}$ & $\mathbf{0}$ & $\mathbf{4}$ & $\mathbf{1 4 \%}$ \\
\hline F3 & $\mathbf{1}$ & $\mathbf{0}$ & & $\mathbf{1}$ & $\mathbf{1}$ & $\mathbf{0}$ & $\mathbf{0}$ & $\mathbf{1}$ & $\mathbf{4}$ & $\mathbf{1 4 \%}$ \\
\hline F4 & $\mathbf{0}$ & $\mathbf{0}$ & $\mathbf{0}$ & & $\mathbf{0}$ & $\mathbf{0}$ & $\mathbf{1}$ & $\mathbf{0}$ & $\mathbf{1}$ & $\mathbf{4 \%}$ \\
\hline F5 & $\mathbf{1}$ & $\mathbf{1}$ & $\mathbf{0}$ & $\mathbf{1}$ & & $\mathbf{0}$ & $\mathbf{1}$ & $\mathbf{0}$ & $\mathbf{4}$ & $\mathbf{1 4 \%}$ \\
\hline F6 & $\mathbf{1}$ & $\mathbf{0}$ & $\mathbf{1}$ & $\mathbf{1}$ & $\mathbf{1}$ & & $\mathbf{1}$ & $\mathbf{0}$ & $\mathbf{5}$ & $\mathbf{1 8 \%}$ \\
\hline F7 & $\mathbf{0}$ & $\mathbf{1}$ & $\mathbf{1}$ & $\mathbf{0}$ & $\mathbf{0}$ & $\mathbf{0}$ & & $\mathbf{0}$ & $\mathbf{2}$ & $\mathbf{7 \%}$ \\
\hline F8 & $\mathbf{1}$ & $\mathbf{1}$ & $\mathbf{0}$ & $\mathbf{1}$ & $\mathbf{1}$ & $\mathbf{1}$ & $\mathbf{1}$ & & $\mathbf{6}$ & $\mathbf{2 1 \%}$ \\
\hline & & & & & & & & TOTAL & $\mathbf{2 8}$ & $\mathbf{1 0 0 \%}$ \\
\hline
\end{tabular}

Elaboración propia

Como resultado de la matriz de enfrentamiento; el factor 8, índice del volumen de importaciones tiene el mayor peso dentro de la matriz con $21 \%$, seguido del factor 6 , consumo total de alcohol per cápita con un $18 \%$ y siendo el segundo factor más importante y relevante dentro de la matriz e idea de negocio.

Asimismo, el índice de consumo de bebidas alcohólicas en países europeos como Francia, Reino Unido y Alemania es superior a los 10 litros per cápita según el último informe de la Organización Mundial de la Salud. (2018)

Para el Banco Mundial (2018), Alemania sobresale manteniendo uno de los menores costos con $\$ 1050$ por contenedor y 7 días de importación, y el primer puesto en el índice de desempeño logístico con una puntuación de 4.2 mostrando liderazgo dentro del aspecto logístico, representa un mercado atractivo dentro del territorio europeo. En adición al comentario anterior, tiene un consumo total per cápita de 13.4 litros de alcohol, la mayor cantidad de consumo de alcohol en Europa, dicho lo anterior, representa una problemática actual que se requiere solucionar y reducir el índice de consumo de bebidas alcohólicas brindado al mercado un producto alternativo.

En la siguiente tabla, se evalúan 5 mercados potenciales, grandes economías mundiales, que pueden generar oportunidades comerciales y de desarrollo para el vino no alcohólico que fueron seleccionados por sus volúmenes de importación de bebidas no alcohólicas e importación de vinos, previamente analizados. 
Tabla 1.3

Indicadores de desarrollo mundial

\begin{tabular}{|c|c|c|c|c|c|c|}
\hline Código & Factor & Alemania & Reino Unido & USA & Canadá & Francia \\
\hline F1 & $\begin{array}{l}\text { Índice de facilidad de hacer negocio }(1= \\
\text { reglamentaciones más favorables para los } \\
\text { negocios) }\end{array}$ & 20 & 7 & 6 & 22 & 31 \\
\hline $\mathrm{F} 2$ & Crecimiento del PBI per Cápita (\% Anual) & 1.8 & 1.1 & 1.5 & 1.7 & 1.4 \\
\hline F3 & $\begin{array}{l}\text { Índice Desempeño Logístico: facilidad para } \\
\text { coordinar embarques a precios competitivos } \\
\text { (1=baja a } 5=\text { alta })\end{array}$ & 4.2 & 3.99 & 3.97 & 3.94 & 3.82 \\
\hline F4 & Costo para Importar (US\$ por Contenedor) & 1.05 & 1.05 & 1.29 & 1.68 & 1.45 \\
\hline F5 & Tiempo de Importación (Días) & 7 & 6 & 5.4 & 10 & 11 \\
\hline F6 & $\begin{array}{l}\text { Consumo de alcohol Total per cápita (Litros } \\
\text { de alcohol puro, mayores de } 15 \text { años) }\end{array}$ & 13.4 & & 9.8 & 8.9 & 12.6 \\
\hline F7 & $\begin{array}{c}\text { Precios Actuales - Importación bienes y } \\
\text { servicios }\end{array}$ & 1.458 & & 2.409 & 548 & 825 \\
\hline F8 & Índice Volumen Importaciones $(2000=100)$ & 126.34 & 96.69 & 132.75 & 139.81 & 94.96 \\
\hline
\end{tabular}

Fuente: Banco Mundial (2018) y Trade Map (2018)

Elaboración propia

Para el ranking de factores previo a la selección, se consideró indicadores de mercado con un peso de $46 \%$ teniendo al nivel de importaciones del 2018 con un peso de $21 \%$; nivel de precios con un peso de $7 \%$ y el consumo per cápita de alcohol en el 2018 con un peso de $18 \%$. Los indicadores logísticos pesan $32 \%$ compuesto por el desempeño logístico general con 14\%, así como costos de importación en 4\% y el tiempo para importar en $14 \%$. Finalmente, los indicadores macroeconómicos tienen un peso de $22 \%$ compuestos por el crecimiento del PBI en 14\%, y la facilidad para hacer negocios con $8 \%$ en base al 2018.

Como resultado del siguiente análisis, Alemania obtiene una puntuación de 3.91, la cual representa el puntaje más alto dentro de los cinco países evaluados, seguido de Los Estados Unidos de América con 3.61 en su puntuación.

En beneficio y gracias a la firma del acuerdo comercial entre Perú y la Unión Europea, vigente desde marzo de 2013, se tiene acceso preferencial a una gran parte de productos agrícolas y para la totalidad de productos procesados provenientes del Perú, lo que representa una clara ventaja comparativa para poder ofrecer nuestra oferta exportable. 
Tabla 1.4

Ranking de factores para selección del mercado destino

\begin{tabular}{|c|c|c|c|c|c|c|c|c|c|c|c|}
\hline Criterio & Peso & Alema & nia & Reino U & nido & USA & & Canac & & Franc & \\
\hline $\begin{array}{l}\text { Entorno } \\
\text { Macroeconómico }\end{array}$ & $22 \%$ & Calificación & Puntaje & Calificación & Puntaje & Calificación & Puntaje & Calificación & Puntaje & Calificación & Puntaje \\
\hline F1 & $8 \%$ & 3 & 0.24 & 4 & 0.32 & 5 & 0.4 & 2 & 0.16 & 1 & 0.08 \\
\hline $\mathrm{F} 2$ & $14 \%$ & 5 & 0.7 & 1 & 0.14 & 3 & 0.42 & 4 & 0.56 & 2 & 0.28 \\
\hline $\begin{array}{l}\text { Logísticos, Costo } \\
\text { y tiempo }\end{array}$ & $32 \%$ & & & & & & & & & & \\
\hline F3 & $14 \%$ & 5 & 0.7 & 4 & 0.56 & 3 & 0.42 & 2 & 0.28 & 1 & 0.14 \\
\hline F4 & $4 \%$ & 1 & 0.04 & 2 & 0.08 & 3 & 0.12 & 5 & 0.2 & 4 & 0.16 \\
\hline F5 & $14 \%$ & 3 & 0.42 & 4 & 0.56 & 5 & 0.7 & 2 & 0.28 & 1 & 0.14 \\
\hline Mercado & $46 \%$ & & & & & & & & & & \\
\hline F6 & $18 \%$ & 5 & 0.9 & 3 & 0.54 & 2 & 0.36 & 1 & 0.18 & 4 & 0.72 \\
\hline F7 & $7 \%$ & 4 & 0.28 & 3 & 0.21 & 5 & 0.35 & 1 & 0.07 & 2 & 0.14 \\
\hline F8 & $21 \%$ & 3 & 0.63 & 2 & 0.42 & 4 & 0.84 & 5 & 1.05 & 1 & 0.21 \\
\hline Total & $100 \%$ & & 3.91 & & 2.83 & & 3.61 & & 2.78 & & 1.87 \\
\hline
\end{tabular}

Elaboración propia

Alison Angus (2018) señala: "Los consumidores están adoptando estilos de vida limpios y minimalistas donde la moderación y la integración son la clave" (p. 3). El comportamiento del consumidor está enfocado en darle un valor más personal a su compra.

El desarrollo de una sociedad con una consciencia más saludable ha impactado en la industria alimentaria alemana generando el desarrollo de bebidas alternativas a las alcohólicas que les permita disfrutar de un buen estilo de vida, gratos momentos sociales sin necesidad de excederse en el consumo, ni perjudicar la salud que es muy apreciada hoy en día. La cerveza sin alcohol ha sido recibida con una gran aceptación por los alemanes y es presentada en importantes ferias internacionales en todo el mundo. El escenario competitivo continúa cambiando en las bebidas alcohólicas, así se aprecia que los niveles de su consumo proyectan caídas de $0.2 \%$ para el 2021 , esto denota que los consumidores beben menos alcohol en busca de otro tipo de bebida que no perjudique su bienestar, según reporte de Euromonitor International (2018).

En el caso del vino, la expectativa es similar a lo que aconteció con la cerveza sin alcohol con la única diferencia del público objetivo, va dirigido a un sector más sofisticado, con hábitos de consumo regulares del vino y la disposición de probar nuevos sabores sin variar la costumbre.

Asimismo, la definición de "Producto sin alcohol y/o natural" está muy valorado en el mercado alemán en donde las mejores bebidas y marcas no pueden ser fácilmente 
encontradas en canales tradicionales como supermercados, sino que requieren de un canal especializado como tiendas por departamento. Las tiendas especializadas tienen un fuerte posicionamiento empero proyecta una caída ponderada de $2.7 \%$ gracias al boom de la venta en linea por lo que los comercializadores estan buscando nuevas formas de integracion con restaurantes, bares y participacion en diversos eventos donde puedan incentivar el consumo de las bebidas no alcohólicas, según Euromonitor (2018).

\subsection{Análisis PESTE}

En el análisis PESTE se evaluará los principales factores externos que nos permitirán un mejor panorama y conocimiento de nuestro mercado objetivo; y pudiesen favorecer o no el accionar de la empresa.

La siguiente herramienta aportará a la investigación en conocer las tendencias externas y está comprendido por cinco variables, las cuales son el entorno político, economía, social, tecnológico y ecológico que influyen en las empresas constituidas o en los potenciales negocios que se desarrollen dentro del país destino. Asimismo, permitirá una mejora en la toma de decisiones y a conocer de las diversas situaciones que Alemania está aconteciendo en la actualidad.

\subsubsection{Análisis Político, Gubernamental y Legal}

Siendo el principal socio comercial de grandes potencias mundiales como Estados Unidos de América, China y Francia. Dentro del marco político, Alemania posee una vasta historia en donde su entorno político y gubernamental estuvieron involucrados, ordenándose después de la segunda guerra mundial. El sistema Político trabaja bajo el documento constitucional de 1949 conocido como "Ley Fundamental". Existen 2 importantes poderes gubernamentales, Poder Ejecutivo y Poder Legislativo.

El poder ejecutivo es presidido por el jefe de gobierno, el canciller, elegido por la Asamblea General cada cuatro años que cumple las funciones y obligaciones de un primer ministro, es representado por Angela Merkel, reelegida por cuarta vez consecutiva, los ministros federales (Consejo de Ministros) son elegidos por el presidente federal bajo recomendaciones de la canciller.

El poder Legislativo es bicameral y es presidido por el jefe de estado, presidente federal de Alemania, elegido por la Convención Federal (delegados de la Asamblea 
General) por un periodo de cinco años, las funciones que desempeña son básicamente ceremonial y es representado por Frank-Walter Steinmeier desde el 2017. Los tribunales de Justicia son autónomos e independientes del poder legislativo y ejecutivo, representan la autoridad más alta de Alemania. Tienen un estatuto civil basado en el derecho romano, pero hacen bastante referencia al derecho germánico.

La reputación de ser una de las principales economías a nivel mundial conlleva a pertenecer a distintos organismos mundiales del comercio internacional; entre las principales, la Unión Europea, Naciones Unidas, La OTAN (Organización del Tratado Atlántico Norte), La Organización para Seguridad y la Cooperación Europea (OSCE), La organización Mundial del Comercio (OMC), El Fondo Monetario Internacional (FMI), entre otros.

\subsubsection{Análisis Económico y Financiero}

Alemania, una economía que ha venido liderando Europa siendo un mercado atractivo para las exportaciones mundiales. Un mercado que ha tenido estabilidad económica en los últimos años.

Según el portal web Santander Trade (2018);

Los tres principales sectores económicos de Alemania son, el sector servicio que representa un $61.9 \%$ del PBI nacional, el modelo económico alemán funciona sobre una red de contactos de empresas pymes con experiencia en el entorno internacional, el sector industrial representa un 27.6\% del PBI, la economía alemana es especialista en la industria automotriz, que para el 2022, tiene previsto remodelar el paisaje industrial. El sector agrícola que representa aproximadamente el 1\% del PBI, y en la actualidad, el país ha empezado un proceso de desindustrialización del sector alimentario. 
Tabla 1.5

Indicadores macroeconómicos de crecimiento de Alemania

\begin{tabular}{l|ccccc}
\hline Indicadores de crecimiento & $\mathbf{2 0 1 6}$ & $\mathbf{2 0 1 7}$ & $\mathbf{2 0 1 8}$ & $\mathbf{2 0 1 9}$ & $\mathbf{2 0 2 0}(\mathbf{e})$ \\
\hline PBI (Miles de Millones USD) & 3.496 & 3.700 & 40.29 & 4.117 & 4.331 \\
PBI (Crecimiento anual en \%, precio constante) & 2.2 & 2.5 & 1.9 & 1.9 & 1.6 \\
PBI per cápita (USD) & 42.46 & 44.76 & 48.67 & 49.69 & 52.27 \\
Endeudamiento del Estado (en \% del PBI) & 67.9 & 63.9 & 59.8 & 56.0 & 52.6 \\
Tasa de Inflación (\%) & 0.4 & 1.7 & 1.8 & 1.8 & 2.1 \\
Tasa de Desempleo (\%) & 4.2 & 3.8 & 3.5 & 3.4 & 3.3 \\
\hline
\end{tabular}

Fuente: Santander Trade (2018)

En la tabla 1.7, Alemania presenta los siguientes indicadores macroeconómicos, se puede apreciar que en el PBI per cápita ha tenido un crecimiento sostenible desde el 2016 hasta el 2020 con un proyectado de \$ 52.27 USD, uno de los más altos del mundo y de Europa. Por otro lado, la tasa de inflación llegaría a un máximo de 1.8\% para el 2019 y un proyectado de $2.1 \%$ para el 2020. La tasa de desempleo muestra una reducción desde el 2016 hasta la actualidad y se proyecta para el 2020 un 3.3\%. En conclusión, Alemania es un interesante mercado con buenos indicadores y poder adquisitivo para el desarrollo y posicionamiento del vino.

La moneda actual de Alemania es el Euro, entró en vigencia el primero de enero del 2002; doce países, incluido Alemania, la adoptaron como moneda oficial. $\mathrm{n}$ el siguiente cuadro se aprecia cual es el tipo de cambio actualizado y su punto de comparación con el dólar, que es la moneda internacional para los negocios y el sol, moneda nacional del Perú.

Tabla 1.6

Tipo de cambio

\begin{tabular}{|c|c|}
\hline \multicolumn{2}{|c|}{ Tipo de Cambio } \\
\hline $1 \mathrm{EURO}=3.71 \mathrm{PEN}$ & $1 \mathrm{PEN}=0.27 \mathrm{EURO}$ \\
\hline $1 \mathrm{EURO}=1.12 \mathrm{USD}$ & $1 \mathrm{USD}=0.89 \mathrm{EURO}$ \\
\hline
\end{tabular}

\subsubsection{Análisis Social, Cultural y Demográfico}

La República Federal de Alemania tiene una población total de 82,8 millones de habitantes de los cuales el 77,3\% viven en zona urbana y el crecimiento poblacional es del 0,4\% anual. Entre las principales ciudades alemanas más pobladas encontramos a las siguientes: 
Tabla 1.7

Población áreas metropolitanas de Alemania

\begin{tabular}{c|c}
\hline \multicolumn{2}{c}{ Áreas Metropolitanas Alemania } \\
\hline Ciudades & Población (Miles Hab.) \\
\hline Berlín & 5.142 \\
Hamburgo & 3.234 \\
Munich & 2.849 \\
Francfort & 2.833 \\
Stuttgart & 2.736 \\
\hline
\end{tabular}

Fuente: Organization for Economic Co-operations and Development, OECD (2018)

Con respecto a los orígenes étnicos raciales, según el portal web Santander Trade (2018):

En el 2015, más del millón de inmigrantes procedentes de zonas de conflicto como Siria, Irak, y Afganistán representaron al $1 \%$ de la población total, y que actualmente están recibiendo el apoyo del estado alemán. El idioma oficial es el alemán, pero para las reuniones de negocio el más usado es el inglés, seguido del alemán. (párr. 5)

Unos de los principales retos que se presentó para el 2018, fue el envejecimiento de la población, una notoria carencia en ingenieros e investigadores jóvenes. Según la Cadena de televisión Deutsche Welle Español (2018):

Alemania va a poder contar desde el 2019 con una nueva "ley de inmigración" que le permitirá conseguir el personal cualificado que tan urgentemente necesita, la ley aplicará principalmente a los países que no estén en la Unión Europea; como requisito se necesitará dominio del idioma alemán y capacidad para solventarse por seis meses. 
Figura 1.3

Distribución por edades de la población en Alemania

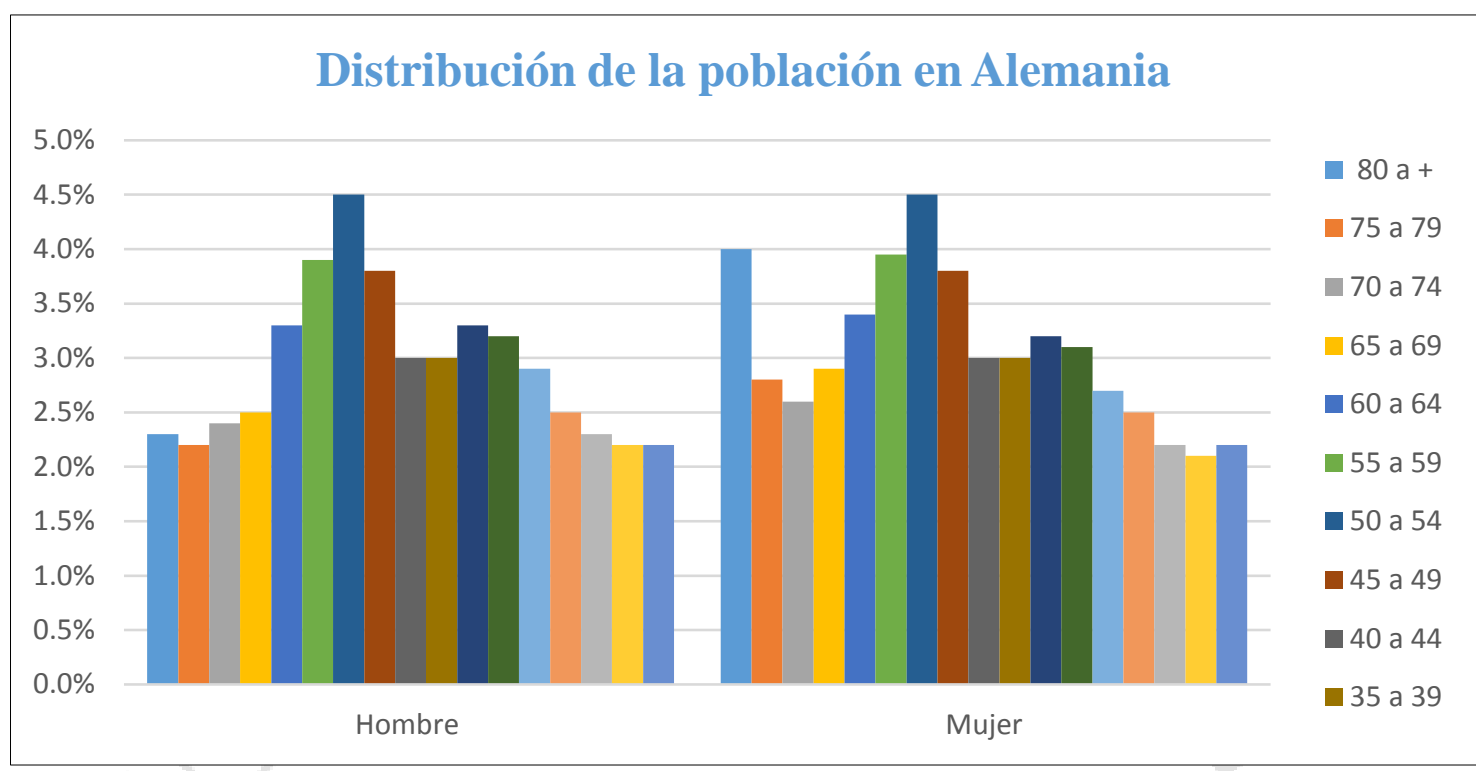

Fuente: Euromonitor International (2018)

La segmentación del público objetivo es de 30 a 54 años que representa el 34\% de la población total de Alemania. Cabe resaltar que el mayor porcentaje va entre las edades de 45 a 59 con un $25 \%$ del total de la población.

Según Datos Mundial (2019), el principal día festivo en Berlín es el día de la Unidad Alemana; como fecha el 3 de octubre, conmemorando el aniversario de la entrada en vigor de la reunificación alemana en 1990. Como es un país que en su mayoría prevalece el cristianismo, celebran la Navidad (25 de diciembre), el día de todos los santos $\left(1^{\circ}\right.$ de noviembre) y la semana santa. Otros días festivos son el Año nuevo $\left(1^{\circ} \mathrm{de}\right.$ enero), lunes de Pentecostés, día festivo de la ascensión, entre los principales.

\subsubsection{Análisis Tecnológico y Científico}

La infraestructura en Alemania es de alta tecnología, desde hace años abordaron con la construcción de la primera red de autopistas a gran escala en el mundo, casi 40,000 km de carreteras, las cuales son gratuitas para vehículos particulares, pero para los camiones de carga deben de pagar un monto de peaje. Asimismo, Alemania es conocido por ser líder en la construcción de numerosos canales, incluidos los fluviales en todo Alemania.

El país cuenta con grandes aeropuertos, entre ellos el que se encuentra ubicado en la capital alemana, Aeropuerto internacional de Berlín Tegel o también llamada Otto 
Lilienthal, y puertos con infraestructura de última generación que le permiten desempeñar un trabajo logístico en la exportación e importación de mercancías.

Según la Comisión Europea (2012):

Pocos países han contribuido tanto a la ciencia y la tecnología como Alemania. Desde la física y la química, los productos de consumo, Alemania es un líder mundial en innovación que cuenta con universidades de primera línea e instituciones de investigación, además de importantes industrias de ingeniería, informática y fabricación. (párr. 3)

Con respecto al grado competitivo, Alemania se encuentra en la tercera ubicación con una puntuación del 82.8, siendo el máximo 85.6 obtenido por Estados Unidos de América, según el Ranking Global de Competitividad (2018). Mientras tanto, Perú se ubica en el puesto 63 con una puntuación de 61.3 del total de 140 países a nivel mundial.

Así mismo, con respecto a la capacidad de innovación, Alemania se encuentra en la novena posición con una puntuación de 58.03, siendo el máximo 68.40 obtenido por Suiza, país del mismo continente. Mientras que Perú se encuentra muy debajo, en el puesto 71 con una puntuación de 31.80 de un total de 126 países a nivel mundial, según el Ranking Global de Innovación (2018).

\subsubsection{Análisis Ecológico y Ambientales}

Alemania es conocido por ser un país con conciencia medio ambiental. Posee importantes parques eólicos y tiene una gran experiencia de trabajar con paneles solares con capacidad de generar grandes fuentes de energía solar. Desde inicios del último siglo, Alemania ha implementado energías renovables como la energía solar fotovoltaica y la energía eólica contribuyendo positivamente un beneficio para el medio ambiente global y dando un claro ejemplo para las demás economías.

Se han puesto como uno de sus principales objetivos para el 2020, producir el $35 \%$ de energía eléctrica mediante fuentes de energía renovable y para el 2050 llegar al $100 \%$.

Por otro lado, Alemania es un país con grandes emisiones de dióxido de carbono, uno de los más altos de la Unión Europea, perjudicando el medio ambiente y 
contribuyendo a la contaminación atmosférica, representará toda una oportunidad de mejora de reducir las emisiones.

\subsection{Comportamiento del Consumidor / Comprador}

El consumidor alemán se caracteriza por aún mantener una tendencia de precio sensibles a pesar de tener un alto poder adquisitivo y una economía desarrollada. Por ello, los compradores siguen siendo cautelosos para la búsqueda de nuevos productos. En la actualidad, gracias a la política de "puerta abierta" de Alemania hacia los inmigrantes procedentes de países del medio oriente que hubo hace algunos años, esta tendencia ha originado un cambio en la mezcla cultural y la demanda para una gama de alimentos en especial de la religión musulmana (5 millones estimado).

Por otro lado, existe un segmento de la población alemana, los jóvenes adultos están interesados en productos que sean elaborados provocando un impacto positivo en el medio ambiente y en el accionar de prácticas éticas.

Así mismo, van desde los 18 hasta los 29 años de edad, en su mayoría universitarios, no tienen decisión de compra; sin embargo, los honorarios de las universidades alemanas son bajos, lo cual se puede asumir que no hay un gran gasto en ese aspecto.

Por otro lado, la juventud media que va desde los 30 a 44 años, casados y con familia en su mayoría, jóvenes con una carrera universitaria terminada y con altas tasas de rentas medias, existe un alto nivel de oportunidades de empleo femenino. Podemos concluir que tienen una gran decisión de compra.

Los alemanes prefieren comprar en cadenas del "discounters" tales como Aldi y Lidl, en segundo lugar, se encuentran los supermercados, estos 2 canales juntos generan un $64 \%$ del sector comestibles. Debido a la forma de vida agitada y con un gran interés por los productos frescos de alta calidad hacen que por lo menos se vaya una vez por semana en las tiendas de comestibles.

Los platos alemanes son básicamente a base de carne, así como los cereales y el pan son bien recibidos por el consumidor alemán. Con respecto al hábito de bebidas, Alemania es conocido como la nación de la cerveza; sin embargo, los jóvenes han reducido el consumo de productos que incluyen alcohol siguiendo un estilo de vida más sano. Las nuevas tendencias mundiales sobre "El beber consciente" están desarrollando 
la creación de nuevas alternativas para el consumo de bebidas, según reportes de Euromonitor International (2018).

Ha emergido una "Cultura del Cóctel" dispuesta a cambiar la perspectiva del consumo de alcohol, entre las principales preferencias por el consumidor son las ginebras sabor a fruta, pero este hábito es difundido por pocas personas debido a las restricciones que hay del consumo antes de conducir; por ello, lo hacen dentro del hogar.

El mercado de bebidas no alcohólicas en Alemania continúa creciendo a pesar de su madurez y de acuerdo a las tendencias del cuidado de la salud. Dentro de este grupo, las bebidas consumidas por los alemanes son el agua en botella, el café y el té.

Sin embargo, las otras bebidas que están dentro del grupo de las no alcohólicas y que representan un mayor volumen tales como los carbonatos y los jugos están decreciendo debido a la gran concentración de azúcar y preservantes en ellos. Según el reporte de bebidas no alcohólicos por Euromonitor International (2019), el volumen de ventas de las bebidas a comparación del 2018 fue muy similar, teniendo un pequeño decrecimiento debido a que el consumidor prefiere productos saludables, optando por agua en botella que bebidas carbonatadas. Los factores de calidad y precio son determinantes.

Según el portal web Santander Trade (2018): "Los alemanes se preocupan cada vez más del impacto medioambiental de los productos que compran y se interesan por los productos "durable" o "verdes" (párr. 2).

Siguiendo las tendencias actuales de consumo de productos sanos, el ambiente para los vinos finos y champagne en Alemania no eran tan esperanzadores; sin embargo, registraron un crecimiento, a pesar de que de un conocimiento del cuidado de la salud por parte de los consumidores. Así como también se tiene un conocimiento profundo sobre los vinos y champagnes premium, los consumidores están dispuestos a pagar más dinero por ello, demuestran una mayor preferencia de productos de una alta calidad, sobre el origen del mismo e ingredientes, inclusive se están popularizando como regalos.

Según el reporte de vinos y champagne en Alemania por Euromonitor International (2019), los vinos premium obtuvieron un crecimiento sólido y positivo, la innovación juega un papel importantísimo en el desempeño del mercado, bebidas como whisky, tequila y vodka reportaron un crecimiento en el volumen de ventas. Se espera 
que las bebidas alcohólicas premium coloquen un crecimiento sostenible en los próximos años.

Casos como Berry Lou, coctel de vino, que en marzo del 2016 lanzó el producto con 5\% de alcohol basado en un mix de frutas dulces; y Astra Kiezmische cerveza con $2.5 \%$ de alcohol y sabor a frutas sin saborizantes, son muestras clave de que los alemanes están desarrollando nuevos nichos de mercados potenciales para las bebidas libres de alcohol.

Según Euromonitor International (2017), la demanda de bebidas sin alcohol, basadas en la preferencia dominante por los sabores de cítricos, han empoderado el lanzamiento de variantes en los sabores de estas bebidas, como Steinie Apfeilwein Alkoholfrei, vino sin alcohol elaborado en base a manzana presentado en noviembre del 2016 en formatos pequeños; Rotkäppchen Fruchtsecco Birne, desarrollando una nueva línea de vinos sabor a pera; y Sambalita SeccoMaracuja con una línea sabor a maracuyá en el 2016.

\subsection{Requisitos de Acceso}

Perú tiene un tratado de libre comercio con la Unión Europea, y Alemania pertenece a la UE, por consiguiente, existe una preferencia arancelaria para algunos productos peruanos que quieran ser exportados para tierras alemanas.

El proceso de importación de la Unión Europea, todos productos importados por la UE pasan en primera instancia por la Unión Aduanera (Customs Union), la unión aduanera brinda un código, La UCC (Union Customs Code). Todo producto que entra a territorio europeo debe poseer una declaración de entrada al país destino, el importador debe presentar una declaración en aduanas (SAD por sus siglas en inglés), documento administrativo único.

Según el portal Trade Helpdesk de la Unión Europea (2018), la documentación para el ingreso de productos y despacho de Aduanas en el mercado destino, son los siguientes:

\section{Factura Comercial}

Declaración del Valor en Aduana

Documentación de Transporte (B/L, Carta de porte por Carretera)

Seguro Internacional 
Lista de carga (Packing List)

$>$ Documento Único Administrativo

$>$ Certificado de Origen

\section{Certificados de Calidad}

La información que va en el packing list debe ser la siguiente: información del exportador, importador y la compañía naviera, fecha de embarque, el número de los documentos de embarque, tipo de envase, número de productos, el contenido del envase, el peso bruto y neto del empaque. La Unión Europea exige requerimientos y certificados de entrada que deben tener los productos, que son mencionados en la tabla posterior.

Tabla 1.8

Certificaciones de entrada al mercado alemán

\begin{tabular}{|c|c|}
\hline Certificaciones & Beneficios \\
\hline Certificado EUR1 & $\begin{array}{l}\text { Certifica el origen de la mercancía para países con los que la Unión } \\
\text { Europea tiene acuerdos preferenciales, y asegura que se aplicarán unos } \\
\text { aranceles preferenciales en destino. }\end{array}$ \\
\hline Certificado de Libre Venta & $\begin{array}{l}\text { Es un certificado que avala que la empresa está legalmente } \\
\text { establecida, y que, en virtud de ello, cumple la normativa vigente, los } \\
\text { productos son aptos para el consumo humano y de libre venta en la } \\
\text { Unión Europea. }\end{array}$ \\
\hline $\begin{array}{l}\text { Certificado de Registro } \\
\text { Sanitario }\end{array}$ & $\begin{array}{l}\text { Asociado a este documento está el Certificado de Libre Venta, emitido } \\
\text { también por la Dirección General de Salud Pública y Consumo. }\end{array}$ \\
\hline $\begin{array}{l}\text { Certificado de análisis } \\
\text { sanitarios }\end{array}$ & $\begin{array}{l}\text { Este certificado avala la elaboración de una empresa, sus vinos, las } \\
\text { partidas, lotes, número de botellas siendo estas por tanto conformes } \\
\text { con la normativa sanitaria. }\end{array}$ \\
\hline $\begin{array}{l}\text { Certificado de denominación } \\
\text { de origen }\end{array}$ & $\begin{array}{l}\text { Documento certifica que la empresa se encuentra registrada al amparo } \\
\text { de la Denominación de Origen. }\end{array}$ \\
\hline Certificado fitosanitario & $\begin{array}{l}\text { Este documento afirma que los productos analizados están libres de } \\
\text { restos de pesticidas. }\end{array}$ \\
\hline $\begin{array}{l}\text { HACCP (Análisis de peligros y } \\
\text { puntos críticos de control) }\end{array}$ & $\begin{array}{l}\text { Certificado sistemático preventivo para garantizar la inocuidad } \\
\text { alimentari,1 de forma lógica y objetiva. }\end{array}$ \\
\hline Fair Trade (Opcional) & $\begin{array}{l}\text { Los productos que llevan el sello Fair trade han sido producidos en } \\
\text { condiciones de trabajo dignas y comprados a un precio justo que } \\
\text { apoya el desarrollo sostenible de la organización productora }\end{array}$ \\
\hline
\end{tabular}

Fuente: Trade Helpdesk de la Unión Europea (2018)

La infraestructura de Alemania representa una ventaja comparativa con respecto a los demás destinos europeos, tiene un alto índice en desempeño logístico, uno de los más altos registros en el continente, cuenta con varias rutas de transporte ya sean estos aéreos, marítimos, fluviales y por tren. A continuación, detallaremos las principales puertas de acceso (aéreo y Marítimo) de Alemania. 
Tabla 1.9

Principales puertos y aeropuertos de Alemania

\begin{tabular}{|l|l|}
\hline \multirow{4}{*}{ Principales puertos } & Puerto de Bremen \\
\cline { 2 - 2 } & Puerto de Bremerhaven \\
\cline { 2 - 2 } & Puerto de Hamburgo \\
\hline \multirow{4}{*}{ Principales aeropuertos } & Aeropuerto de Berlín \\
\cline { 2 - 2 } & Aeropuerto de Bremen \\
\cline { 2 - 2 } & Aeropuerto de Bremerhaven \\
\cline { 2 - 2 } & Aeropuerto de Colonia \\
\cline { 2 - 2 } & Aeropuerto de Dortmund \\
\hline & Aeropuerto de Frankfurt \\
\hline & Aeropuerto de Hanover \\
\cline { 2 - 2 } & Aeropuerto de Münich \\
\hline
\end{tabular}

Fuente: Sistema de Inteligencia Comercial Legiscomex (2017)

\subsection{Análisis de la Demanda}

Alemania es el cuarto principal importador de bebidas no alcohólicas a nivel mundial registrando 491,708 en el 2018 de acuerdo a Trademap (2018) mostrando un pequeño incremento a comparación del 2017 que registró 422,216 se puede deducir que tuvo un aumento del $16 \%$, y sólo por detrás del Reino Unido dentro del continente europeo.

Tabla 1.10

Volumen de países importadores de bebidas no alcohólicas (Valores)

\begin{tabular}{|l|c|c|}
\hline \multicolumn{3}{|c|}{ Principales países importadores de bebidas no alcohólicas } \\
\hline Países Importadores & $\mathbf{2 0 1 7}$ & $\mathbf{2 0 1 8}$ \\
\hline Estados unidos & 893.383 & 832.057 \\
\hline Canadá & 564.151 & 516.493 \\
\hline Reino Unido & 562.980 & 576.018 \\
\hline Alemania & $\mathbf{4 2 2 . 2 1 6}$ & $\mathbf{4 9 1 . 7 0 8}$ \\
\hline China & 329.821 & 454.136 \\
\hline
\end{tabular}

Fuente: Trade Map (2018)

Por otro lado, el volumen de la importación de vino en el 2018 ha sido liderado por Reino Unido con un volumen de 672,400 a comparación del 2017 que registró un volumen de 587,285, obteniendo un crecimiento del 14.50\%. Así mismo, Alemania registró un volumen de 564,110 en el 2017 y 676,445 en el 2018, obteniendo un crecimiento de casi el $20 \%$. 
Tabla 1.11

Volumen de países importadores de vino (Valores)

\begin{tabular}{|l|c|c|}
\hline \multicolumn{3}{|c|}{ Principales países importadores de vino } \\
\hline Países Importadores & $\mathbf{2 0 1 7}$ & $\mathbf{2 0 1 8}$ \\
\hline Reino Unido & 587.285 & 672.400 \\
\hline Alemania & $\mathbf{5 6 4 . 1 1 0}$ & $\mathbf{6 7 6 . 4 4 5}$ \\
\hline Francia & 313.731 & 391.147 \\
\hline Estados Unidos & 305.179 & 262.768 \\
\hline China & 157.041 & 186.708 \\
\hline
\end{tabular}

Fuente: Trade Map (2018)

\subsubsection{Distribución geográfica del mercado consumo}

Alemania tiene una ubicación estratégica ocupando una posición central en Europa Occidental, limitando al norte con el mar Báltico y el mar de norte; al este con Polonia y la República Checa; al sur con Austria y Suiza y al oeste con Francia, Luxemburgo, bélgica y Holanda (Central Intelligence Agency, 2018), definitivamente es una puerta de entrada para el comercio internacional en Europa.

Figura 1.4

Mapa de Alemania

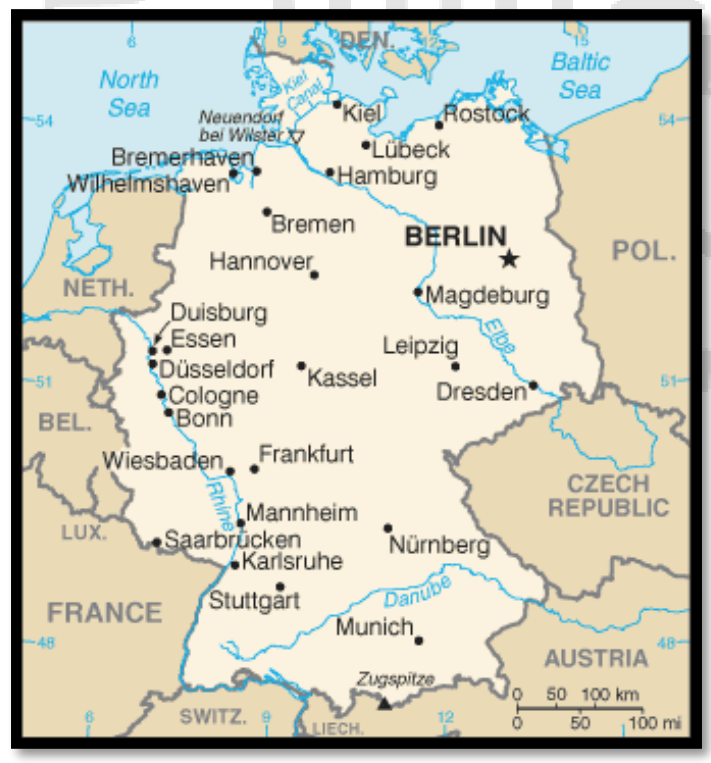

Fuente: Central Intelligence Agency, CIA (2018) 
Tabla 1.12

Estados de Alemania y sus capitales

Estados o Länder

(Capital del Estado)

\begin{tabular}{|l|l|}
\hline Badem - Wurtemberg (Stuttgart) & Baja Sajonia (Hanover) \\
\hline Baviera (Münich) & Westfalia (Dusseldorf) \\
\hline Berlín & Palatinado (Maguncia) \\
\hline Brandeburgo (Potsdam) & Sarre (Saarbrücken) \\
\hline Bremen (Bremen) & Sajonia - Anhalt (Magdeburgo) \\
\hline Hamburgo (Hamburgo) & Holstein (Kiel) \\
\hline Hesse (Wiesbaden) & Sajonia (Dresde) \\
\hline Mecklemburgo (Schwerin) & Turingia (Erfurt) \\
\hline
\end{tabular}

Fuente: Embajada de Alemania (2019)

Alemania posee “348,500 km2” según Euromonitor International (2018) y su población según Destatis (2018), bordea los 83 millones de habitantes en la actualidad. Así mismo, posee de 16 estados federados llamados "Länder", cada uno de ellas tiene su propio gobierno regional.

Como resultado de la evolución de bebidas no alcohólicas en Alemania, incluyendo agua, jugos, gaseosas y demás bebidas no alcohólicas hay un crecimiento en lo que involucra los años desde el 2014 al 2018, ese crecimiento representa a un $16 \%$ con respecto al 2017, y se espera que la tendencia de importación siga creciendo en los próximos años.

Figura 1.5

Evolución de importación de bebidas no alcohólicas en Alemania (Valores)

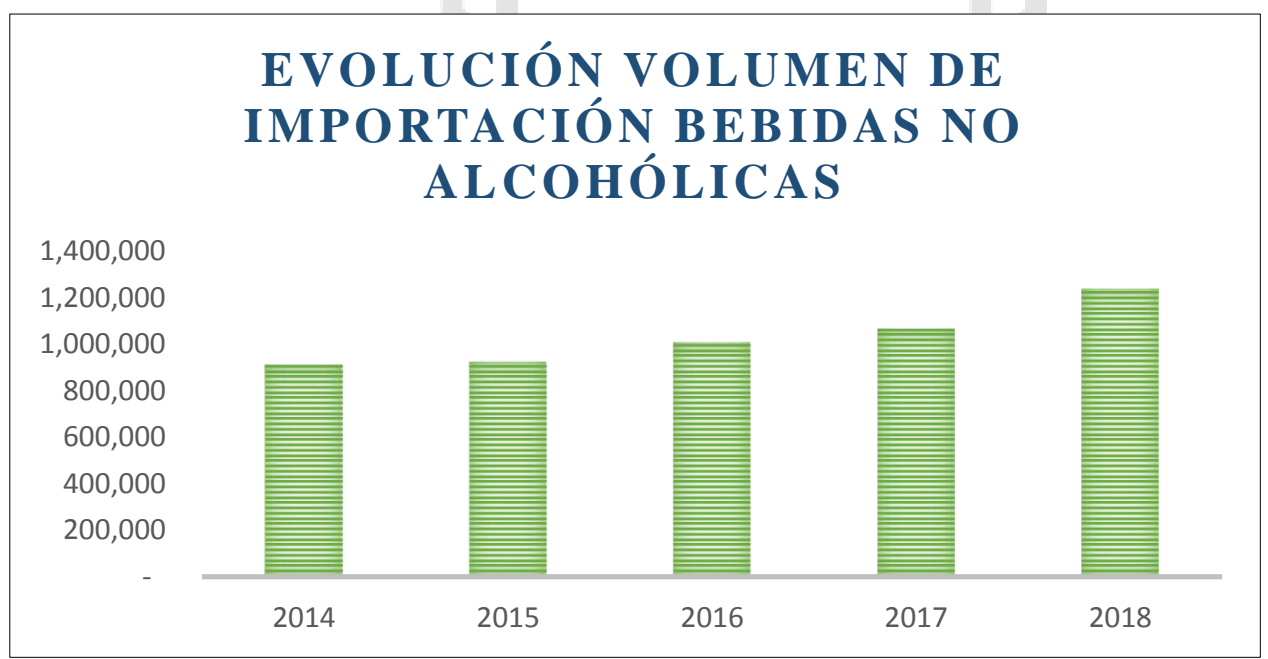

Fuente: Euromonitor International (2018) 
Por otro lado, las estadísticas informan que se proyecta un ligero incremento con respecto a las ventas de bebidas no alcohólicas en Alemania para los próximos 5 años, este incremento se debe a la preferencia de consumo de bebidas saludables como agua embotellada y representa una buena noticia para el vino no alcohólico ya que estaría dentro de la misma categoría; sin embargo, también se sitúan bebidas carbonatadas como gaseosas y jugos procesados que no son un beneficio para la salud, por ese detalle, no puede haber un incremento mayor con respecto a las importaciones y a las ventas en el mercado destino.

Figura 1.6

Volumen de ventas de bebidas no alcohólicas en Alemania (Valores)

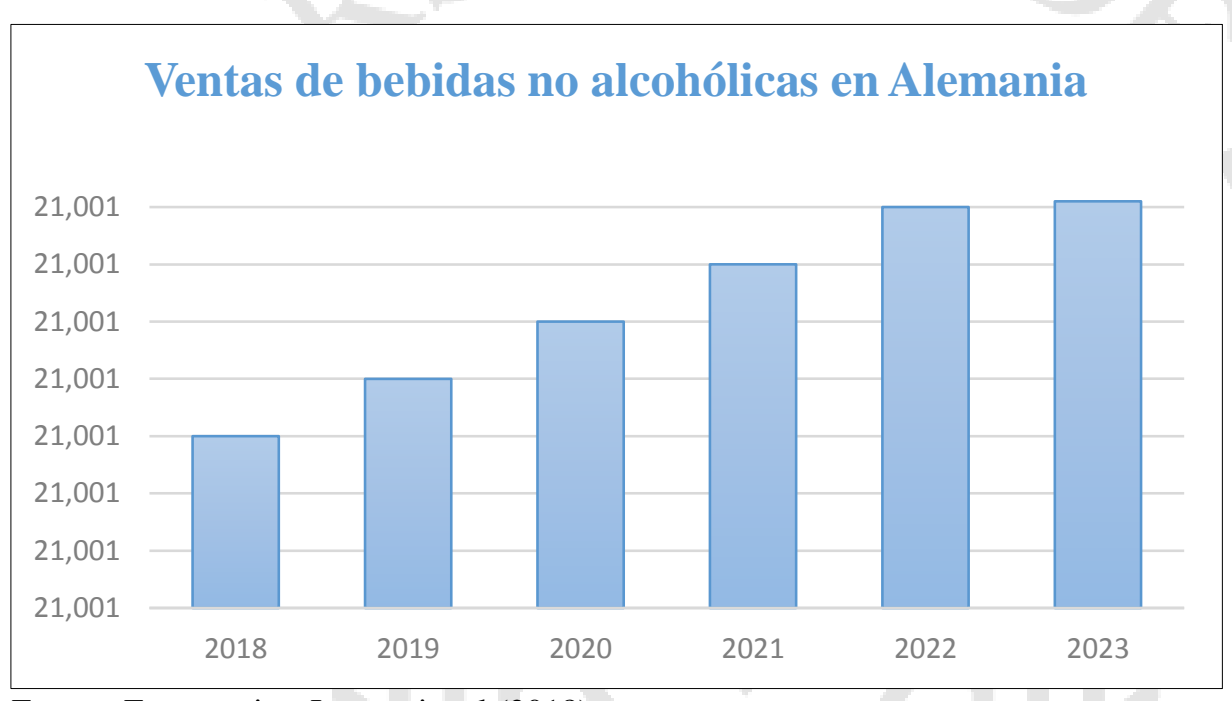

Fuente: Euromonitor International (2018)

\section{Figura 1.7}

Principales países importadores de Uva (Valores)

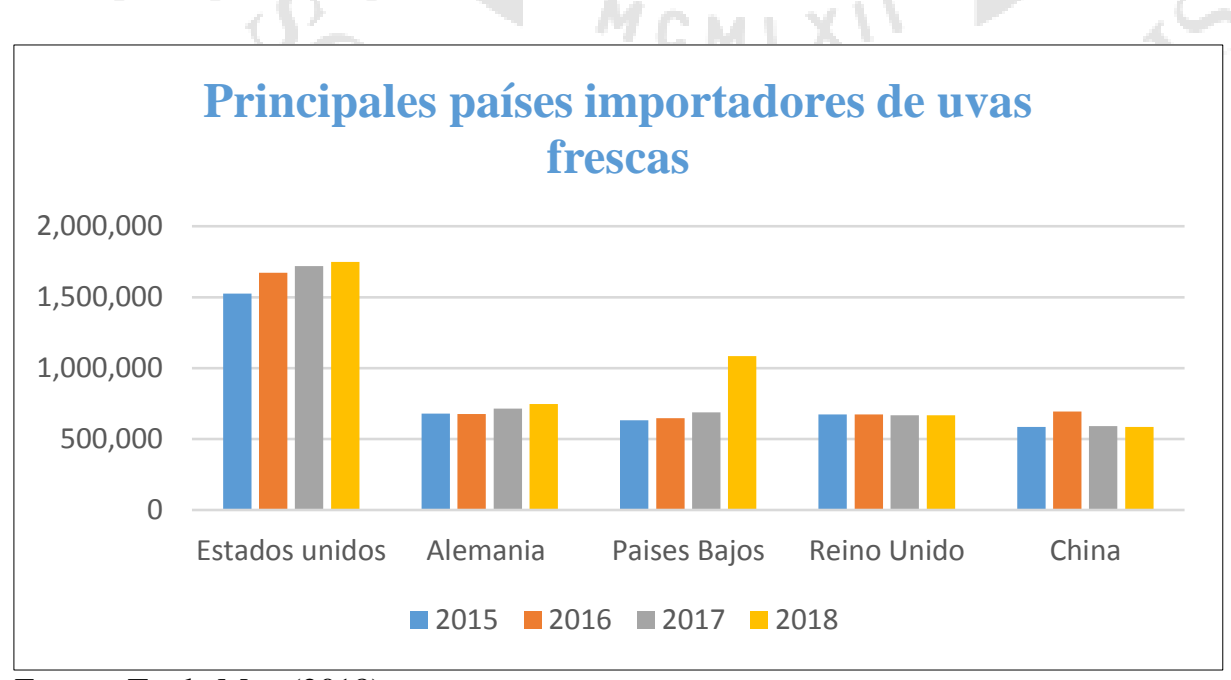

Fuente: Trade Map (2018) 
Figura 1.8

Principales países importadores de productos frescos y cítricos (Valores)

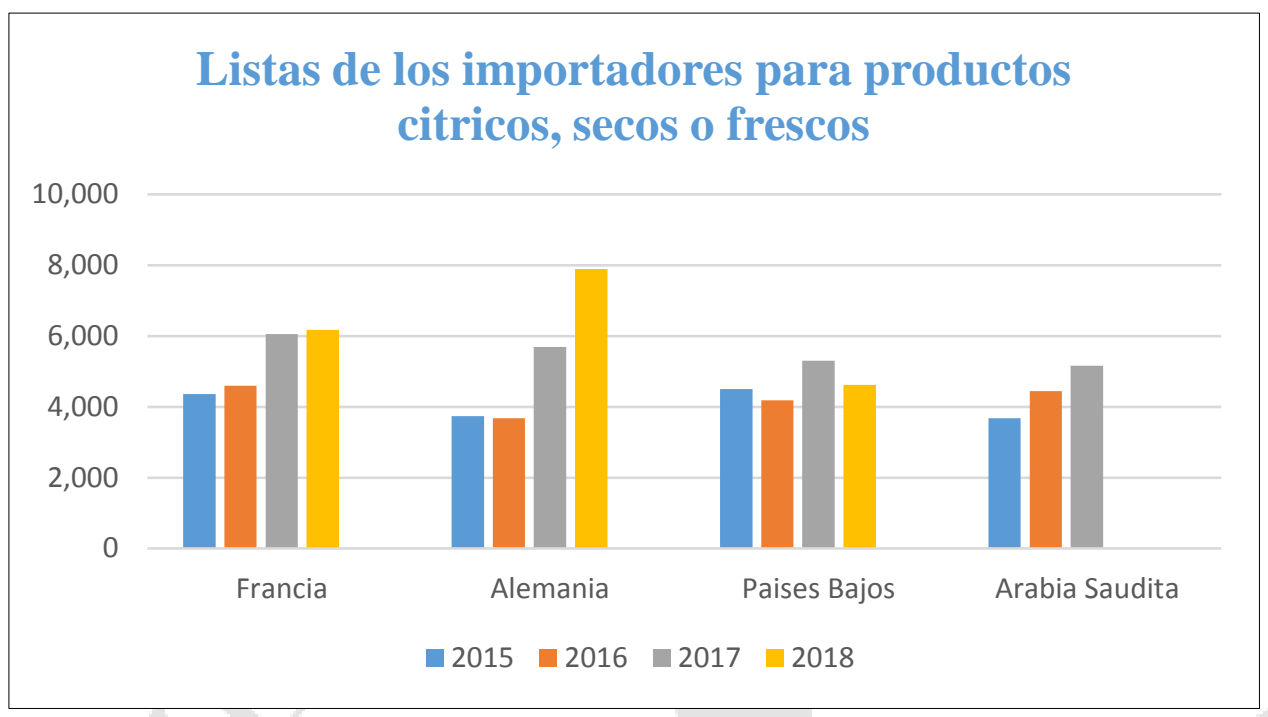

Fuente: Trade Map (2018)

Con respecto a la Tabla 1.18 y 1.19 que hace referencia a los principales importadores de insumo de nuestro producto; como la uva, el camu camu y aguaymanto, podemos apreciar que Alemania es un mercado atractivo con buenos números de volumen para la importación de los mismos.

Figura 1.9

Principales países exportadores de vino a Alemania (Valores)

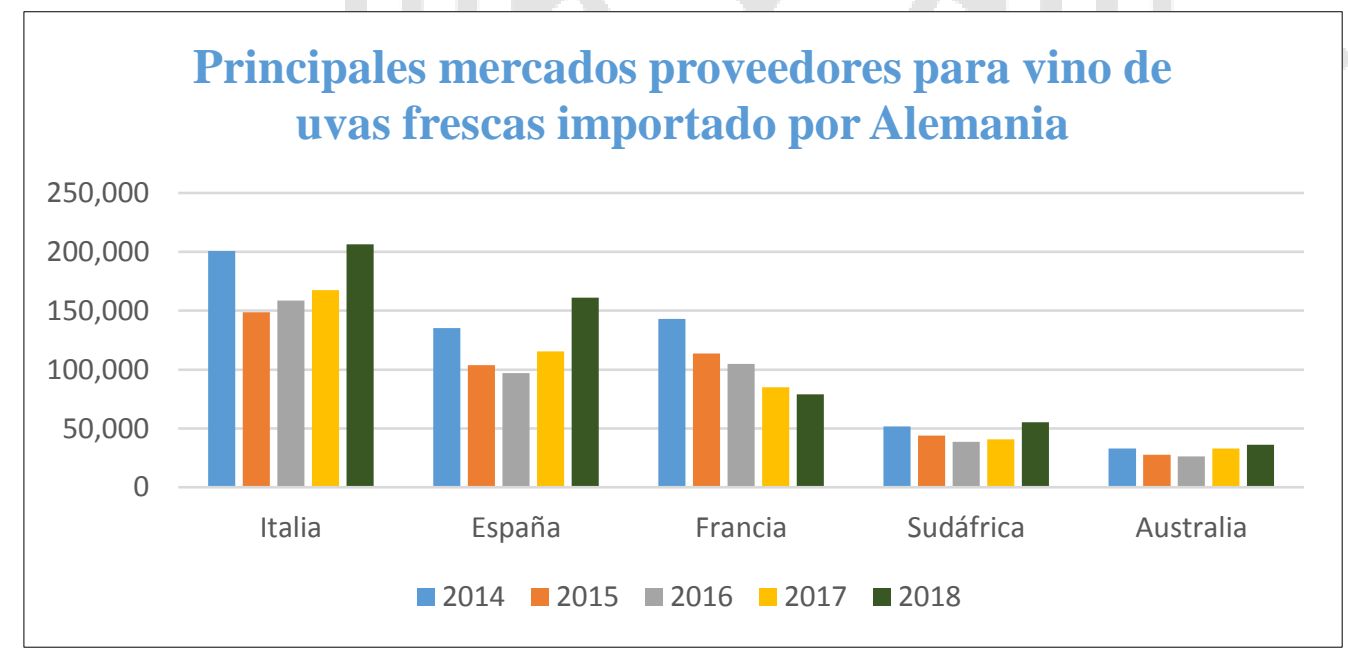

Fuente: Trade Map (2018)

Entre los principales proveedores de vinos a Alemania, viene liderando Italia, España y Francia. Por otro Lado, Perú, el mercado de origen, ya existe un histórico con respecto a la exportación de vino a Europa, entre ellos Bélgica y el Reino Unido. 
Figura 1.10

Principales países Importadores de vino exportado por Perú

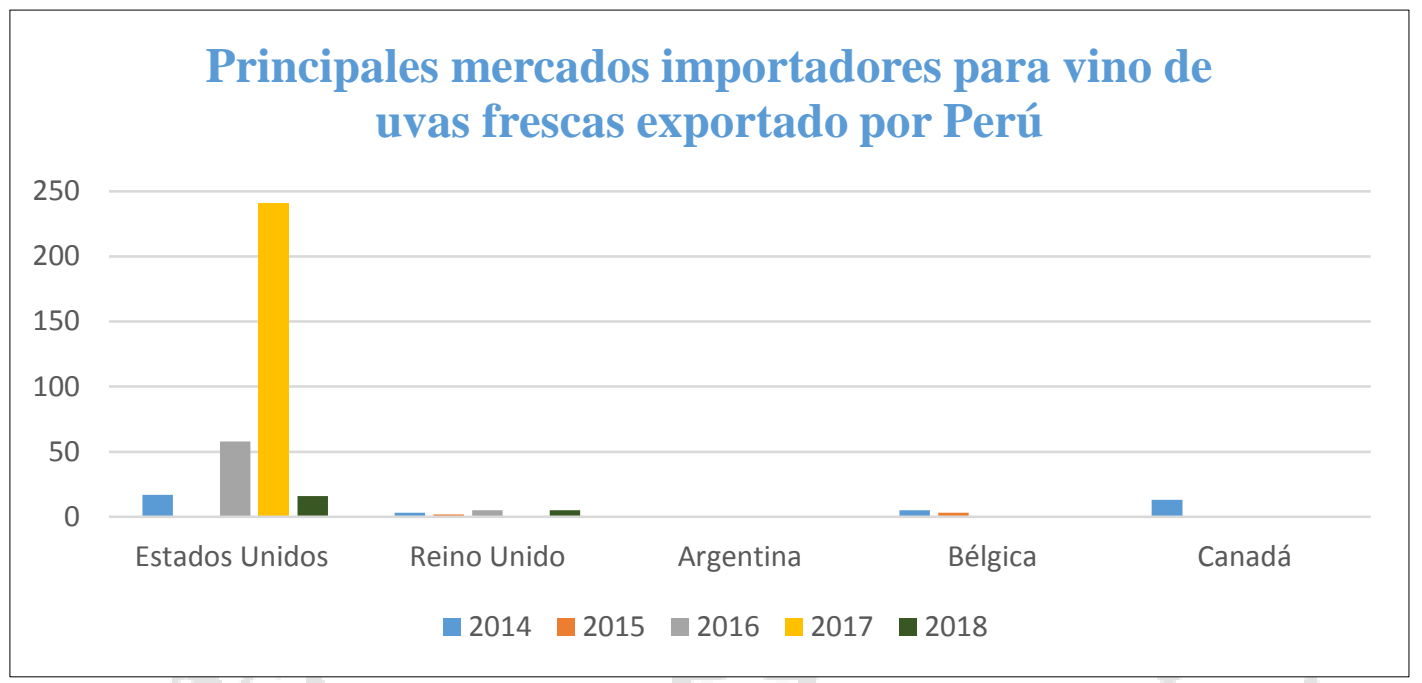

Fuente: Trade Map (2018)

Figura 1.11

Comercio Bilateral de vinos entre Perú y Alemania

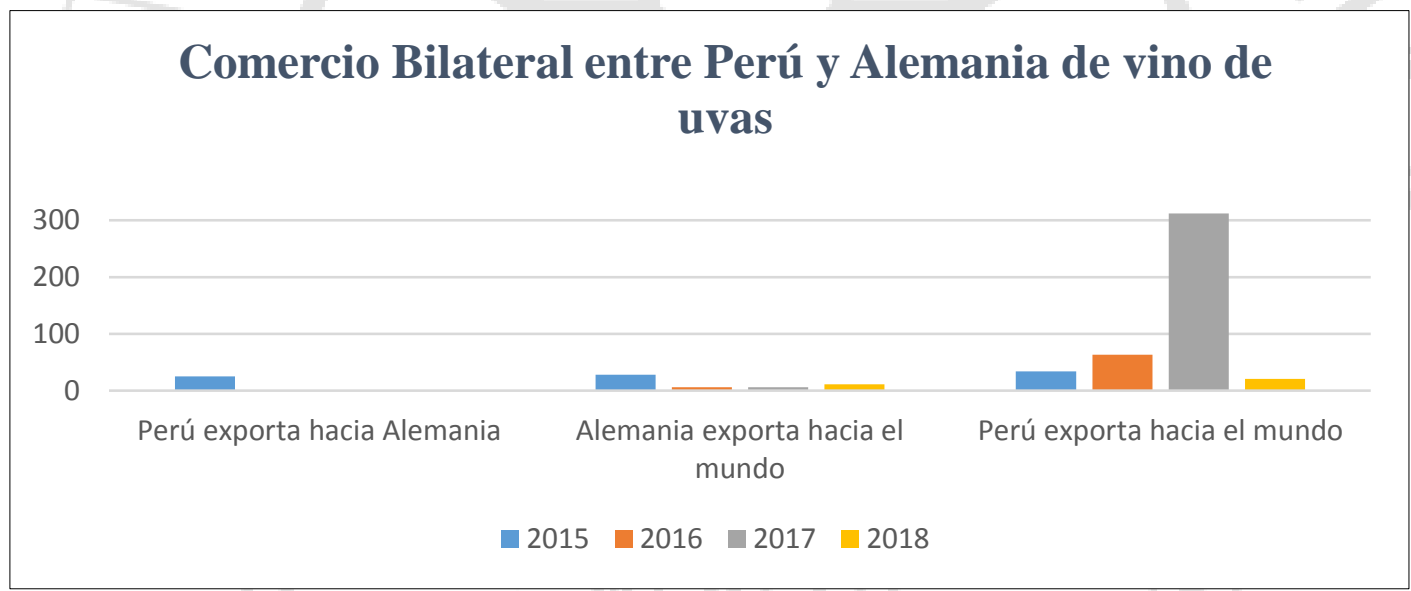

Fuente: Trade Map (2018)

Existe muy poca información histórica sobre el intercambio de bienes y servicios entre Perú y Alemania; sin embargo, esta situación más allá de la poca información numérica es una oportunidad de negocio y de innovación.

\subsubsection{Proyección de la demanda internacional}

\section{a) Población Total del país destino}

Alemania tiene una población de 82,9 millones de habitantes estimada durante el 2018, es una de las más viejas del mundo con una edad promedio de 45.9 años en el 2018. Se 
estima que para el 2030 se incremente a 83.5 millones con una edad promedio de 46.3 años, según Euromonitor International (2019).

\section{b) Población total de la ciudad del país destino}

El producto irá dirigido a la capital, Berlín, que cuenta con un poco más de 5 millones de habitantes.

\section{c) Segmento de la población}

El producto va dirigido para hombres y mujeres jóvenes adultos de entre 30 - 54 años que al menos consuman 1 vez al mes y estrato socioeconómico A y B.

Tabla 1.13

Población segmentada de Alemania

\begin{tabular}{|c|c|c|}
\hline Población (años) & Hombre & Mujer \\
\hline 80 a + & $2,30 \%$ & $3 \%$ \\
\hline 75 a 79 & $2,20 \%$ & $2,80 \%$ \\
\hline 70 a 74 & $2,40 \%$ & $2,60 \%$ \\
\hline 65 a 69 & $2,50 \%$ & $2,90 \%$ \\
\hline 60 a 64 & $3,30 \%$ & $3,40 \%$ \\
\hline 55 a 59 & $3,90 \%$ & $3,95 \%$ \\
\hline 50 a 54 & $4,50 \%$ & $4,50 \%$ \\
\hline 45 a 49 & $3,80 \%$ & $3,80 \%$ \\
\hline 40 a 44 & $3 \%$ & $3 \%$ \\
\hline 35 a 39 & $3 \%$ & $3 \%$ \\
\hline 30 a 34 & $3,30 \%$ & $3,20 \%$ \\
\hline 25 a 29 & $3,20 \%$ & $3,10 \%$ \\
\hline 20 a 24 & $2,90 \%$ & $2,70 \%$ \\
\hline 15 a 19 & $2,50 \%$ & $2,50 \%$ \\
\hline 10 a 14 & $2,30 \%$ & $2,20 \%$ \\
\hline 5 a 9 & $1,90 \%$ & $2,10 \%$ \\
\hline 0 a 4 & $2,10 \%$ & $2,10 \%$ \\
\hline
\end{tabular}

Fuente: Datos Mundial (2018)

\section{d) Mercado Potencial anual en el país destino}

El consumo per cápita promedio del producto se estima en 1 unidad mensual, 12 anuales, con lo cual la demanda mensual es de 5,474 unidades. 
Tabla 1.14

Estimación mercado objetivo

\begin{tabular}{l|cc}
\hline \multicolumn{3}{c}{ Estimación Mercado Objetivo } \\
\hline \multicolumn{1}{c|}{ Criterio } & Valores & Porcentaje \\
\hline Población & $82,695,000$ & $100 \%$ \\
Berlín (Ciudad Destino) & $3,575,000$ & $4.33 \%$ \\
Consumidores de Vino (50\%) & $1,787,500$ & $2.16 \%$ \\
NSE: Alto (35\%) & 625,625 & $0.70 \%$ \\
Población de 30 - 54 años (17.50\%) & 109,484 & $0.22 \%$ \\
Conocedores Vino No alcohólico (5\%) & $\mathbf{5 , 4 7 4}$ & $\mathbf{0 . 0 5 \%}$ \\
\hline
\end{tabular}

Fuente: Datos Mundial (2018)

\subsection{Dimensiones Claves del Mercado}

\subsubsection{Determinación del Costo Promedio}

Para la determinación del costo promedio se analizaron los precios al consumidor final de los vinos vendidos en Alemania. Después de ello, se realizó una estimación del costo mediante el método pricing.

Tabla 1.15

Determinación del precio promedio al consumidor final

\begin{tabular}{|c|c|c|c|c|c|}
\hline Marcas & Empresa & $\begin{array}{l}\text { Puntos de } \\
\text { Ventas }\end{array}$ & $\begin{array}{c}\text { Tamaño } \\
\text { del } \\
\text { envase }\end{array}$ & $\begin{array}{l}\text { Precio } \\
\text { Local } \\
\text { (Euro) } \\
\end{array}$ & $\begin{array}{r}\text { Precio } \\
\text { (US\$) }\end{array}$ \\
\hline Rotkäppchen / Mumm & $\begin{array}{l}\text { Rotkäppchen-Mumm } \\
\text { Sektkellereien GmbH }\end{array}$ & $\begin{array}{l}\text { Tiendas de } \\
\text { descuento }\end{array}$ & $750 \mathrm{ml}$ & 7.99 & 8.75 \\
\hline Andresen Porto & JH Andresen & $\begin{array}{l}\text { Tiendas } \\
\text { Especializadas }\end{array}$ & $750 \mathrm{ml}$ & 16.67 & 18.78 \\
\hline $\begin{array}{l}\text { Moët \& Chandon Grand } \\
\text { Vintage } 2006\end{array}$ & $\begin{array}{l}\text { LVMH Moët Henessy } \\
\text { Louis SA }\end{array}$ & $\begin{array}{l}\text { Tiendas } \\
\text { especializadas }\end{array}$ & $750 \mathrm{ml}$ & 86.65 & 104.06 \\
\hline Sandeman & $\begin{array}{l}\text { Grands Chais de France } \\
\text { SA, Les }\end{array}$ & $\begin{array}{l}\text { Tiendas } \\
\text { especializadas }\end{array}$ & $750 \mathrm{ml}$ & 7.72 & 8.70 \\
\hline Aldi & $\begin{array}{l}\text { Aldi Einkauf GmbH \& } \\
\text { Co oHG }\end{array}$ & $\begin{array}{l}\text { Tiendas de } \\
\text { descuento }\end{array}$ & $750 \mathrm{ml}$ & 5.99 & 6.75 \\
\hline Lidl & Private Label & $\begin{array}{l}\text { Tiendas de } \\
\text { descuento }\end{array}$ & $750 \mathrm{ml}$ & 3.99 & 4.49 \\
\hline $\begin{array}{l}\text { Henriques \& Henriques } \\
\text { Madeira }\end{array}$ & $\begin{array}{l}\text { Mertes KG Weinkellerei, } \\
\text { Peter }\end{array}$ & $\begin{array}{l}\text { Tiendas } \\
\text { especializadas }\end{array}$ & $750 \mathrm{ml}$ & 18.00 & 20.29 \\
\hline Mumm & $\begin{array}{l}\text { Godefroy H von Mumm } \\
\& \text { Co Sektkellereien } \\
\text { GmbH }\end{array}$ & Supermercados & $750 \mathrm{ml}$ & 7.72 & 8.70 \\
\hline Lidl & $\begin{array}{l}\text { Lidl \& Schwarz Stiftung } \\
\text { \& Co KG }\end{array}$ & $\begin{array}{l}\text { Tiendas de } \\
\text { descuento }\end{array}$ & $750 \mathrm{ml}$ & 7.99 & 9.00 \\
\hline Concha y Toro & Viña Concha y Toro SA & $\begin{array}{l}\text { Tiendas de } \\
\text { descuento }\end{array}$ & $750 \mathrm{ml}$ & 23.00 & 25.66 \\
\hline
\end{tabular}

Fuente: Euromonitor International (2019) 
Con respecto a la proyección de precio, al ser un producto nuevo o con poco desarrollo no existe un análisis del histórico de precios, existe una gran diversidad de vinos entre nacionales e importados que se venden en Alemania a diferentes precios como se puede ver en la tabla anterior, entre vinos premium y económicos.

Una de las principales características de Vinka es ser un vino premium de la más alta calidad; por ello, se espera que el precio final a los consumidores sea superior a los vinos económicos pero un poco más económico que los vinos premium que con la experiencia en el mercado y el reconocimiento que llevan, no sería factible considerar el mismo precio.

Según Euromonitor International (2018), los precios de vinos premium han tenido un ligero aumento del 3\% el 2018 a comparación del 2017. Se estima que los siguientes 5 años tenga una proyección en aumento.

Tabla 1.16

Evolución de precios estimados del vino premium en Alemania (Millones - Euros)

\begin{tabular}{|c|c|c|c|c|c|c|c|}
\hline Año & $\mathbf{2 0 1 7}$ & $\mathbf{2 0 1 8}$ & $\mathbf{2 0 1 9}$ & $\mathbf{2 0 2 0}$ & $\mathbf{2 0 2 1}$ & $\mathbf{2 0 2 2}$ & $\mathbf{2 0 2 3}$ \\
\hline Vinos Premium & $1.068,00$ & $1.102,30$ & $1.141,80$ & $1.178,40$ & $1.214,50$ & $1.250,40$ & $1.285,90$ \\
\hline
\end{tabular}

Fuente: Euromonitor International (2018)

\subsubsection{Canales de comercialización y distribución del producto}

El producto va a ser comercializado por canal Off-trade debido a que representa más del $80 \%$ de uso en Alemania. Dentro de este canal tenemos los "discounters" o tiendas por descuento, tiendas especializadas y supermercados con una participación de más del 50\%, esto debido a la gran accesibilidad para realizar compras.

Uno de los objetivos en el largo plazo, se proyecta que la empresa cuente con un punto de venta propio sin la necesidad de distribuidores, cuando la marca se encuentre posicionada y consolidada con un gran portafolio de productos capaz de satisfacer las necesidades competitivas del mercado destino. 
Figura 1.12

Canales de vinos premium Off Trade - On Trade en Alemania

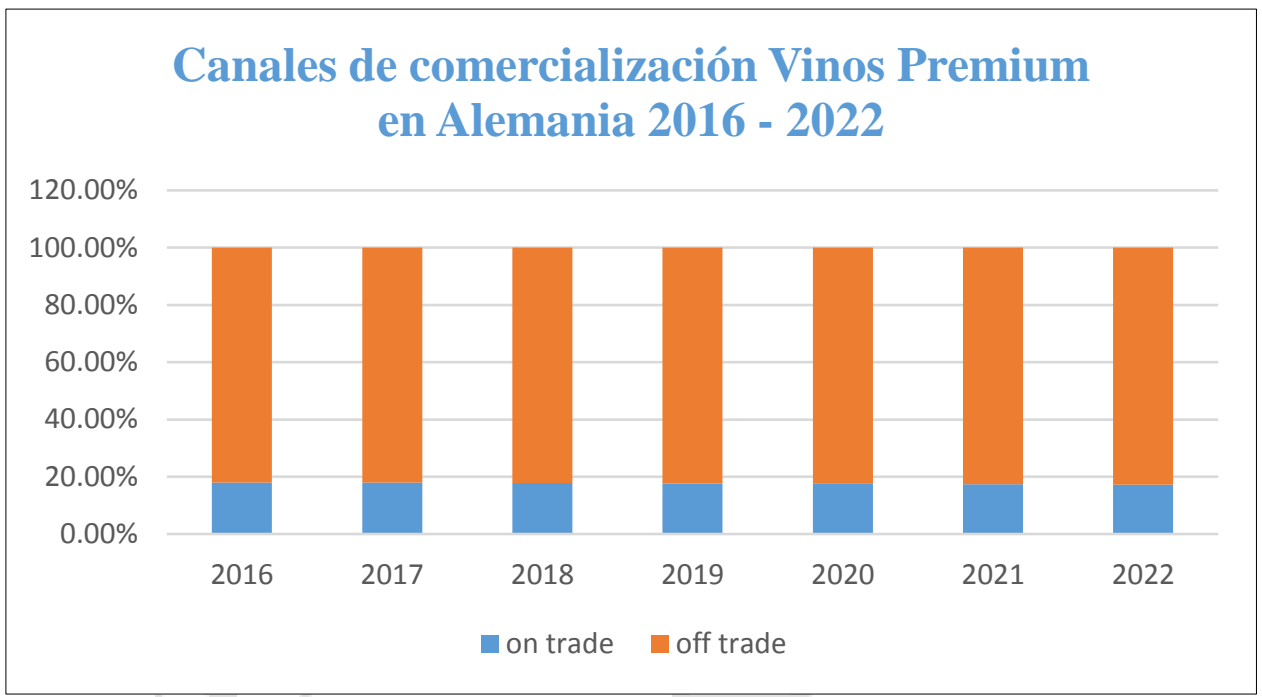

Fuente: Euromonitor International (2018)

Tabla 1.17

Tiendas de descuento y tiendas especializadas en Berlín, Alemania

\begin{tabular}{l|l}
\hline \multicolumn{2}{c}{ Tiendas de Descuentos, Especializadas y Supermercados en Alemania } \\
\hline TEDI Top Euro Store & Tienda de Descuento \\
Euroshop Store & Tienda de Descuento \\
LiDL Store & Tienda de Descuento, Supermercado \\
ALDI Store & Tienda de Descuento, Supermercado \\
Tchibo Prozente & Tienda de Descuento \\
Garlipp Weinhandlung Berlín & Tienda especializada de Vinos \\
Le Flaneur & Tienda especializada de Vinos \\
Weinhandlung Baumgart \& Braun & Tienda especializada de Vinos \\
Ursula Kierzek Berlín & Tienda especializada de Vinos \\
\hline
\end{tabular}

Fuente: Tiendas de descuento y especializadas en Berlín (2018)

Entre las cuales destacan ALDI Store y Garlipp Weinhandlung Berlín como potenciales tiendas de distribución de los vinos no alcohólicos. 
Figura 1.13

Empresas que comercializan Vinos Premium en Alemania

\begin{tabular}{|c|c|c|c|}
\hline \multicolumn{2}{|c|}{$\begin{array}{l}\text { Company Shares of Fine Wines/Champagne and Spirits } \\
\% \text { Share (NBO) - Retail Value RSP - } 2017\end{array}$} & \multicolumn{2}{|c|}{ 卧曲 } \\
\hline Moët Hennessy Deutschlan... & ש & $6.4 \%$ & $\boldsymbol{\Delta}$ \\
\hline Eggers \& Franke GmbH & 【 & $1.9 \%$ & $\boldsymbol{\nabla}$ \\
\hline Vranken-Pommery Deutschl... & I & $1.6 \%$ & $\boldsymbol{\Delta}$ \\
\hline Bacardi GmbH & I & $0.8 \%$ & $\boldsymbol{\Delta}$ \\
\hline Diageo Deutschland GmbH & I & $0.7 \%$ & $\boldsymbol{\Delta}$ \\
\hline Pernod Ricard Deutschlan... & I & $0.6 \%$ & $\boldsymbol{\Delta}$ \\
\hline Champagne Taittinger & I & $0.6 \%$ & $\boldsymbol{\nabla}$ \\
\hline Campari Deutschland GmbH & 1 & $0.2 \%$ & $\boldsymbol{\Delta}$ \\
\hline Rémy Cointreau Group & I & $0.2 \%$ & $\boldsymbol{\Delta}$ \\
\hline Diversa Spezialităten Gm... & & $0.0 \%$ & $\boldsymbol{\nabla}$ \\
\hline Others & - & $87.1 \%$ & $\boldsymbol{\nabla}$ \\
\hline
\end{tabular}

Fuente: Euromonitor International (2018)

\section{Figura 1.14}

Marcas que comercializan Vinos Premium en Alemania

\begin{tabular}{|c|c|c|c|}
\hline \multicolumn{2}{|c|}{$\begin{array}{l}\text { Brand Shares of Fine Wines/Champagne and Spirits } \\
\% \text { Share (LBN) - Retail Value RSP - } 2017\end{array}$} & \multicolumn{2}{|c|}{ 再目 } \\
\hline Moet \& Chandon & - & $2.2 \%$ & $\boldsymbol{\Delta}$ \\
\hline Veuve Clicquot & Ш & $2.0 \%$ & $\boldsymbol{\Delta}$ \\
\hline Piper-Heidsieck Champagn... & 匹 & $1.9 \%$ & $\boldsymbol{\nabla}$ \\
\hline Pommery & I & $1.6 \%$ & $\boldsymbol{\Delta}$ \\
\hline Ruinart & $\mathbf{I}$ & $0.9 \%$ & $\boldsymbol{\nabla}$ \\
\hline Grey Goose & $\mathbf{I}$ & $0.8 \%$ & $\boldsymbol{\Delta}$ \\
\hline Belvedere & $\mathbf{I}$ & $0.8 \%$ & $\boldsymbol{\Delta}$ \\
\hline Taittinger & $\mathbf{I}$ & $0.6 \%$ & $\boldsymbol{\nabla}$ \\
\hline Hennessy XO & 1 & $0.5 \%$ & $\boldsymbol{\Delta}$ \\
\hline Ciroc & 1 & $0.3 \%$ & $\boldsymbol{\Delta}$ \\
\hline Gosset & 1 & $0.2 \%$ & $\boldsymbol{\Delta}$ \\
\hline Lagavulin 16 YO & 1 & $0.2 \%$ & $\boldsymbol{\Delta}$ \\
\hline Ballantine's 21 YO & 1 & $0.2 \%$ & $\boldsymbol{\Delta}$ \\
\hline Talisker & & $0.2 \%$ & $\boldsymbol{\Delta}$ \\
\hline
\end{tabular}

Fuente: Euromonitor International (2018)

Por otro lado, los vinos no alcohólicos están despegando en el continente europeo, es la Marca "WIN ZERO" de la empresa española WIN, con gran potencial en el continente y con el respaldo de una empresa con muchos años de experiencia en el mercado. 
Figura 1.15

Vino Tinto no alcohólico WIN

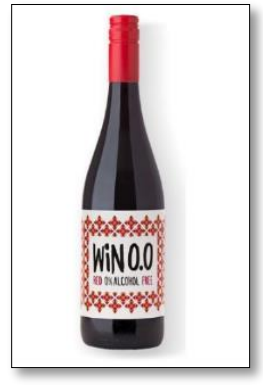

Fuente: Win Zero (2018)

Una competencia más cercana, en América del Sur, nuestro vecino país del sur, Chile ha desarrollado un vino alcohólico llamado "INVICTO" de la Cooperación de Vitivinícola en San Javier, al sur de Santiago de Chile.

Figura 1.16

Vino No Alcohólico INVICTO

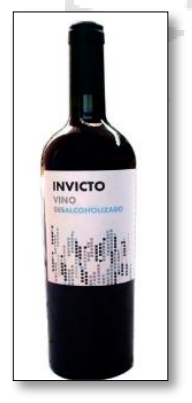

Fuente: Invicto (2016)

Alemania es un país conocido por tener un gran consumo en cerveza. Sin embargo, encontramos bebidas alternativas que también son consumidas en el mercado destino, ocupando el segundo lugar, y donde más preferencia y consumo hay dentro de la categoría de bebidas alcohólicas es el vino que se inserta como una bebida alternativa, con un sabor diferente que atiende costumbres y hábitos de consumo de un nicho de mercado en Alemania. A diferencia del vino tradicional, nuestro producto será no alcohólico y con sabores diversificados. 
Figura 1.17

Productos alternativos de mayor consumo en Alemania

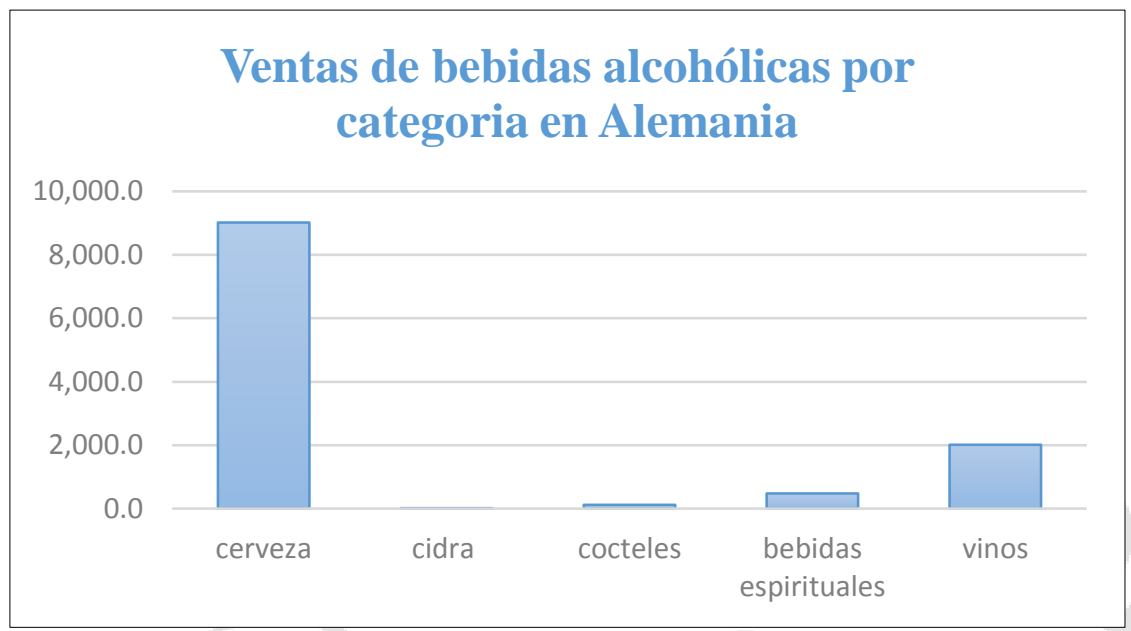

Fuente: Euromonitor International (2018)

\subsection{Análisis de la Oferta}

Los niveles de exportación de bebidas no alcohólicas a nivel mundial se encuentran liderado por países europeos, dentro del Top 5 están Suiza, Holanda, y Alemania, ubicados en el primer, tercer y cuarto lugar con respectivamente; Tailandia y Estados Unidos América completan la lista. Alemania tuvo un ligero incremento de $12 \%$ aproximadamente con respecto a la partida arancelaria 2202990000 perteneciente a bebidas no alcohólicas con excepción de agua, jugos de frutas, leche y cerveza.

Figura 1.18

Principales países exportadores de bebidas no alcohólicas en el Mundo (Valores)

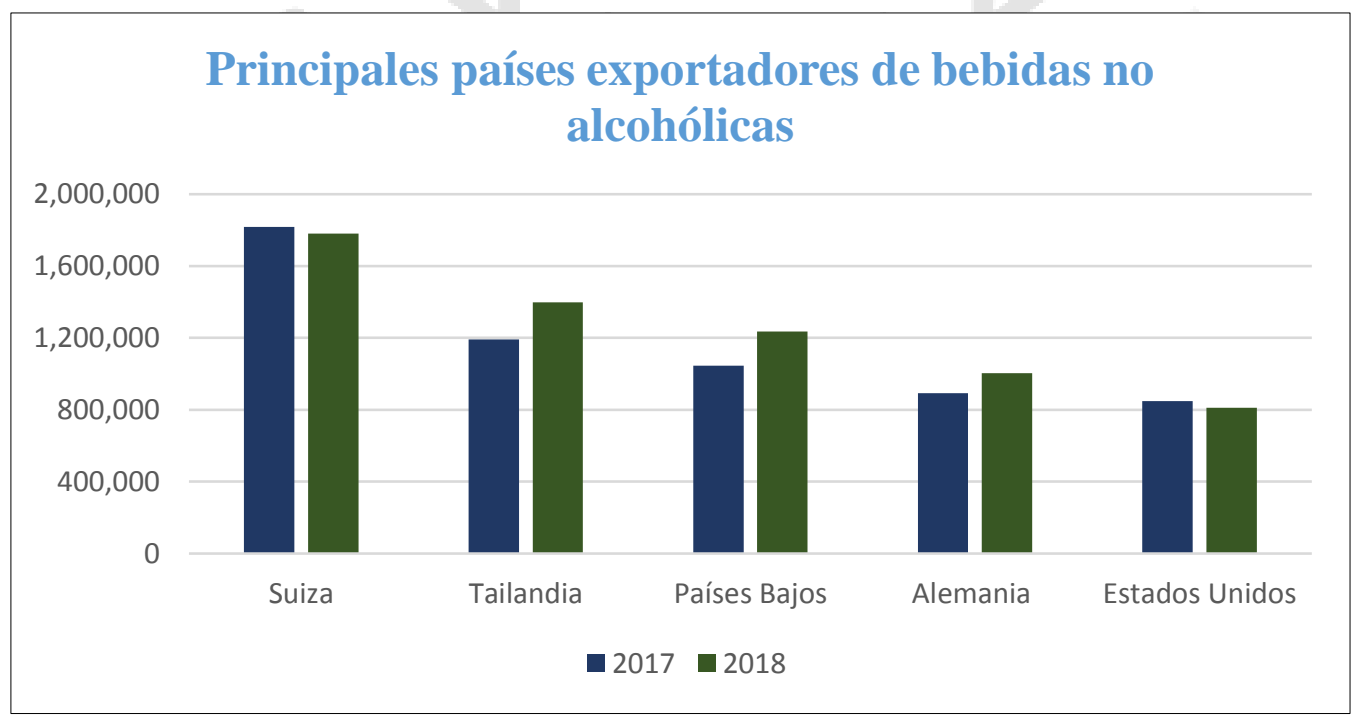

Fuente: Trade Map (2018) 
Figura 1.19

Principales países exportadores de bebidas no alcohólicas por Alemania (Valores)

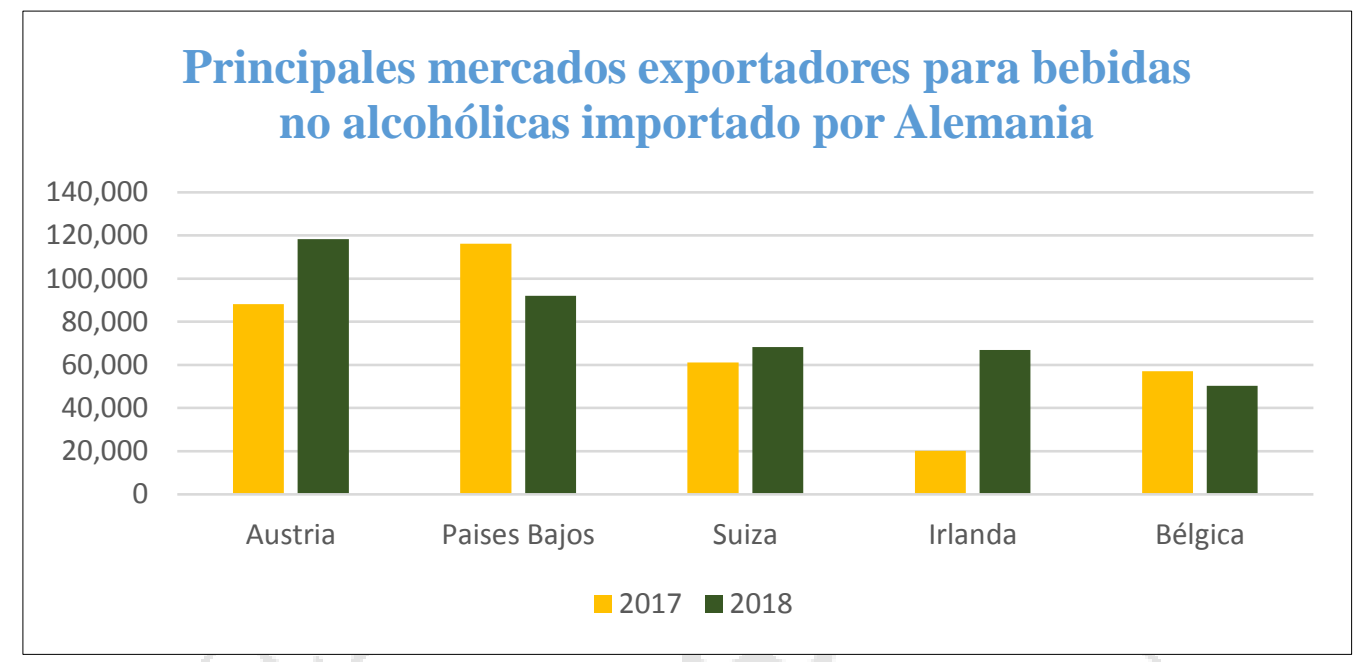

Fuente: Trade Map (2018)

Mientras tanto, los 5 principales países que exportan bebidas no alcohólicas a Alemania son todos europeos, entre ellos ubicados de mayor a menor con respecto a volumen, Austria, Holanda, Suiza, Irlanda y Bélgica. Irlanda tuvo un importante crecimiento de casi 3 veces más el volumen que exportó durante el 2017, Austria incrementó en un 34\% y Suiza en un 11\%; sin embargo, Holanda y Bélgica tuvieron un descenso de $26 \%$ y $13 \%$ respectivamente.

Con respecto al mercado de vinos a nivel mundial, se tiene a España como el mayor exportador de vinos con una participación de $20.90 \%$ en el mercado, seguido de Italia en segundo lugar y Chile en tercer lugar con $11.35 \%$, podemos deducir que un competidos directo con ventajas comparativas al mercado peruano es Chile que representa un reto ya que Perú se encuentra en el puesto 59 en este ranking, según Trade Map (2018) 
Figura 1.20

Principales países exportadores de vinos en el Mundo (Valores)

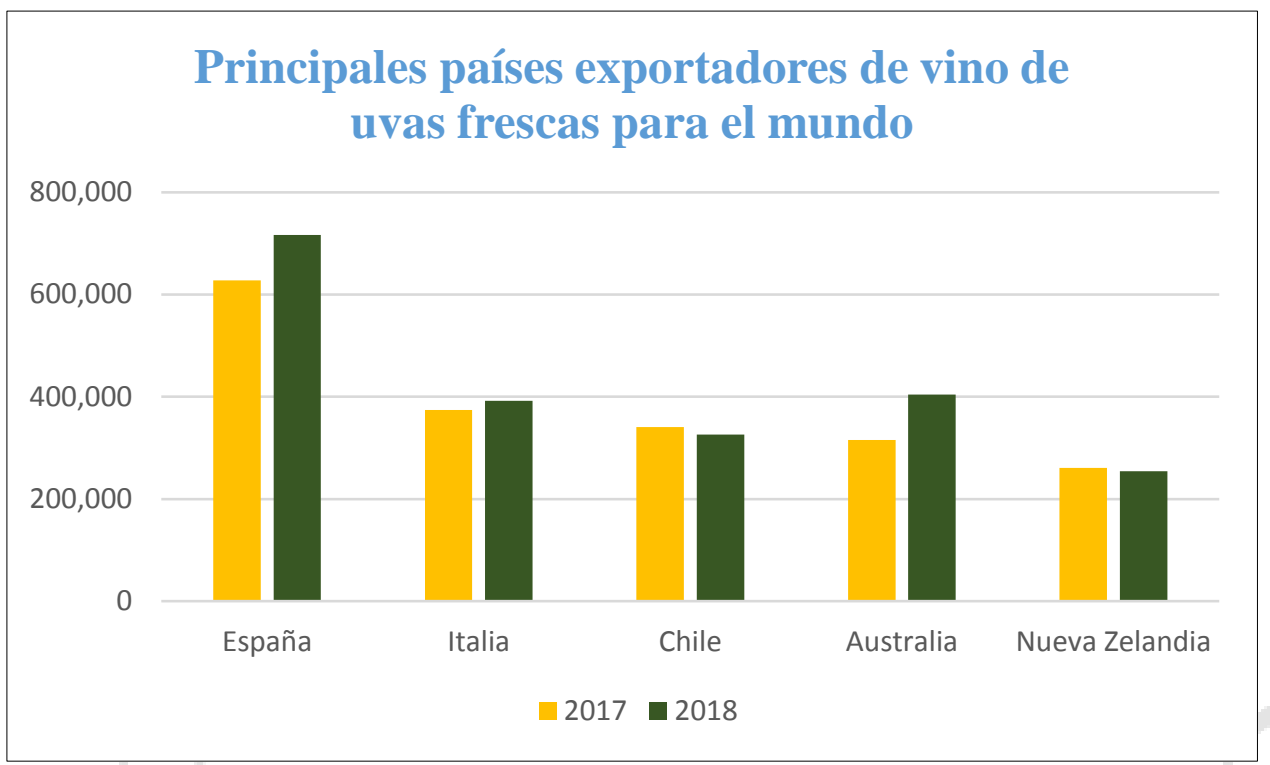

Fuente: Trade Map (2018)

Como proveedores del mercado alemán, Italia lidera la lista con una participación del $30.5 \%$ en el 2018, seguido de España con el 23.8\%, Francia con $11.6 \%$ y Sudáfrica con $8.2 \%$ en el cuarto lugar. Dentro del Top 10, se encuentra Chile ubicado en el sexto lugar con una participación de $5,2 \%$, quien vendría a ser un competidor directo para la marca Vinka.

Figura 1.21

Principales países exportadores de vinos importado por Alemania (Valores)

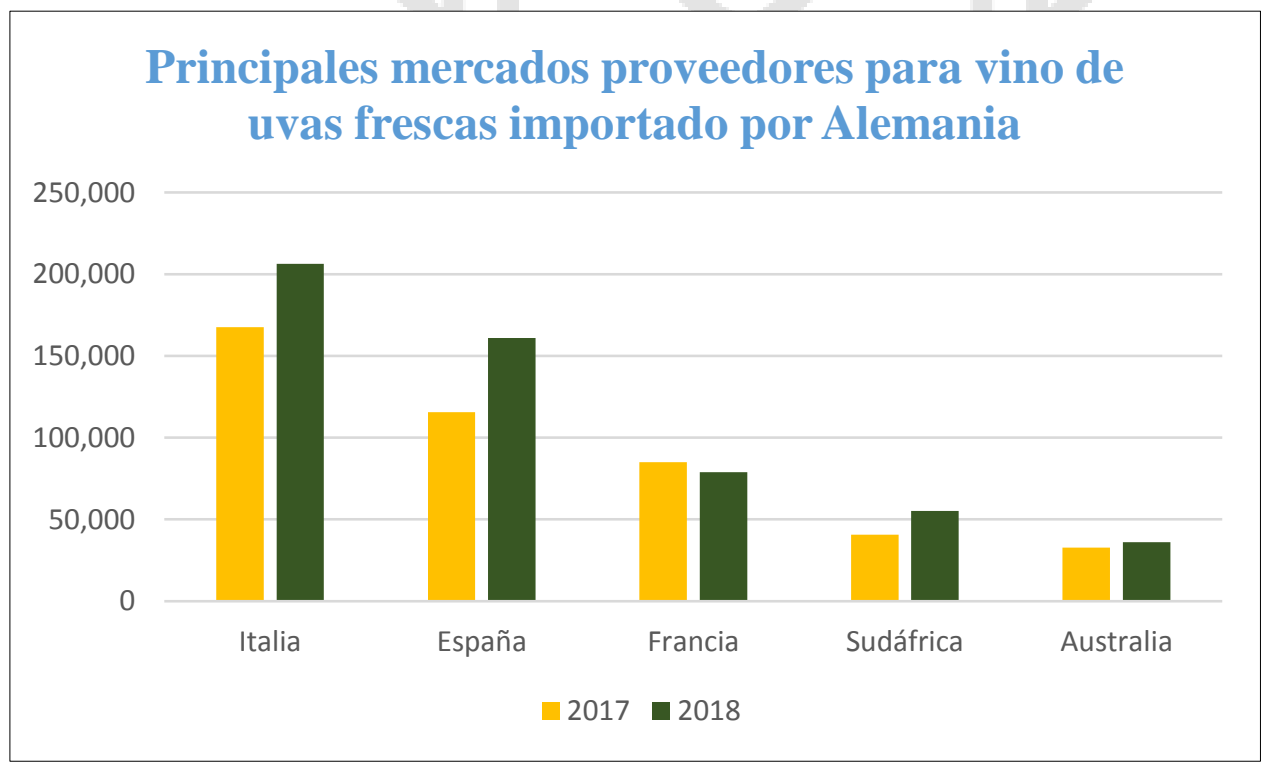

Fuente: Trade Map (2018) 


\subsubsection{Proyección de la Oferta}

Según Euromonitor International (2018), se espera que las ventas de vinos premium pasaron de ser 1,068.0 al 2017 a 1,285.90 millones de euros para el 2023. Obteniendo un crecimiento porcentual del periodo 2017-2023 del 20.40\%.

Figura 1.22

Proyección de ventas de vinos Premium Alemania (Valores)

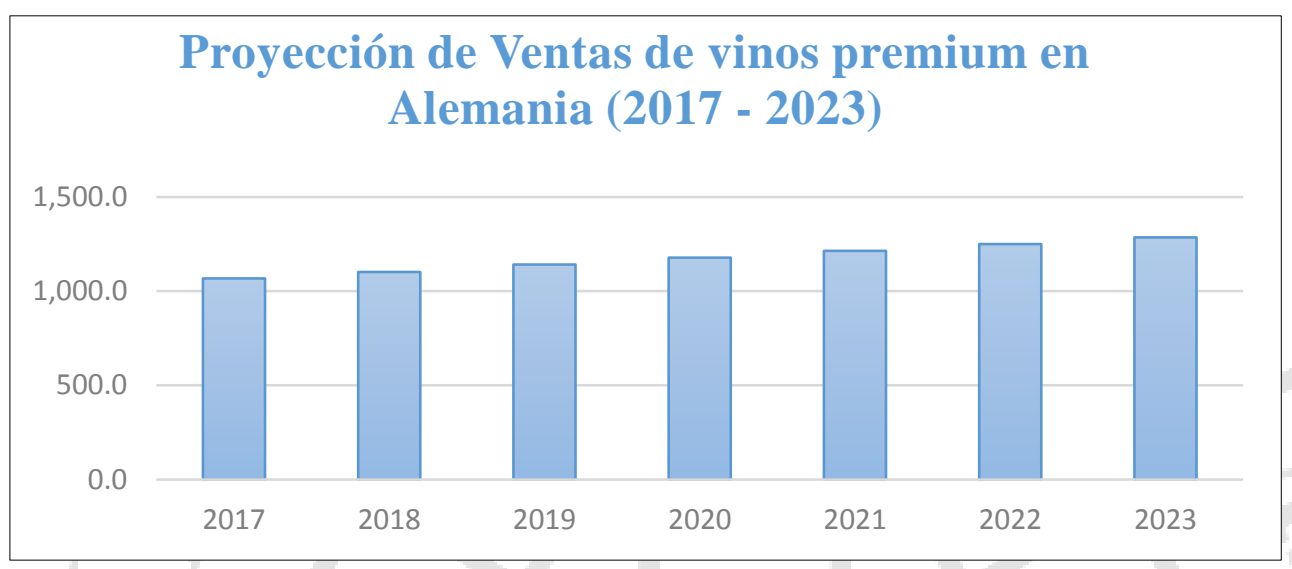

Fuente: Euromonitor International (2018)

\subsection{Matriz del Perfil Competitivo}

En la siguiente matriz evaluaremos a la competencia. Hemos identificado factores claves que nos hacen competitivos con respecto a las demás empresas exportadores de vino alcohólico en el mercado internacional. Y serán claves en la administración, gestión y desarrollo de las actividades para la empresa. Se presentan 8 Factores determinantes de éxito y lo hemos medido dándole una puntuación máxima de 4 (Fortaleza Mayor) y mínima de 1 (Debilidad Mayor); en donde, los factores deben tener un peso de $100 \%$ en total.

Tabla 1.18

Matriz del perfil competitivo

\begin{tabular}{|l|l|}
\hline \multicolumn{2}{|c|}{ PUNTUACION } \\
\hline Fortaleza Mayor & 4 \\
Fortaleza Menor & 3 \\
Debilidad Menor & 2 \\
Debilidad Mayor & 1 \\
\hline
\end{tabular}




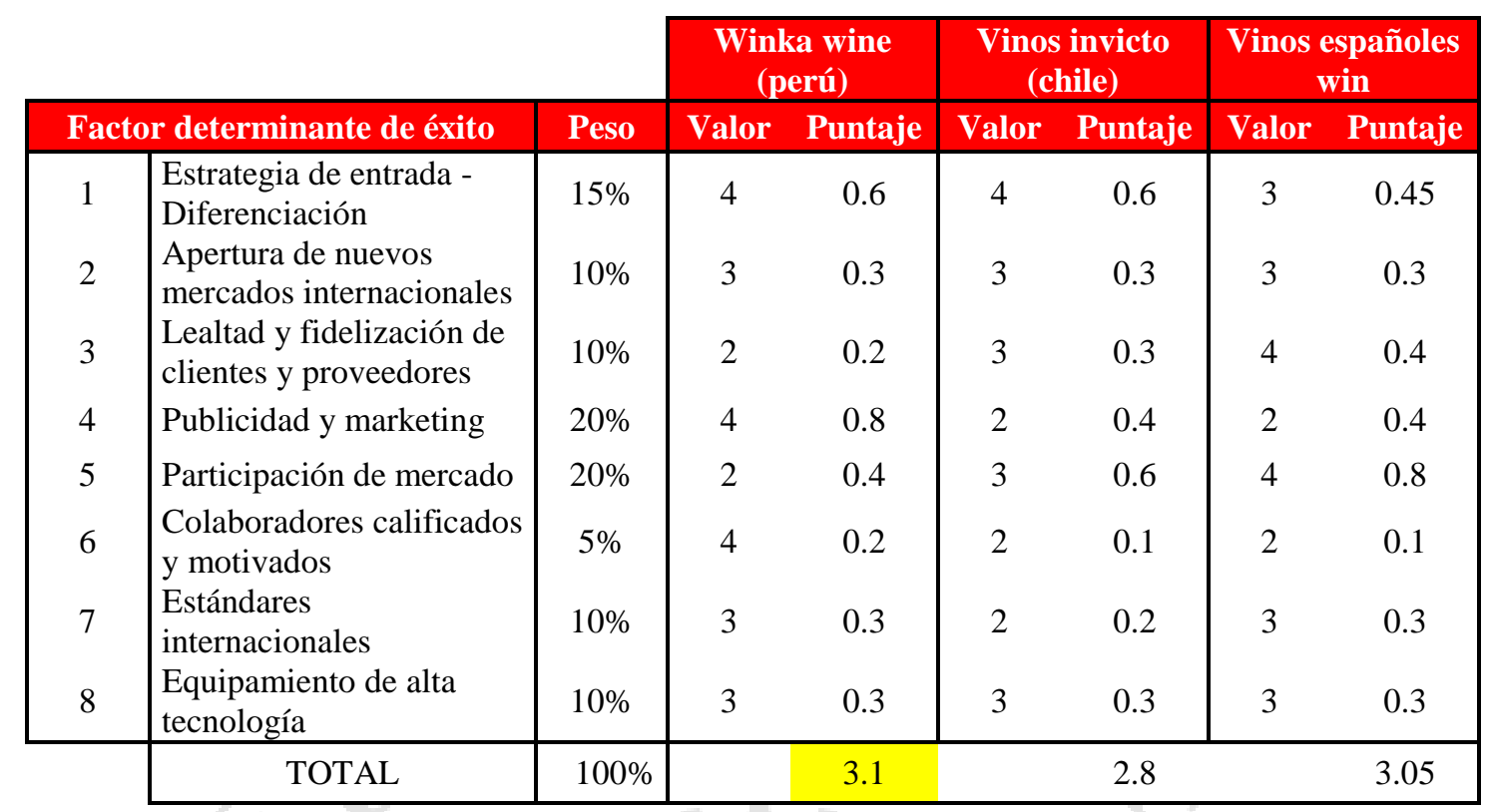

Elaboración propia

Habiéndose ejecutado la matriz, se alcanzó una puntuación de 3.10 para Vinka. Esta puntuación nos indica que se tiene una ventaja competitiva con Vinos Invicto de Chile, nuestro principal competidor de la región; con un puntuación de 2.80. Asimismo, la la empresa española WIN-Zero productora de vinos sin alcohol en españa obtuvo una puntuación de 3.05, se tiene una ligera ventaja ya que nuestro producto es más premium que los vinos WIN, sin embargo el expertise de la empresa española hace un competidor fuerte sobre todo porque se encuentra en el continente europeo. 


\section{CAPÍTULO II: PLAN DE MARKETING Y COMERCIALIZACIÓN INTERNACIONAL}

El plan de marketing estará precedido por el área comercial y de marketing que se trabajará en sinergia para el cumplimiento de los objetivos.

Según Juan Manuel de Toro y Julián Villanueva (2017), la mayoría de las compañias usan el concepto de marketing para el grupo de actividades comerciales; mientras tanto para otras empresas representa a las acciones para mejorar el proceso de venta. (p. 22)

Se utilizará la matriz DAFO para analizar las características internas y externas de la empresa; es decir, sus fortalezas y debilidades como facttores internos, factores externos compuestos por sus amenazas y oportunidades, a partir de un analisis exhaustivo se podrá plantear las estrategias en el corto plazo 


\begin{tabular}{|c|c|c|}
\hline & Fortalezas: F & Debilidades: D \\
\hline & $\begin{array}{l}\text { 1.- Certificaciones de Calidad (HACCP, BPM). } \\
\text { 2.- Producto Premium con alto valor agregado e innovación. } \\
\text { 3.- Producto con insumos naturales. } \\
\text { 4.- La imagen de la marca asociada con el desarrollo sostenible, la } \\
\text { responsabilidad social y la ética empresarial. } \\
\text { 5.- Insumos abastecidos por asociaciones de productores. } \\
\text { 6.- Empaque y envase biodegradable. } \\
\text { 7.- Diversificación de productos }\end{array}$ & $\begin{array}{l}\text { 1.- Marca nueva en el mercado. } \\
\text { 2.- Larga distancia del mercado destino. } \\
\text { 3.- Se necesita de canales de comercialización ya que no cuenta } \\
\text { con tienda propia. } \\
\text { 4.- Bajo nivel de inversión para la realización de la promoción. } \\
\text { 5.- Mercado de vinos no alcohólicos incipiente (No desarrollado). } \\
\text { 6.- La nula data histórica de exportación de vinos de Perú a } \\
\text { Alemania. }\end{array}$ \\
\hline Oportunidades: 0 & \begin{tabular}{|l} 
Estrategias - FO \\
\end{tabular} & \begin{tabular}{|c|} 
Estrategias - DO \\
\end{tabular} \\
\hline $\begin{array}{l}\text { 1.- Nuevas tendencias de consumo de productos saludables. } \\
\text { 2.- Preferencia de Alemania por el consumo de bebidas premium } \\
\text { y no alcohólicas. } \\
\text { 3.- TLC entre Perú y la Unión Europea (UE) vigente desde el } \\
\text { 2013 que cuenta con preferencias arancelarias para productos } \\
\text { peruanos. } \\
\text { 4.- Alto poder adquisitivo del público objetivo ( } 30 \text { - } 50 \text { años). } \\
\text { 5.- Mercado incipiente con grandes oportunidades de desarrollo. } \\
\text { 6.- La creciente inmigración de musulmanes a Alemania que por } \\
\text { religión no consumen bebidas alcohólicas podría significar otro } \\
\text { público objetivo en el corto plazo. }\end{array}$ & $\begin{array}{l}\text { (F1 y O1, O2) Penetración de mercado a un público exigente de busca } \\
\text { productos de calidad. } \\
\text { (F2 y O2) Estrategia de conocimiento para el consumidor como vino } \\
\text { Premium. } \\
\text { (F3 y O1, O3, O4) Los productos naturales representan a las tendencias } \\
\text { mundiales en los próximos } 10 \text { años. } \\
\text { (F4 y O2, O4) Internacionalización de un producto requiere una gran } \\
\text { estrategia de posicionamiento de marca y branding. } \\
\text { (F5 y O2) Los consumidores alemanes tienen preferencia por productos } \\
\text { elaborados por asociaciones. } \\
\text { (F6 y O1) Atraer personas con conocimiento del cuidado del medio } \\
\text { ambiente. } \\
\text { (F7 y O5, O6) }\end{array}$ & $\begin{array}{l}\text { (D1 y O1, O2, O5, O6) Se va a crear un nuevo producto capaz de } \\
\text { satisfacer necesidades previamente identificadas. } \\
\text { (D2 y O3) Aprovechar el TLC para beneficios arancelarios y la } \\
\text { infraestructura del destino que es un país de primer mundo. } \\
\text { (D3 y O4) Desarrollar estrategias de buenas relaciones y } \\
\text { fidelización con las principales cadenas de tiendas especializadas } \\
\text { en vino. } \\
\text { (D4 y O1 O2 O4 O5) Promocionar los vinos vía redes sociales que } \\
\text { son un medio de promoción gratuito. } \\
\text { (D5 y O1, O5) Aprovechar las nuevas tendencias de preferencias y } \\
\text { consumo en los próximos } 10 \text { años. } \\
\text { (D6 y O3) La oportunidad de incursionar en un rubro no tan } \\
\text { conocido y hacernos conocidos por la calidad del producto. }\end{array}$ \\
\hline Amenazas: A & $\begin{array}{l}\text { Estrategias- FA } \\
\end{array}$ & Estrategias- DA \\
\hline $\begin{array}{l}\text { 1.- Productos sustitutos y alternativos por parte de la } \\
\text { competencia. } \\
\text { 2.- La poca costumbre y conocimiento sobre el consumo del vino } \\
\text { no alcohólico. } \\
\text { 3.- Los productos de la competencia que se encuentran en Europa, } \\
\text { ventaja logística. } \\
\text { 4.- Fenómenos climatológicos que puedan afectar la } \\
\text { estacionalidad y producción de los insumos del vino (Uva, camu } \\
\text { camu, aguaymanto). } \\
\text { 5.- La percepción de la presentación convencional del vino que } \\
\text { por años ha sido una tradición. }\end{array}$ & $\begin{array}{l}\text { F2 y A1, A2) Diferenciarse de los productos sustitutos y competidores, } \\
\text { por medio de una estrategia de branding internacional y manejo de } \\
\text { marca. } \\
\text { (F3 y A1) Los consumidores han hecho costumbre de preferir productos } \\
\text { prácticos de fácil uso. Nuestro producto además de natural será } \\
\text { diferenciador. } \\
\text { (F4 y A5) Fomentar un aprendizaje y conocimiento del vino no } \\
\text { alcohólico como bebida no alcohólica. } \\
\text { (F5 y A4) Hacer una planificación de trabajo con las asociaciones de tal } \\
\text { manera de reducir los efectos climatológicos. } \\
\text { (F7 y A3) Aprovechar la infraestructura logística del país destino en } \\
\text { relación a las competencias más cercanas. }\end{array}$ & $\begin{array}{l}\text { (D1 y A1, A3, A5) Ampliar la diversificación de productos y los } \\
\text { mercados destinos para un mejor desarrollo del producto. } \\
\text { (D4 y A2, A3) Formar alianzas estratégicas con distribuidores en el } \\
\text { país destino, que sean aliados en el proceso de marketing y } \\
\text { comercialización. }\end{array}$ \\
\hline
\end{tabular}

por años ha sido una tradición.

- Se necesita de canales de comercialización ya que no cuenta con tienda propia.

5.- Mercado de vinos no alcohólicos incipiente (No desarrollado).

6. La nula data histórica de exportación de vinos de Perú a Alemania. (D2

O3) Aprovechar el TLC para beneficios arancelarios y

fidelización con las principales cadenas de tiendas especializadas en vino.

y 0102 O4 O5) Promocionar los vinos vía redes sociales que de promoción gratuito.

consumo en los próximos 10 años.

(D6 y O3) La oportunidad de incursionar en un rubro no tan

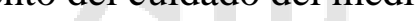
ambiente.

relación a las competencias más cercanas.

\section{Estrategias- FA}

F2 y A1, A2) Diferenciarse de los productos sustitutos y competidores, marca.

Fomentar un aprendizaje y conocimiento del vino no

(F5 y A4) Hacer una planificación de trabajo con las asociaciones de tal manera de reducir los efectos climatológicos. re
(D1 y A1, A3, A5) Ampliar la diversificación de productos y los mercados destinos para un mejor desarrollo del producto.

país destino, que sean aliados en el proceso de marketing y

comercialización. 


\subsection{Matriz Interna- Externa (IE)}

Tabla 2.2

Matriz de Evaluación de Factores Externos (EFE)

\begin{tabular}{|c|c|c|c|}
\hline EFE & $\begin{array}{c}\text { Pes } \\
0\end{array}$ & $\begin{array}{l}\text { Valo } \\
\text { r }\end{array}$ & $\begin{array}{c}\text { Ponderació } \\
\mathrm{n}\end{array}$ \\
\hline \multicolumn{4}{|l|}{ Oportunidades } \\
\hline 1.- Nuevas tendencias de consumo de productos saludables. & 0.11 & 4 & 0.44 \\
\hline $\begin{array}{l}\text { 2.- Preferencia de Alemania por el consumo de bebidas premium y no } \\
\text { alcohólicas. }\end{array}$ & 0.10 & 4 & 0.40 \\
\hline $\begin{array}{l}\text { 3.- TLC entre Perú y la Unión Europea (UE) vigente desde el } 2013 \text { que } \\
\text { cuenta con preferencias arancelarias para productos peruanos. }\end{array}$ & 0.10 & 4 & 0.40 \\
\hline 4.- Alto poder adquisitivo del público objetivo ( 30 - 50 años). & 0.09 & 4 & 0.36 \\
\hline 5.- Mercado incipiente con grandes oportunidades de desarrollo. & 0.12 & 4 & 0.48 \\
\hline $\begin{array}{l}\text { 6.- La creciente inmigración de musulmanes a Alemania que por religión } \\
\text { no consumen bebidas alcohólicas podría significar otro público objetivo } \\
\text { en el corto plazo. }\end{array}$ & 0.08 & 3 & 0.24 \\
\hline Subtotal & 0.60 & & 2.32 \\
\hline \multicolumn{4}{|l|}{ Amenazas } \\
\hline 1.- Productos sustitutos y alternativos por parte de la competencia. & 0.09 & 2 & 0.18 \\
\hline $\begin{array}{l}\text { 2.- La poca costumbre y conocimiento sobre el consumo del vino no } \\
\text { alcohólico. }\end{array}$ & 0.08 & 2 & 0.16 \\
\hline $\begin{array}{l}\text { 3.- Los productos de la competencia que se encuentran en Europa, ventaja } \\
\text { logística. }\end{array}$ & 0.10 & 2 & 0.20 \\
\hline $\begin{array}{l}\text { 4.- Fenómenos climatológicos que puedan afectar la estacionalidad y } \\
\text { producción de los insumos del vino (Uva, camu camu, aguaymanto). }\end{array}$ & 0.07 & 2 & 0.14 \\
\hline $\begin{array}{l}\text { 5.- La percepción de la presentación convencional del vino que por años } \\
\text { ha sido una tradición. }\end{array}$ & 0.06 & 1 & 0.06 \\
\hline Subtotal & 0.40 & & 0.74 \\
\hline Total & | & & 3.06 \\
\hline
\end{tabular}

Nota: Valor $=4$. Muy bien; 3. Bien; 2. Promedio: 1 . Mal

Elaboración propia

En la siguiente matriz se evaluarán los factores externos que competen a la empresa. Como resultado final si representa mayor o igual a 2.5 significa que se tiene respuesta positivas frente a las oportunidades y amanezas; sin embrago si es menor a 2.5 significa que no se encuentra capaz de afrontar las amenzas planteadas previamente. 


\section{Tabla 2.3}

Matriz de Evaluación de Factores Internos (EFI)

\begin{tabular}{|c|c|c|c|}
\hline EFI & Peso & Valor & Ponderación \\
\hline \multicolumn{4}{|l|}{ Fortalezas } \\
\hline 1.- Certificaciones de Calidad (HACCP, BPM). & 0.08 & 3 & 0.24 \\
\hline 2.- Producto Premium con alto valor agregado e innovación. & 0.09 & 4 & 0.36 \\
\hline 3.- Producto con insumos naturales. & 0.09 & 4 & 0.36 \\
\hline $\begin{array}{l}\text { 4.- La imagen de la marca asociada con el desarrollo sostenible, la } \\
\text { responsabilidad social y la ética empresarial. }\end{array}$ & 0.10 & 4 & 0.40 \\
\hline 5.- Insumos abastecidos por asociaciones de productores. & 0.09 & 4 & 0.36 \\
\hline 6.- Empaque y envase biodegradable. & 0.08 & 3 & 0.24 \\
\hline 7.- Diversificación de productos & 0.08 & 3 & 0.24 \\
\hline Subtotal & 0.61 & & 2.20 \\
\hline \multicolumn{4}{|l|}{ Debilidades } \\
\hline 1.- Marca nueva en el mercado. & 0.07 & 2 & 0.14 \\
\hline 2.- Larga distancia del mercado destino. & 0.05 & 1 & 0.05 \\
\hline $\begin{array}{l}\text { 3.- Se necesita de canales de comercialización ya que no cuenta con } \\
\text { tienda propia. }\end{array}$ & 0.07 & 2 & 0.14 \\
\hline 4.- Bajo nivel de inversión para la realización de la promoción. & 0.08 & 2 & 0.16 \\
\hline 5.- Mercado de vinos no alcohólicos incipiente (No desarrollado). & 0.06 & 1 & 0.06 \\
\hline 6.- La nula data histórica de exportación de vinos de Perú a Alemania. & 0.06 & 1 & 0.06 \\
\hline Subtotal & 0.39 & & 0.61 \\
\hline Total & & & \\
\hline
\end{tabular}

Nota: Valor $=4$. Fortaleza Mayor; 3. Fortaleza Menor; 2. Debilidad Mayor; 1. Debilidad Menor

Elaboración propia

En la siguiente matriz a difrencia de la MEFE, las fortalezas solo reciben calificaciones (valores) de 4 o 3, y las debilidades solo de 1 o 2 . Las calificaciones están orientadas a la empresa. Si el resultado final es mayor a 2.5 significa que la empresa es fuerte, mientras si el total es menor a 2.5 se considera débil. 
Matriz Interna- Externa (IE)

Tabla 2.4

Matriz Interna y externa

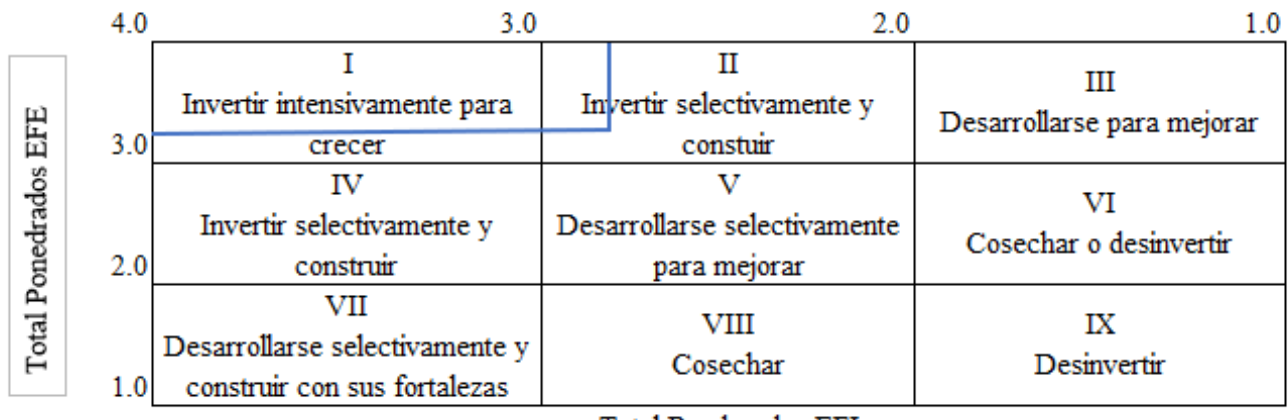

Elaboración propia

La empresa se encuentra en el segundo cuadrante, debiendo invertir y construir selectivamente.

\subsection{Visión, Misión y valores}

\section{Visión}

Para el 2022, ser la empresa peruana líder en la exportación e internacionalización de vinos no alcohólicos de frutas exóticas oriundas del Perú reconocida por la calidad, protección a la salud, al medio ambiente y por el constante trabajo con las asociaciones de productores.

\section{Misión}

Nuestra misión es brindar un producto premium con un alto valor nutricional, generando experiencias extraordinarias que transforman mercados internacionales en bienestar para la sociedad. Buscamos innovar para generar valor y satisfacción que puedan cumplir con las necesidades de nuestros consumidores.

\section{Valores}

* Creatividad: Nuestro principal valor, nuestra empresa cuenta con los mejores profesionales y personas altamente calificados para proveer los mejores productos a los principales mercados mundiales. Los empoderamos para el desarrollo de excelentes gestiones. 
* Disciplina: En nuestra empresa nos caracterizamos por ser líderes emprendedores y apasionados. Personas con el espíritu triunfador lo que nos mueve a brindar una experiencia culinaria de calidad.

* Integridad: Somos un equipo de colaboradores que gestiona y opera de manera correcta, siendo honestos y responsables siempre bajo el marco de la ley de cada comunidad al cual nos dirigimos.

* Responsabilidad: Cada colaborador se siente identificado con las gestiones y actividades de la empresa y tomándolos como propios. Nuestra empresa se caracteriza por el buen trabajo y toma de decisiones en equipo.

* Confianza y Respeto: Creemos en las capacidades y trabajo de nuestros clientes y proveedores; asimismo, respetamos los diferentes puntos de vista en un grato ambiente laboral y nos expresamos de manera clara.

* Vocación de servicio: Estamos forjados con un mismo objetivo común, el servicio personalizado con el fin de poder de conocer muy de cerca las necesidades y requerimientos de nuestros consumidores.

\subsection{Objetivos específicos - Generales del Plan de Marketing}

\section{A. Objetivo General del Plan de Marketing}

El objetivo del plan de marketing es desarrollar un enfoque comercial que permita conocer el mercado para el lanzamiento de una marca de vinos sin alcohol dirigido al consumidor alemán, de berlín, con la finalidad de atender necesidades de acuerdo a las tendencias globales que existirá en los próximos años y contribuir al bienestar social con productos saludables, sin cambiar los hábitos de consumo, así como obtener buenas rentabilidades para el emprendimiento desarrollado.

La planificación para cumplir con los objetivos específicos y generales del Plan de marketing incluye en el conocimiento del mercado de bebidas alcohólicas y del vino en Alemania y Berlín, para poder profundizar en las características del producto que será lanzado al mercado.

\section{B. Objetivos específicos del Plan de Marketing}

Lograr el posicionamiento de la marca en tres años en el mercado objetivo, Berlín. 
En el tercer año hacer un estudio de mercado de otras ciudades alemanas donde el producto pueda entrar y posicionarse, asimismo la búsqueda de oportunidades de internacionalización para los demás países europeos con potencial en oportunidades comerciales.

$>$ Fidelización a un $25 \%$ de los clientes totales de la empresa al finalizar el tercer año.

Lograr la obtención de una participación del $1 \%$ en un periodo de 5 años.

$>$ Lograr un alto nivel de satisfacción que nos permita captar más clientes y obtener una buena reputación en la satisfacción de los mismos.

\subsection{Mercado Potencial y Objetivo}

\section{Mercado Potencial}

Hombres y mujeres, jóvenes adultos que habitan Berlín entre 30 a 54 años pertenecientes a la población económicamente activa que consumen una vez al mes vino no alcohólico y se encuentran en los niveles socioeconómicos A y B.

\section{Mercado Objetivo}

El mercado Objetivo por los primeros 2 años se espera que atienda el $0.5 \%$ del mercado potencial previamente comentado.

\subsection{Segmentación del Mercado}

Geográfica:

$\checkmark$ País: Alemania

$\checkmark$ Región: Bandeburgo

$\checkmark$ Capital: Berlín

$\checkmark$ Sector: Urbano

Demográficas:

$\checkmark$ Géneros: Hombres y mujeres

$\checkmark$ Edad: 30 a 54 años

$\checkmark$ Estrato socioeconómico: A y B

$\checkmark$ PEA: si 
Juventud Media (30-44): Representa el 10\% de la población total

Mediados de Lifers (45 - 64): Representa el 15\% de la población total, pero como solo se está considerando hasta los 54 años, se va a considerar el $7.5 \%$ de la población total.

\subsection{Posicionamiento}

$\checkmark$ Producto Natural; fabricado sin conservantes, ni con aditivos que puedan ser perjudiciales para la salud; además de contar con las certificaciones de calidad que respaldan nuestro producto y con el cuidado al medioambiente en el empaque y envase.

$\checkmark$ Producto Socialmente responsable, trabajo íntegro con las asociaciones de productores y comunidades creando un desarrollo sostenible.

\subsection{Estrategias comerciales de entrada al mercado}

\section{Estrategia Push}

Se va a utilizar la estrategia "Push" o estrategia de "empuje" debido a que los vinos se dirigen a los canales de distribución y la comunicación va directa con el distribuidor. El objetivo será fidelizar o tener una relación laboral muy cercana con los distribuidores, en función a las promociones y descuentos que se ofrecerá.

En conclusión, lo que se va a buscar es que nuestros "socios estratégicos", los distribuidores, den a conocer nuestra marca al consumidor final; es decir, a los clientes que sean consumidores de vinos habituales. Se dispondrá de una comunicación cercana y herramientas necesarias que permitan lograr los objetivos de la estrategia; actividades como promociones constantes de los productos, muestras gratis, participación en la publicidad que desarrollan, brochures o merchandising, entre otros, de los cuales están incluidos las innovaciones en estrategia comercial.

Como objetivo a largo plazo, una vez que la marca se posicione y sea reconocida en el mercado alemán se va a formular una estrategia "Pull”, y realizar actividades como BTLs (Activaciones) con el fin de tener más contacto con los consumidores finales. 


\subsection{Estrategias de producto, plaza, precio y promoción internacional}

El producto, vino no alcohólico, es más que una bebida tradicional hecho a bases de uvas, es una sinergia de atributos tangibles e intangibles, que incluye un plan, una idea, una marca, una etiqueta, un color, un empaque y sobre todo el prestigio del fabricante exportador y de la asociación que pertenece a la cadena de valor del producto final, elementos que en conjunto brindan los beneficios para la satisfacción de las necesidades de los clientes finales. El plan comercial deberá ofrecer la internacionalización del producto que atienda necesidades de los clientes alemanes con excelente calidad, innovador, con características organolépticas (sabor, textura, olor), perfeccionado de manera continua para así contribuir a las necesidades cambiantes del consumidor.

\section{$>$ Estrategias de Producto}

El producto a internacionalizar tendrá una presentación diferente y con una diversificación con frutos exóticos originarios de la selva peruana obteniendo ventajas comparativas con relación a la competencia.

El vino sin alcohol específicamente se obtiene de uvas que provienen de un sistema de producción sin el uso de insumos de origen artificial, ni pesticidas, ni herbicidas que mantiene o mejora los recursos naturales del agro-ecosistema, protegiendo también al trabajador de las fincas y al consumidor, de toda contaminación. Si bien el vino no será de Elaboración propia, es importante considerar que se analizará, en la bodega proveedora, cada paso por el que pase nuestro producto para asegurarnos de su calidad y que se cumplan con los requisitos que las normativas indican.

Así mismo, no solo tendrá como presentación el vino tradicional de uva, sino que incluirá 2 presentaciones más, la del camu camu y aguaymanto, éste último muy cotizado en el mercado alemán. El valor diferencial será que el vino no tendrá alcohol en su composición y conservando los mismos beneficios y atributos que un vino convencional posee.

Según Isabel Rodríguez (2012), "La única diferencia con el vino normal es que no contiene alcohol, pero si su aroma, su sabor y sus propiedades; entre ellas la de ser bueno para salud cardiovascular" (párr. 1). 
Juan de Toro (2017) señala una herramienta para el desarrollo de nuevos productos que nos permite entender el mapa mental de necesidades del consumidor y visualizar mejor las características del producto. De esta forma, el modelo de Kano permite medir la calidad de los bienes según dos parámetros, la medida en que una empresa puede desarrollar un atributo determinado y el grado de satisfacción que este provoca en el cliente que va utilizar el producto. (p. 87)

Figura 2.1

Vino a base de frutos peruanos

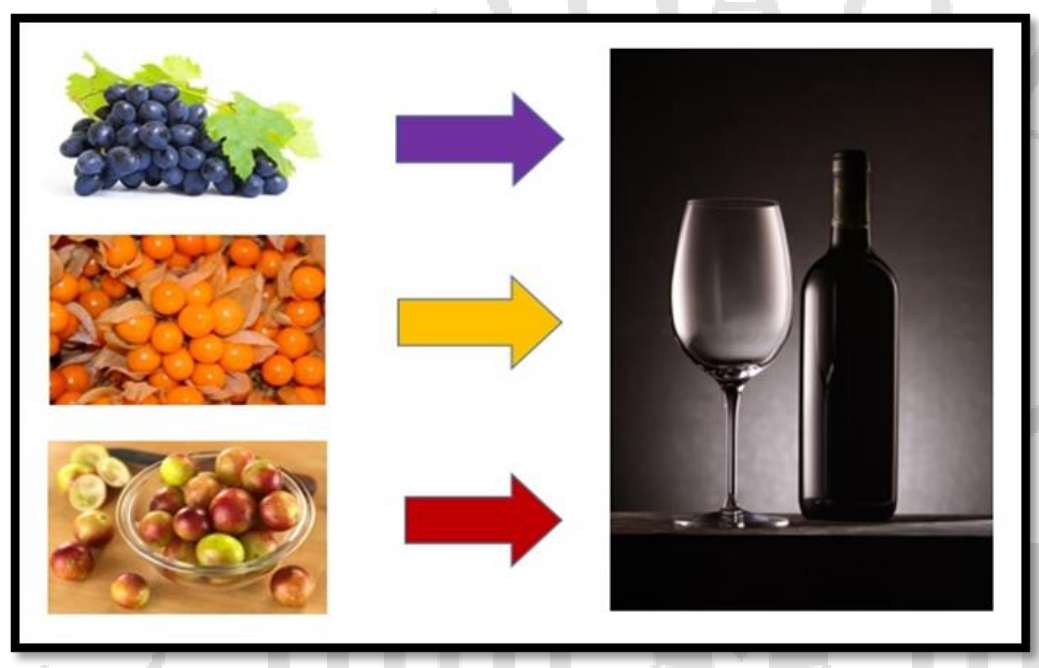

Elaboración propia

La formulación de la propuesta de valor es indispensable para conocer más de cerca nuestro mercado y ofrecer un producto que cumpla las expectativas y necesidades de los clientes. La estrategia de posicionamiento será por ventaja diferencial ya que se basa en el atributo y beneficios por el cual el producto se diferencia de la competencia. Nuestro gran valor diferencial viene en parte por los sabores diversificados y el contenido sin alcohol que dará satisfacción al exigente consumidor alemán y las tendencias globales en los próximos años. 
Figura 2.2

Logo y Slogan de la Marca en español

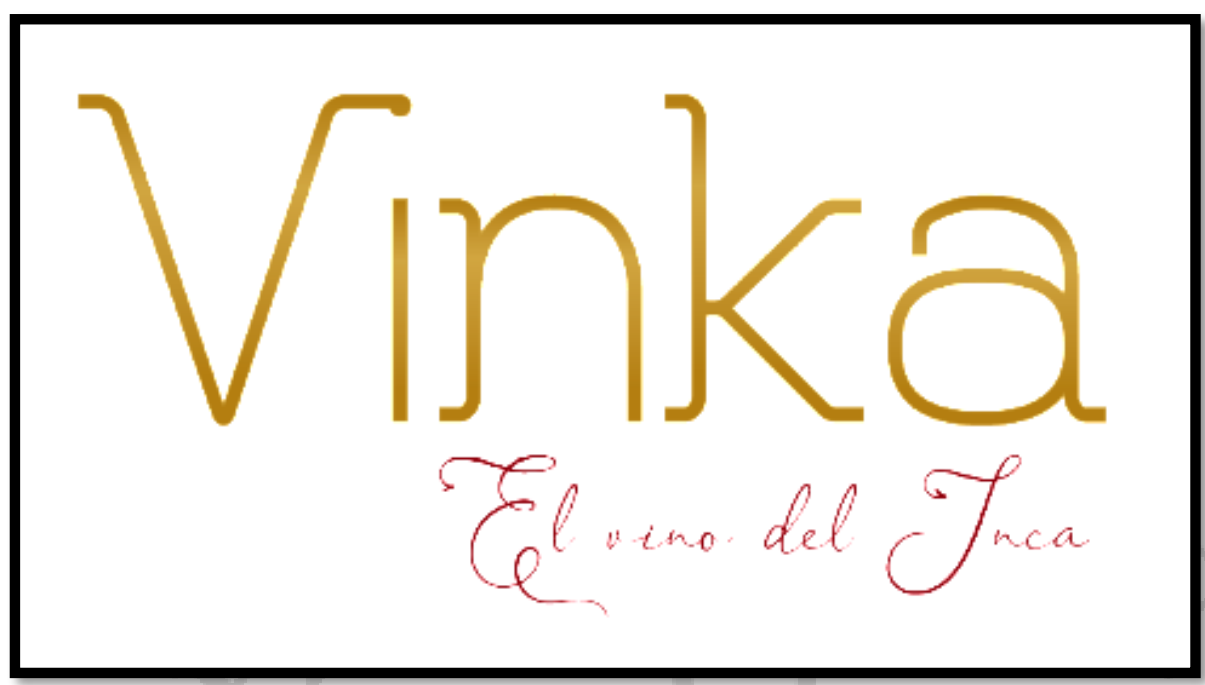

Elaboración propia

Figura 2.3

Logo y Slogan de la Marca en inglés

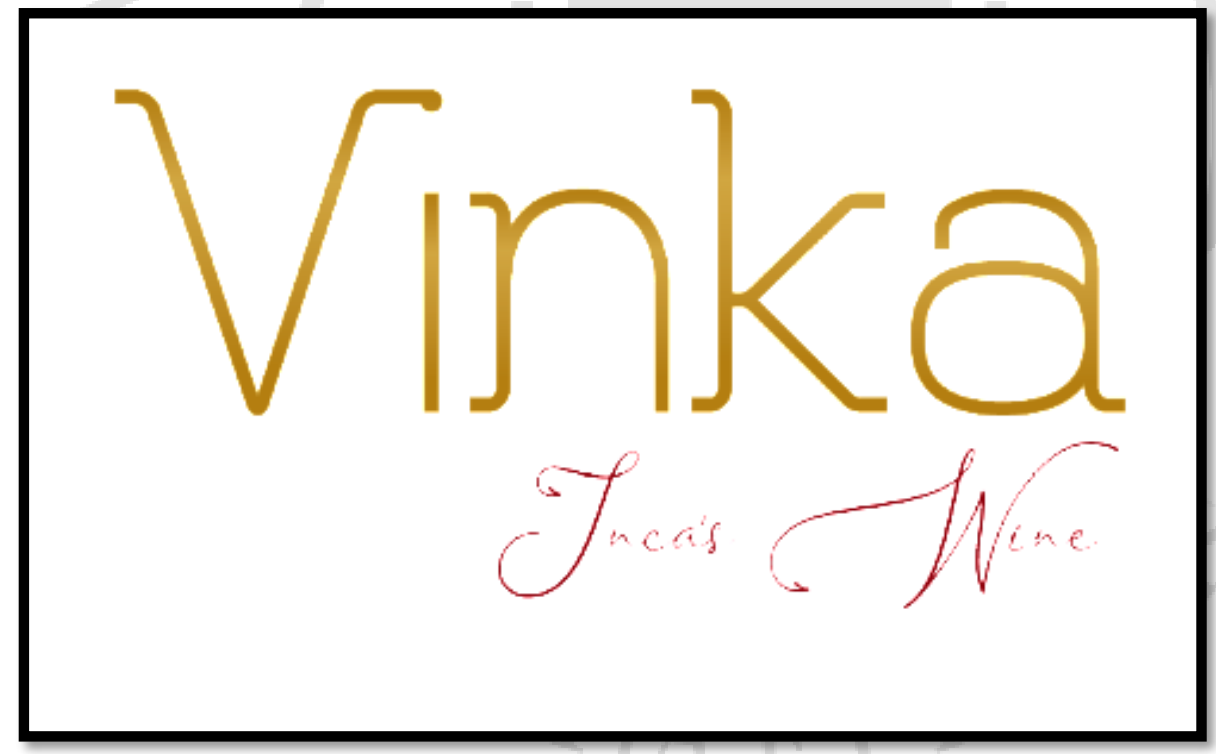

Elaboración propia 
Figura 2.4

Logo y Slogan de la Marca en alemán

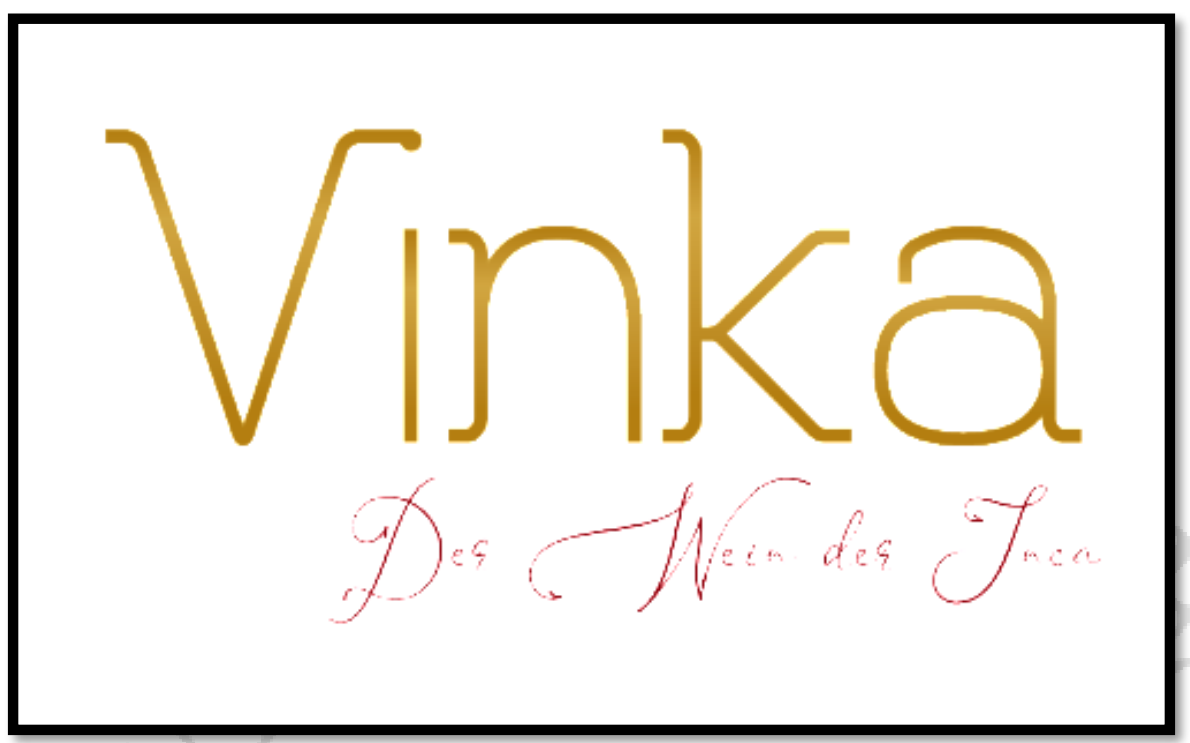

Elaboración propia

Con respecto al empaque, la botella elegida es la "Vintage" ergonómica biodegradable de $620 \mathrm{ml}$, estos modelos responden a los niveles de calidad y más estéticos que los modelos tradicionales de la competencia. Innovación en la botella y el diseño en el empaque van a lograr el valor diferencial y ser competitivos. 
Figura 2.5

Etiqueta Vino no alcohólico de Uvas

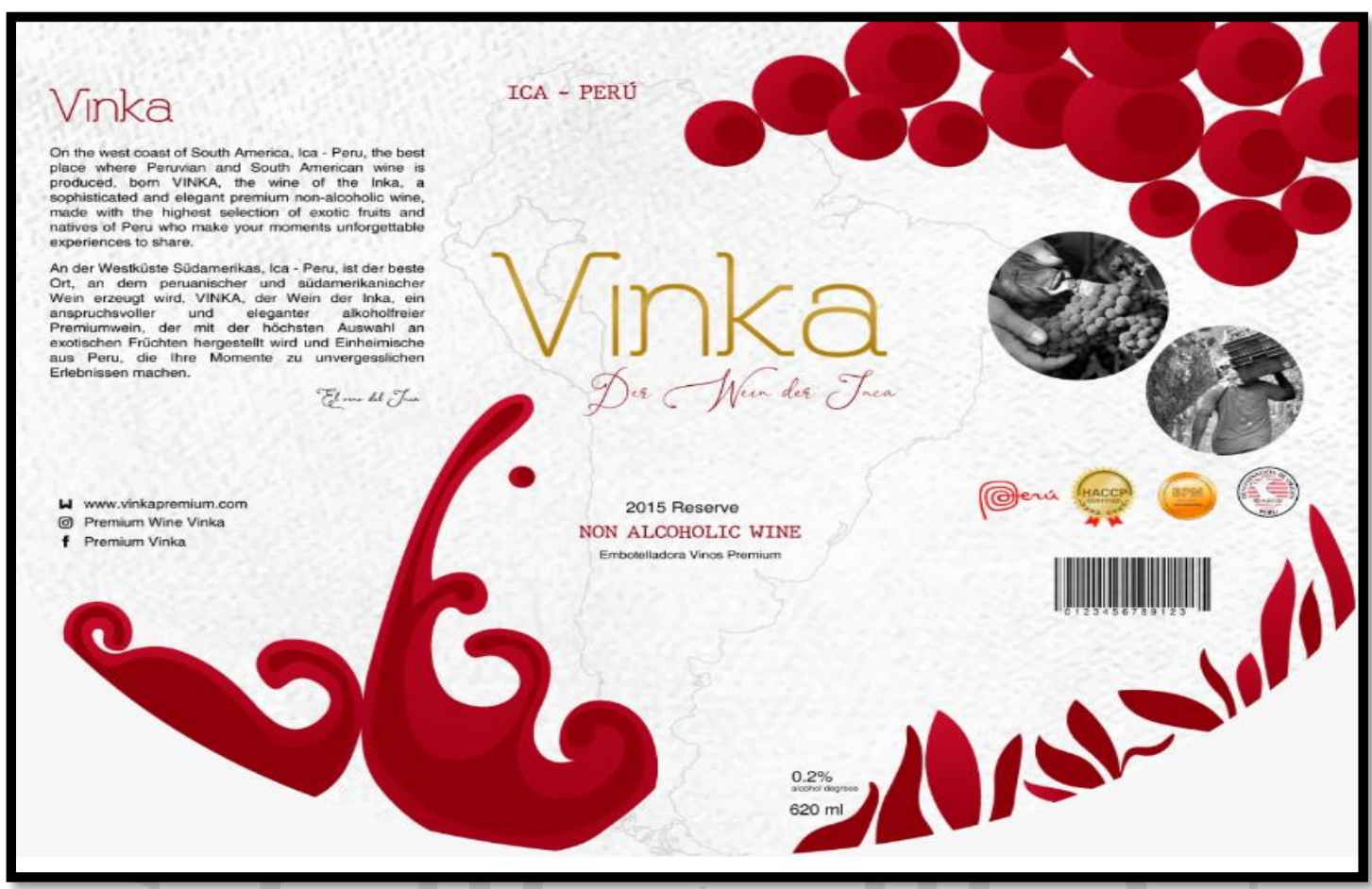

Elaboración propia

La etiqueta contendrá la siguiente información; marca del vino, nombre de la variedad del vino, el volumen del contenido del vino, el año de la cosecha, indicación geográfica, contenido de los insumos del vino, logos de los certificados de calidad y registros sanitarios. La empresa busca darle una identidad a la Marca centrada en su concepción de nueva presentación "No alcohólico", en la búsqueda de una conciencia social, por medio de la creación de un producto que respeta y enfatiza el cuidado del medio ambiente, así como el de la salud de las personas. 
Figura 2.6

Etiqueta Vino no alcohólico de Camu Camu

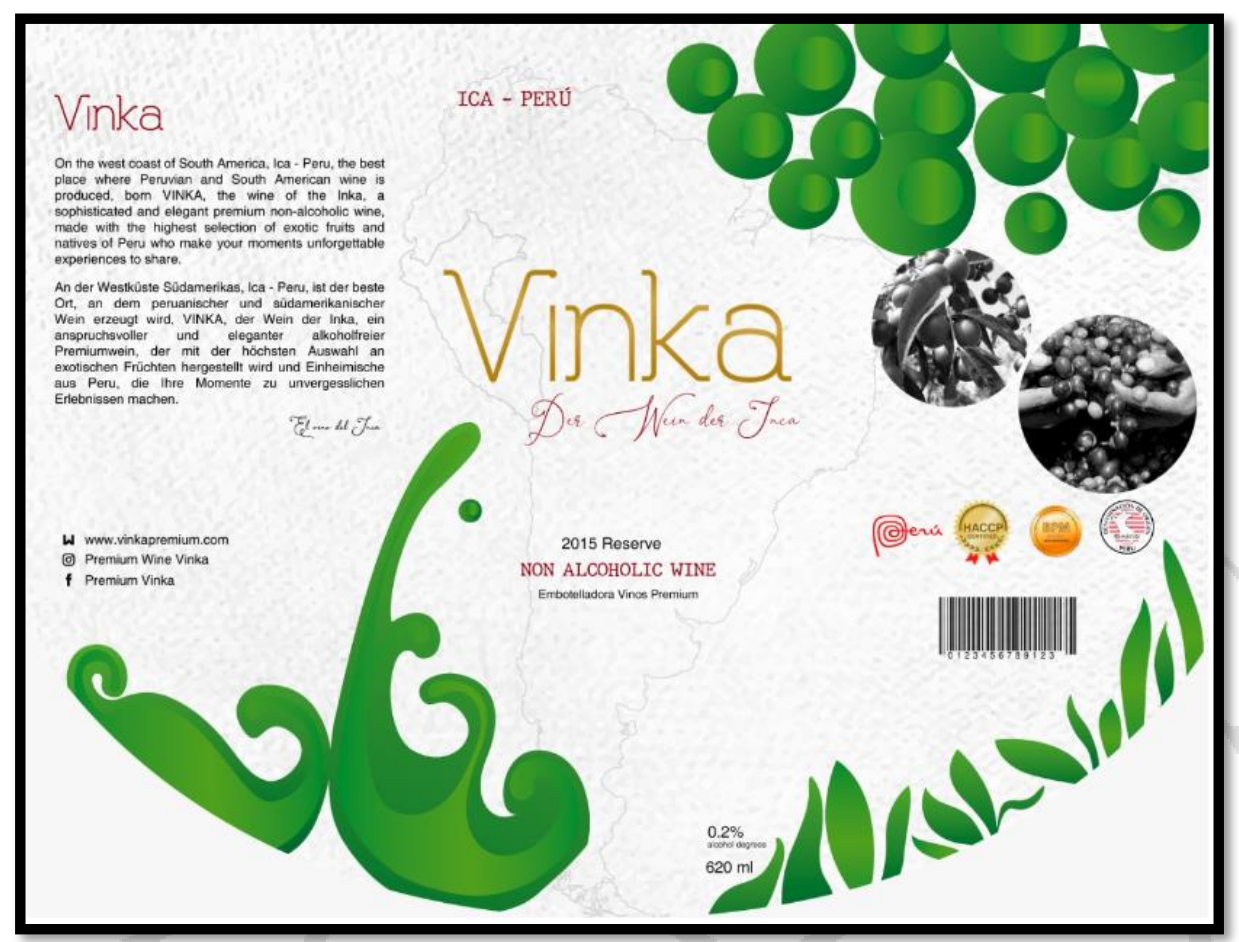

Elaboración propia

Figura 2.7

Etiqueta Vino no alcohólico de Aguaymanto

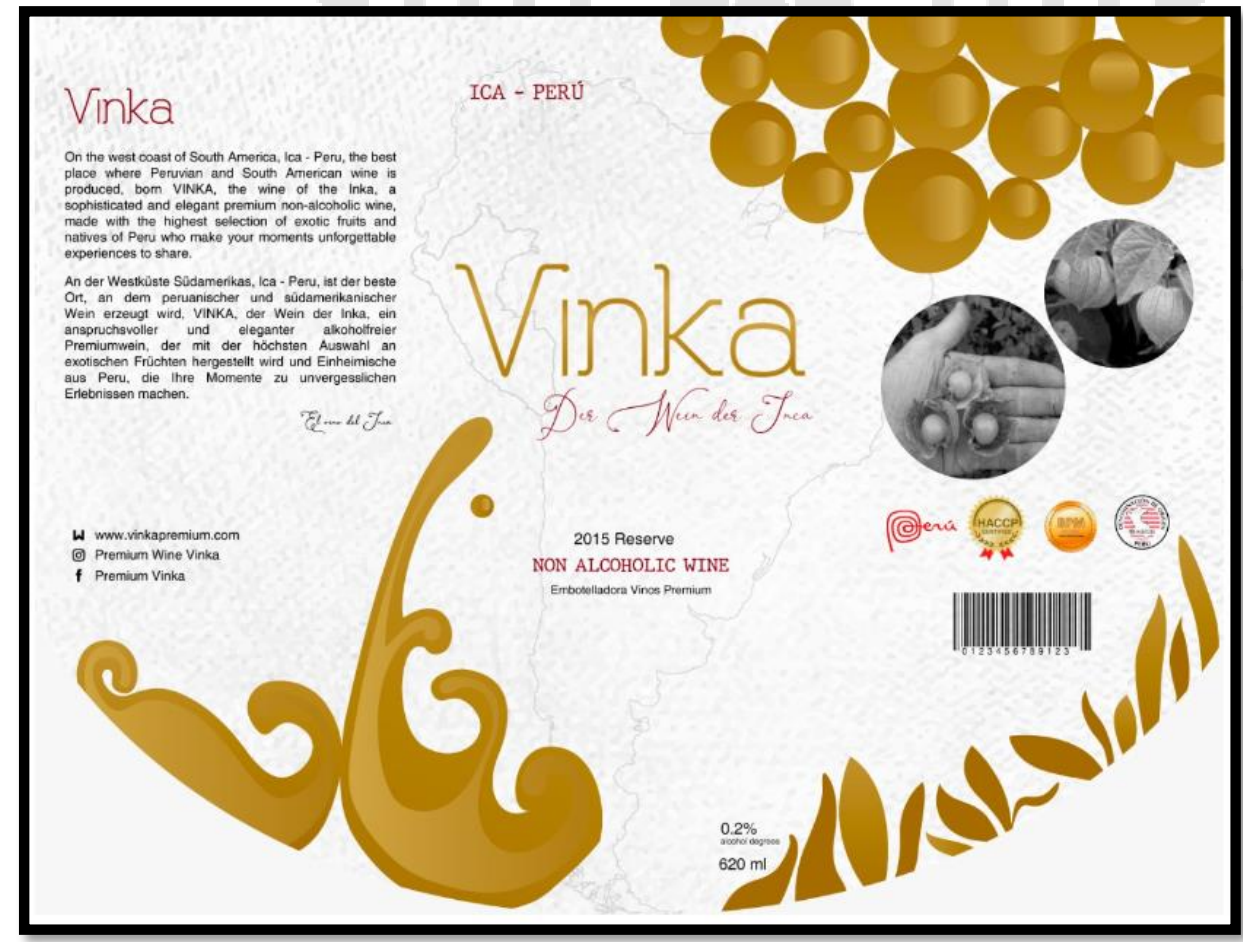

Elaboración propia 


\section{$>$ Estrategias de Plaza}

Los principales canales de distribución del producto por medio de los cuales se comercializará los vinos no alcohólicos "VINKA" será muy selectiva de manera que enriquezca el presente plan comercial. La distribución se realizará a través de tiendas especializadas; es decir, tiendas de vinos y en tiendas de descuento.

$\checkmark$ Tiendas Especializadas: Serán los principales distribuidores e introducción del producto. La presencia de Vinka en este canal de distribución, ayudará a consolidar la identidad de marca dentro del mercado de vinos en Alemania.

$\checkmark$ Tiendas por Descuento: Otro canal alternativo son las tiendas de descuento, que son los canales más transcurridos por los alemanes para la compra de insumos.

Canal Horeca (Restaurantes, Hoteles): Una tercera alternativa es el Canal Horeca, que representa solo el 19\% de participación en canales de distribución; es un porcentaje bajo, pero de cierta manera la ventaja de este canal es que se utilizará para captar consumidores que no conozcan sobre la existencia de los vinos no alcohólicos ni de sus beneficios. Lo que resulta muy necesario ya que el consumidor no asegura una eficiente rentabilidad del negocio, por lo que nos exigimos desarrollar nuevos consumidores, educarlos en este nuevo producto.

\section{Estrategias de Precio}

La categoría de bebidas no alcohólicas ofrece una gran gama de opciones como las cervezas sin alcohol, premium y artesanales; asimismo, bebidas espirituosas como el vodka han empezado a adaptarse a la nueva tendencia creando cocteles en base a frutas como MSK Moscow Mule como parte de su línea Moskovskaya o el Encore Vodka, un vodka premium dulce, según Euromonitor (2017).

Por otro lado, en la categoría propia de los vinos, se encuentran marcas como Bowle to go en una presentación de 0.33 litros elaborada en base a duraznos y el Mia Cocktails, un vino premium desarrollado en el 2016 en presentaciones de botellas de $750 \mathrm{ml}$ y latas de 0.25 litros.

\section{$>$ Estrategias de Promoción}

Una de las estrategias de promoción que se aplicará es la Publicidad; se impulsará el producto por medio de revistas y periódicos más importantes de la ciudad de Berlín y Alemania en las páginas de ocio, vinos y entretenimiento; la prestigiosa revista 
Weinwirtschaft del grupo corporativo Mieninger, líder en el ámbito del vino; o la revista Der Stern, revista alemana de actualidad social o el periódico prestigioso de Berlín de Morgenpost.

Se elaborarán brochures, presentaciones virtuales, catálogos y tarjetas de presentación, paneles y banners donde habrá información relevante sobre la empresa, los productos, el nuevo concepto de "bebida sin alcohol”, las características del producto, los beneficios para la salud y para el medio ambiente, también contará con datos técnicos de los insumos del producto, y fotos del producto y de las plantas de producción.

Otra importante herramienta de promoción es la asistencia a ferias internacionales, ferias realizadas anualmente en Alemania, de preferencia en la ciudad de Berlín, ferias de bebidas no alcohólicas, para dar a conocer el producto. Se rentará un stand, en donde habrá varias muestras en físico y materiales de publicidad que influyan positivamente en la promoción del vino. Se harán degustaciones y catas en la feria. Entre las 2 principales ferias de vinos en Alemania, son la feria Weinverliebt que se realizará en noviembre del 2019 en la ciudad de Berlín con más de 200 exponentes entre nacionales e internacionales. La feria ProWein, feria líder internacional de vinos y bebidas alcohólicas que se realiza en Dusseldorf durante el 17 al 19 de marzo 2019. La Feria Vinessio realizada entre 24 y 25 de noviembre del 2019, es una feria de alimentos y bebidas en Berlín.

La promoción de ventas hacia los distribuidores, se les ofrecerá a los distribuidores la promoción " $3 * 1$ ”; es decir, por cada 10 cajas de vino compradas, se les regalará 1 caja, motivando la compra de grandes cantidades; además de todo el merchandising que vendrán con las cajas. Asimismo, se apoyará en la gestión de implementación del plan de marketing con los distribuidores, para óptimas decisiones en un futuro con respecto al producto y la marca.

\subsection{Tácticas de e-commerce}

En la actualidad, se vive en una era digital que la empresa que no cuenta con herramientas informáticas de promoción comercial, tiene una desventaja a comparación de sus competidores. Asimismo, se va a formar una sinergia de trabajo con los distribuidores con el fin de plantear estrategias de marketing digital. Como los distribuidores van a contar con una página web en donde se va a dar a conocer los vinos no alcohólicos, la 
estrategia que se planteará es que cada vez que los consumidores y/o empresarios entren a la web del distribuidor y visualicen las fotos de los vinos; exista un link que los dirija a la página web de la empresa.

Es decir; si se va a contar con una página web, pero sólo de manera informativa, donde se va a conocer detalles de la empresa y todo sobre los vinos no alcohólicos; características, atributos, e información de la empresa.

\subsection{Balance del plan de Marketing y Comercialización Internacional}

Tabla 2.5

Balance Plan Anual de Marketing

Balance Anual Plan de Marketing

\section{Herramientas Promoción Comercial}

Presupuesto Anual Presupuesto Mensual

Publicidad en Medios Impresos Alemanes (Revistas \&

Periódicos)

Merchandising

Diseño Gráfico

Creación y Mantenimiento Página Web Informativa

Ferias Internacionales (Prowein, Wein)

Relaciones Públicas (Clusters de Empresas de Vinos,

OCEX de Perú en Berlín)

Gasto en Agencia de Branding e Identidad Corporativa

Material de Promoción (Brochures, tarjetas de

presentación, Banners, Paneles,etc.)

Eventos de Promoción Comercial Innovadores

Total Presupuesto

$\$ 5,000.00$

$\$ 2,000.00$

$\$ 2,500.00$

$\$ 1,000.00$

$\$ 15,000.00$

$\$ 3,500.00$

$\$ 10,000.00$

$\$ 2,000.00$

$\$ 3,000.00$

$\$ 44,000.00$
$\$ 416.67$

$\$ 166.67$

$\$ 208.33$

$\$ 83.33$

$\$ 1,250.00$

$\$ 291.67$

$\$ 833.33$

$\$ 166.67$

$\$ 250.00$

Elaboración propia

Se presenta un balance del plan de marketing anual y mensual de las herramientas de promoción comercial que se realizarán en el año 2019. Como resultado el presupuesto anual de marketing asciende a 44,000.00 USD; por consiguiente, el mensual asciende a 3,666.67 USD, (S/. 12,000 soles).

En el siguiente cuadro observamos la planificación de las actividades de promoción comercial durante 1 año y el impacto que se generan que ayudan a contribuir a los objetivos del Plan de Marketing. 
Tabla 2.6

Cronograma de la Planificación

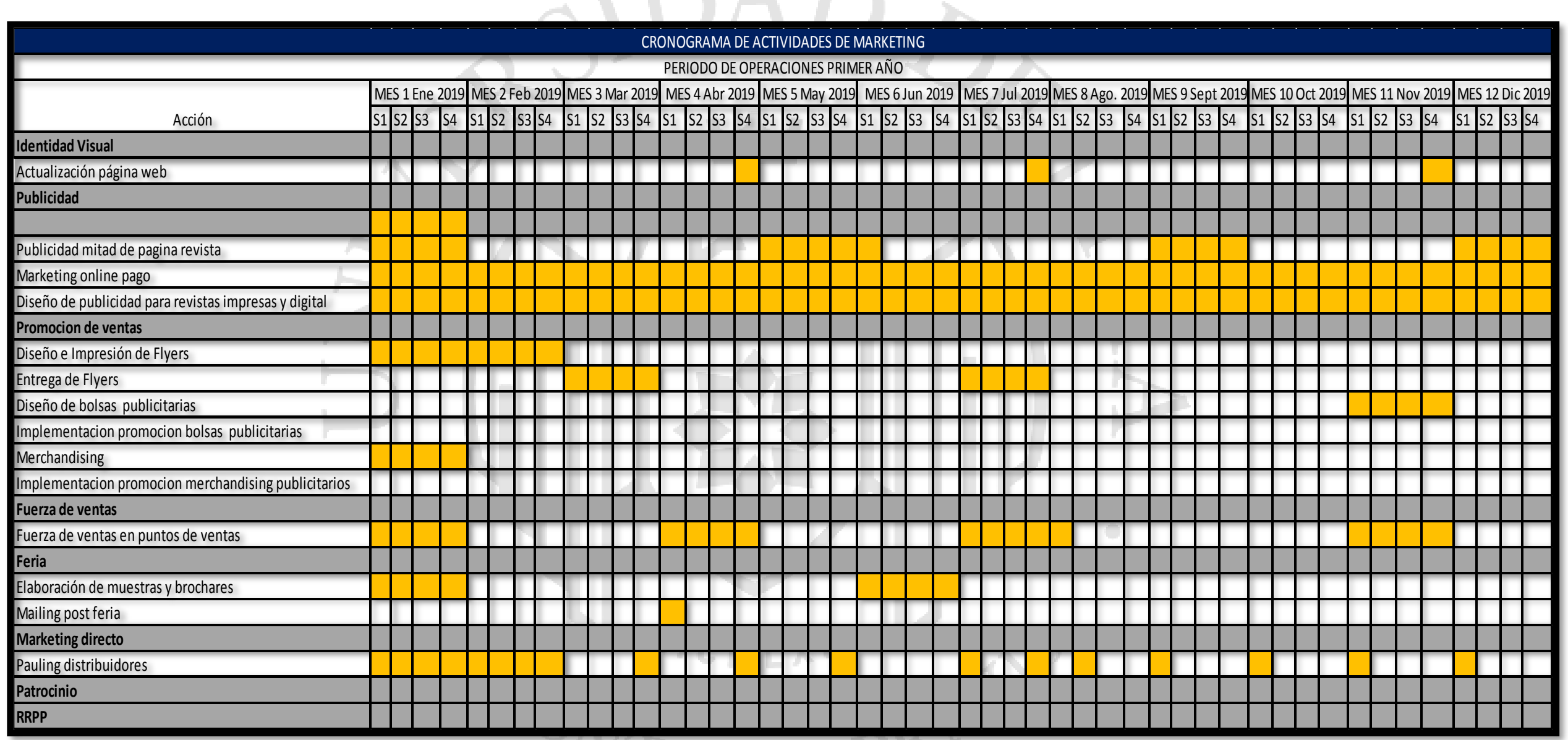

Elaboración propia

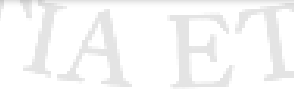




\subsection{Factores críticos de éxito de la planificación comercial y de marketing internacional.}

Se ha estudiado y analizado muchos casos de éxitos de grandes corporaciones y marcas a nivel mundial que son reconocidas, que han obtenido buenos resultados; por consiguiente, son un ejemplo a seguir para nuevos negocios y emprendimientos.

En primer lugar, uno de los factores de éxito importante es el manejo eficiente de la gestión empresarial, el liderazgo y trabajar dentro de una estructura de gobierno novedosa. Para gestionar el plan comercial es trascendental un recurso humano estratégico motivado que se sienta identificado con los objetivos y orientado a resultados de la empresa, identidad corporativa, ya que conlleva a ser un factor de éxito dentro de la planificación comercial.

Según el portal de internet Estrategias y Negocios (2017):

Alibaba Group tiene un enfoque poco ortodoxo para gobernarse a sí misma. Como resultado de ello, en el 2010 se estableció la Alibaba Asociación. La firma dice que este acuerdo permite a los ejecutivos centrarse en el largo plazo, colaborar mejor y anular la burocracia o jerarquía. (párr.7)

Otro factor clave de éxito que se ha considerado es el detalle en el diseño de la marca; Según John Sculley (2014), ex director ejecutivo de la compañía de Cupertino, "Para Steve Jobs el diseño era (y sigue siendo hoy para la compañía) fundamental" (párr. 2). Así mismo en palabras del mismo Sculley sobre Apple (2014): "Primero están los diseñadores, luego los programadores y finalmente, los jefes” (párr. 2).

Enriqueciendo al párrafo anterior, la presentación del producto, la comunicación adecuada en las estrategias de marketing y publicidad. Según el portal web, Mercado Actual (2014): “Apple fue una de las primeras marcas en implicarse en las campañas publicitarias hasta controlar cada aspecto al detalle" (párr.4).

La simplicidad, autenticidad y valor del producto sin dejar de lado la calidad y el valor agregado que éste pueda brindar representan mucha importancia para la entrada a mercados globales y ser competitivos.

Según Greg Joswiak (2014), vicepresidente de marketing de iOS en Apple: 
"La simplicidad es muy complicada: "Mucha gente piensa que eso significa tomar algo simple y dejarlo es su núcleo esencial. Pero no es así. Cuando se empieza a construir algo, rápidamente se vuelve muy complejo. Si uno conoce realmente su producto y los problemas, entonces puede tomar algo que es complejo y hacer que sea sencillo" (párr. 7).

Según Aguirre (2018), Gerente de Marketing de la división de bebidas Premium en Vinos Concha y Toro, "Es muy importante los contenidos en el marketing y publicidad acompañadas de estrategias de branding”.

En conclusión, si se planea ingresar a un mercado internacional con marca propia se debe implementar un plan eficiente en la construcción de marca y aplicar estrategias de branding. 


\section{CONCLUSIONES}

- El perfil del mercado destino, se descubre un potencial nicho de mercado, incipiente para bebidas no alcohólicas, como es el vino sin alcohol. Debido a las tendencias globales de consumo en los próximos diez años; y según Euromonitor, los principales consumidores del mundo van a preferir productos no perjudiciales para la salud, productos naturales y de gran calidad internacional.

- Así mismo, se ha identificado un mercado con mucho potencial para futuros años cuyo público objetivo ideal, dado que representan un buen porcentaje de su población que va entre 30 y 54 años, siendo el principal mercado seleccionado la capital alemana, Berlín.

- En la actualidad existen alimentos y bebidas que la ingesta en exceso es perjudicial para las personas. El ingerir bebidas sin alcohol, es una manera de vivir pleno en búsqueda del bienestar social y de salud para futuras generaciones. El vino sin alcohol ha sido producido bajo los más estrictos estándares de calidad, respetando su proceso productivo, sus propiedades y beneficios organolépticos, conservando el aroma, el sabor, y las características principales del vino tradicional.

- Por otro lado, Alemania se encuentra dentro de los 5 principales importadores de bebidas no alcohólicas y como consumidores de vinos, teniendo una alta demanda y consumo per cápita.

- El plan de marketing y comercialización; las estrategias de entrada al mercado se ha planteado la estrategia push y una estrategia de posicionamiento diferencial con respecto a la competencia. En adición, el canal principal de distribución del vino sin alcohol, es el canal Off trade; especialmente en tiendas especializadas y tiendas por descuentos, que representan más del $60 \%$ de los canales usados para estos productos. Las herramientas de promoción internacional utilizadas van desde ferias internacionales en Alemania, en Berlín y Dusseldorf, hasta la elaboración de material, merchandising y publicidad informativa para los clientes corporativos. 


\section{RECOMENDACIONES}

- Visitar el mercado alemán periódicamente para tener información primaria acerca del comportamiento del consumidor que permita mantener o adaptar nuestras líneas productivas según las tendencias

- Estudiar y analizar la demanda potencial y objetivo en los próximos años debido a tasas de crecimiento poblacional, así como la expansión a otras regiones de Alemania

- Innovar en el desarrollo de nuevos sabores, diseños y presentaciones, plan de producción que permitan dar diversificación al negocio generando mayor consolidación comercial internacional.

- Explotar las ventajas comparativas con respecto a las estrategias de posicionamiento de ventaja diferencial que se ha identificado para los vinos.

- Diversificar mercado en el mediano plazo, buscar oportunidades en Europa o América del norte, donde se encuentran países con buen consumo per cápita de vino.

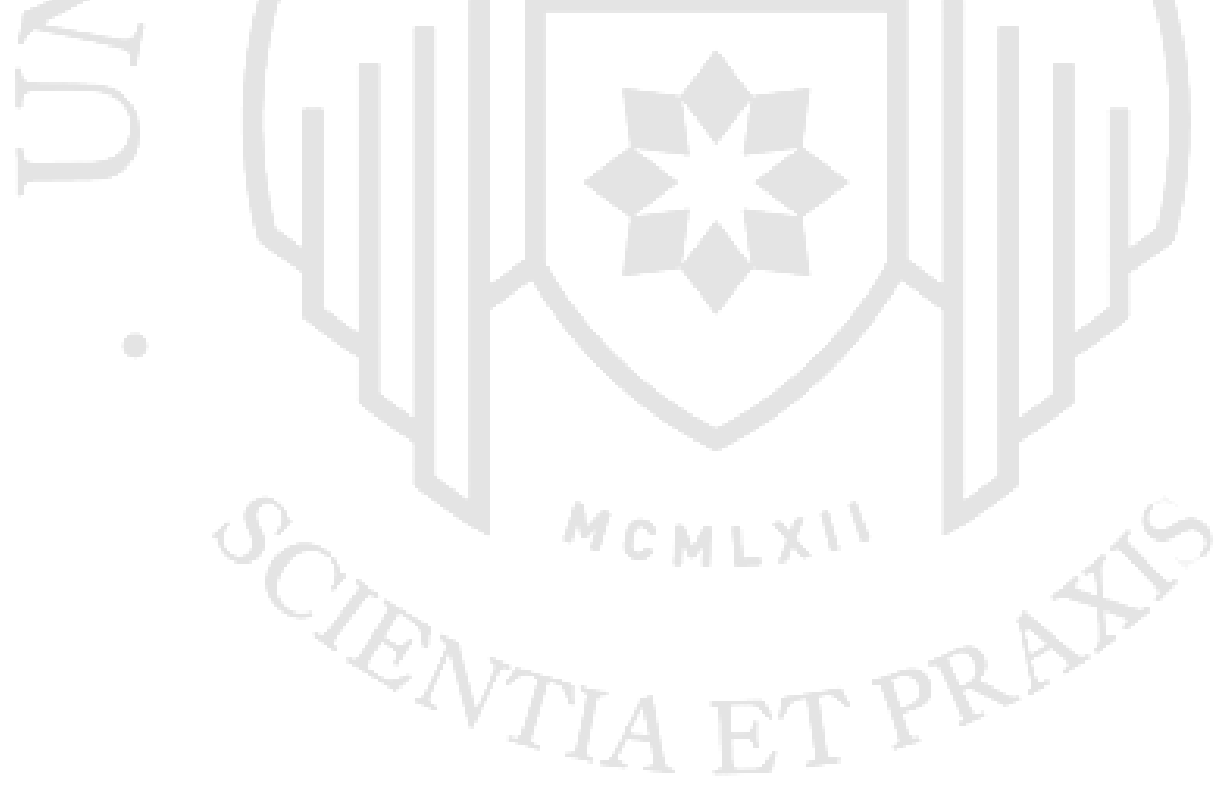




\section{REFERENCIAS}

Agencia nacional de Estadística Alemana (2018). Orígenes étnicos raciales.

Recuperado de www.destatis.de/e

Aguirre, J. (29 de Agosto de 2018). Concha y Toro - Caso de éxito Summit Chile.

Recuperado de www.conchaytoro.com/summitchile2018

Angus, A. (2018). Factores que impulsan cambios en el comportamiento de los consumidores. Recuperado de http://www.portal.euromonitor.com/portal/analysis/tab\#

Ayala, P. (2018). Método de evaluación de localización aplicado a los negocios internacionales. Recuperado de http://repositorio.ulima.edu.pe/bitstream/handle/ulima/6647/Ayala_Pedro_Evalu acion.pdf? sequence $=1 \&$ isAllowed $=y$

Banco Mundial (2018). Data - Banco Mundial. Recuperado de https://datos.bancomundial.org/indicador

Banco Mundial (2018). Indicadores Microeconómicos del Banco Mundial. Recuperado de https://data.worldbank.org

Central Intelligence Agency (2018). Recuperado de

https://www.cia.gov/library/publications/resources/the-world-

factbook/geos/gm.html

Comisión Europea (11 de Diciembre de 2012). Alemania, líder mundial en tecnología, ingeniería e innovación. Recuperado de https://cordis.europa.eu/result/rcn/89457_es.html

Cornell SC Johnson College of Business (2018). Índice Global de Innovación 2018. Recuperado de http://www.iberglobal.com/files/2018-2/Innovation_Index.pdf

Danty, J., Gasic, C., Díaz, M., Mendoza, V., Urbina, C. y Acuña, E. (2018). Propectivas del mercado mundial de la avena para consumo humano. Santiago de Chile: Oficina de estudios y políticas agrarias del ministerio de agricultura.

Datos Mundial (2018). Estimación mercado objetivo. Recuperado de https://www.datosmundial.com/europa/alemania/index.php

Datos Mundial (2019). Días festivos en Alemania 2019 - 2023. Recuperado de https://www.datosmundial.com/europa/alemania/dias-festivos.php

Destatis Statistisches Bundesamt (2018). Población en Alemania. Recuperado de https://www.destatis.de/EN/Press/2019/01/PE19_029_12411.html 
Foro Económico Mundial (Abril del 2018). Análisis político y gubernamental. Recuperado de www.weforum.org

Embajada de Alemania (2019). Estados de Alemania. Recuperado de http://www.embajadadealemania.org/pages/estados-dealemania.php\#.XKhZymhKjIU

Estrategia y Negocios (30 de Julio de 2017). 5 Claves de éxito de la china Alibaba, la reina del Ecommerce. Recuperado de www.estrategiaynegocios.net

Euromomitor (2018). Volumen de ventas - Bebidas alcohólicas Alemania. Recuperado de $\underline{\text { www.euromonitor.com }}$

Euromonitor (2017). Bebidas alcohólicas en Alemania. Recuperado de http://www.portal.euromonitor.com/portal/analysis/related

Euromonitor (2017). Canales de comercialización de bebidas alcohólicas en Alemania. Recuperado de www.euromonitor.com

Euromonitor (2017). Canales de comercialización de vino en Alemania. Recuperado de www.euromonitor.

Euromonitor (2017). Canales de distribución de vinos en Alemania. Recuperado de www.euromonitor.com

Euromonitor (2017). Marcas de vinos distintos de uva. Recuperado de www.euromonitor.org

Euromonitor (2017). Principales distribuidores del vino en Alemania. Recuperado de www.euromonitor.com

Euromonitor (2017). Productos alternativos de mayor consumo en alemania. Recuperado de www.euromonitor.com

Euromonitor (2018). Consumer LifeStyle 2018. Recuperado de www.euromonitor.com

Euromonitor (2018). Country Profile 2018. Recuperado de www.euromonitor.com

Euromonitor (2018). Las 10 Principales tendencias globales de consumo para el 2018. Recuperado de www.euromonitor.com

Euromonitor. (2018). Precios vinos en Alemania. Recuperado de www.euromonitor.com

Euromonitor (2018). Volumen ventas vinos en Alemania. Recuperado de www.euromonitor.com

Euromonitor (2019). Fines Wines/Champagne and Spirits in Germany. Recuperado de http://www.portal.euromonitor.com.ezproxy.ulima.edu.pe/portal/Analysis/Tab

Euromonitor (2019). Soft Drinks in Germany. Recuperado de http://www.portal.euromonitor.com.ezproxy.ulima.edu.pe/portal/Analysis/Tab 
Euromonitor International (2018). Productos alternativos por categoría - Alemania. Recuperado de www.euromonitor.com

Euromonitor International (2019). Pricing. Recuperado de www.euromonitor.com

Foro Económico Mundial (2018). Reporte Mundial de Competitividad 2018 .

Recuperado de http://www.iberglobal.com/files/20182/TheGlobalCompetitivenessReport2018.pdf

Index Mundi (Abril de 2017). Países consumidores de vinos. Recuperado de www.indexmundi.com

Invicto (2016). Primer vino sin alcohol chileno. Recuperado de www.elmaule.cl

Ipsos. (2018). Nivel Consumo de alcohol. Recuperado de www.ipsos.com

La Economía Global (2016). Población urbana en Alemania. Recuperado de www.theglobaleconomy.com

Leandro, A. (2009). El proceso de internacionalización de empresas. Valencia.

Mercado Actual (6 de enero de 2014). 10 Claves del éxito de Apple. Recuperado de www.ecommerce-new.es

Ministerio de Comercio Exterior y Turismo (2013). Acuerdo Comercial entre Perú y la Unión Europea. Recuperado de

http://www.acuerdoscomerciales.gob.pe/index.php?option=com_content\&view= $\underline{\text { category } \& \text { layout }=\text { blog } \& i d=50 \& \text { Itemid }=73}$

Organización Mundial de la Salud (2018). Recuperado de http://apps.who.int/gho/data/view.main.1800

Organization for Economic Co-operation and Development. (2018). Población áreas metropolitanas de Alemania. Recuperado de https://stats.oecd.org/Index.aspx? DataSetCode=CITIES

Plan de Marketing vinos Argentinos (2013). Precio según calidad de vinos. Recuperado de http://bdigital.uncu.edu.ar/objetos_digitales/5717/tesis-cs-ec-peterlecaram.pdf

Rodriguez, I. (30 de Octubre de 2012). Vino sin alcohol: Beneficios que nos ofrece . Recuperado de Ella Hoy: https://www.ellahoy.es/ocio/articulo/vino-sin-alcoholbeneficios-que-nos-ofrece/106765/

Santader Trade (Noviembre de 2018). Alemania: Política y Economía. Recuperado de https://es.portal.santandertrade.com/analizar-mercados/alemania/politica-yeconomia

Santander Trade (Diciembre de 2018). Alemania: Llegar al consumidor. Recuperado de https://es.portal.santandertrade.com/analizar-mercados/alemania/llegar-alconsumidor 
Santander Trade (2018). Distribución de la población por edades. Recuperado de www.santandertrade.com

Sistema de Inteligencia Comercial Legiscomex (2017). Principales puertos y aeropuertos de Alemania. Recuperado de https://www.legiscomex.com/Documentos/principales-puertos-aeropuertosalemania-2016

Superintendencia de Banca y Seguros (SBS). (Marzo de 2019). Tipo de Cambio. Recuperado de https://www.sbs.gob.pe/app/pp/SISTIP_PORTAL/Paginas/Publicacion/TipoCa $\underline{\text { mbioPromedio.aspx }}$

The CIA World FactBook (2018). Distribución por edades en Alemania. Recuperado de https://www.cia.gov/library/publications/the-world-factbook/

Trade Helpdesk de la Unión Europea (2018). Documentación de Ingreso para la UE. Recuperado de http://trade.ec.europa.eu/tradehelp/

Trade Map (2018). Exportadores de vinos por Alemania. Recuperado de https://www.trademap.org/

Trade Map (2018). Volumen de países importadores de bebidas alcohólicas TN. Recuperado de www.trademap.org.pe

Trade Map (2018). Volumen paises importadores del vino TN. Recuperado de www.trademap.org

Trademap (2016 - 2021h). Proyección de la demanda. Recuperado de www.trademap.org

Trademap (2017). Niveles de precios unitarios - Niveles de importación. Recuperado de www.trademap.org

Trademap (2017). Principales proveedores de vinos para alemania. Recuperado de www.trademap.org

Trademap (2017). Proyección de precios unitarios - bebidas no alcohólicas. Recuperado de www.trademap.org

Trademap (2018). Evolución de bebidas no alcohólicas en Alemania. Recuperado de www.tardemap.org

Trademap (2018). Importadores de bebidas no alcohólicas. Recuperado de www.trademap.com

Trademap (2018). Países importadores de vino. Recuperado de www. trademap.org

Trademap (2018). Principales importadores de bebidas no alcohólicas. Recuperado de www.trademap.org 
Trademap (2018). Proyección de demanda bebidas no alcohólicas en Alemania. Recuperado de www.trademap.org

Vexels (2018). Mapa regional: Alemania. Recuperado de https://www.vexels.com/graphics/mapa-de-alemania/

Win Zero (2018). Vino no alcohólico WIN. Recuperado de www.win-zero.com

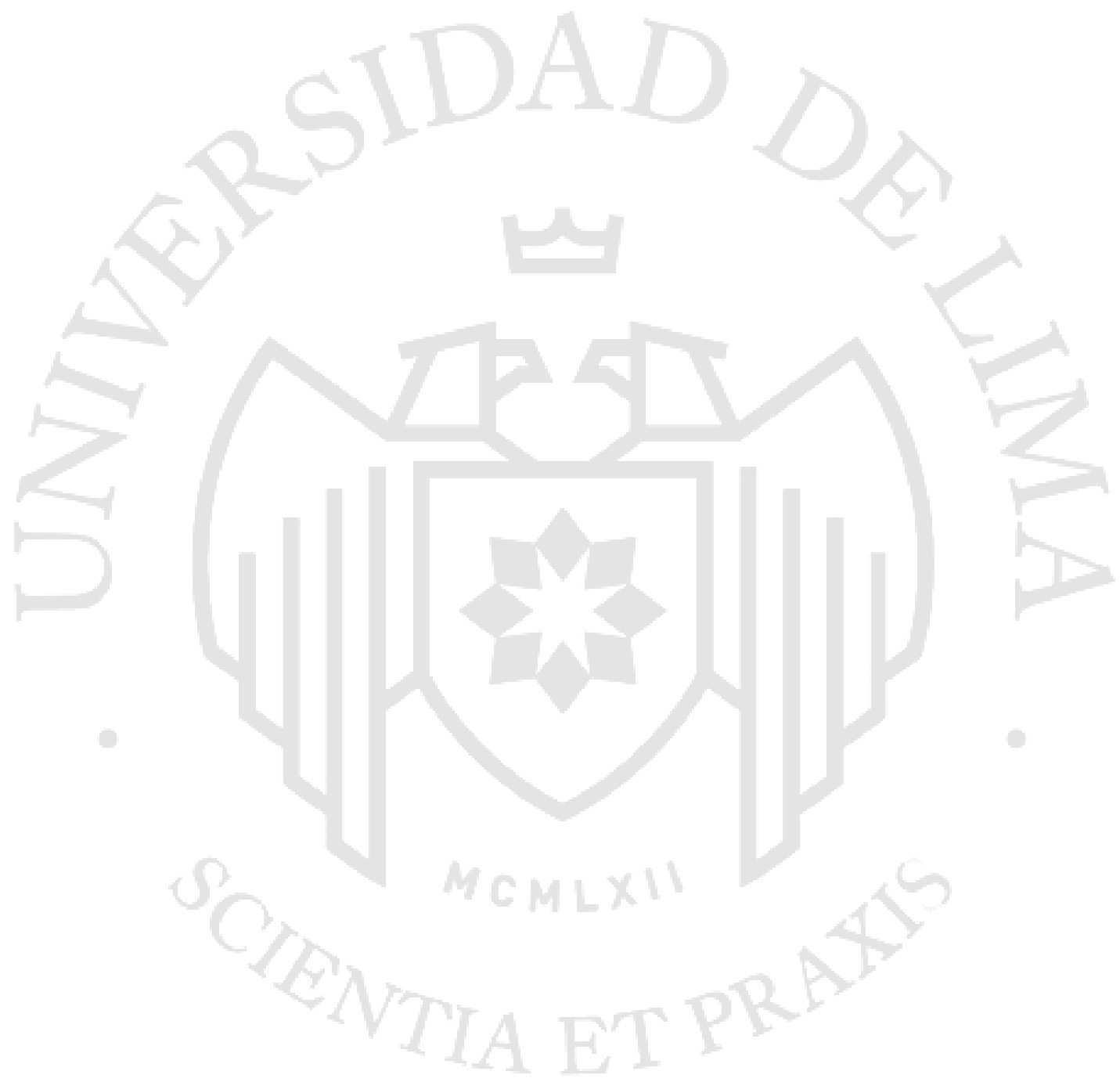




\section{BIBLIOGRAFÍA}

Alet, J. (2007). Marketing directo e interactivo. España: ESIC editorial.

Anderson, D., Peralta, R., Navarro, S., Cardiel, H., Pino, J. y Sandoval, B.

(2016). Métodos cuantitativos para los negocios. Australia: Cengage Learning.

Cateora, P.; Gilly, M.; Graham, J. y Estañol, R. (2014). Marketing internacional (16 ${ }^{a}$ ed.). México: Mc Graw Hill.

Czinkota, M., Jasso, H. y Ronkainen, I. (2008). Marketing internacional. México D.F: Cengage Learning.

Doyle, M., Fryer, T. y Cere, R. (2011). Exito comercial: Prácticas administrativas y contextos culturales. Boston: Cengage Learning.

Ferrell, O., Islas, L., Rosas, L., Ferrell, L. y Fraedrich, J. (2017). Ética en los negocios: Casos y toma de decisiones. México: Cengage Learning.

Graham, B. y Anouti, C. (2018). Promocionar la moda (1 ${ }^{a}$ ed.). España: Promopress.

Hoffmann, L., Bradley, G., Rosen, K., León, C., Romo, M. y López, S. (2006). Cálculo aplicado: Para administración, economía, contaduría y ciencias sociales. México: McGraw-Hill.

Levine, D., Berenson, M. y Krehbiel, T. (2014). Estadística para administración. Nauclapan de Juárez, México: Pearson.

Llamazares, O. (2011). Cómo negociar con éxito en 50 países. Madrid: Global Marketing Strategies.

López, A. (2017). El poder de las relaciones digitales en el mundo actual ( ${ }^{a}$ ed.). Lima: Mesa redonda S.A.C.

Malhotra, N. y Pineda, A. (2016). Investigación de mercados: Conceptos esenciales. México, D.F: Pearson.

Oliveros, M., Esparragoza, D., Sotomayor, Z., Carrillo, A., Camargo, J. y Stein, H. (2016). Gerencia de marketing. Bogotá: La imprenta editores.

Osterwalder, A. y Pigneur, Y. (2018). Generación de modelos de negocio: Un manual para visionarios, revolucionarios y retadores. Barcelona: Deusto.

Vázquez, R., Trespalacios, J., Álvarez, B., Bello, L., González, C., Herrero, A., Del Río, A.; Rodríguez, I. y Suárez, A. (2006). Estrategia de distribución comercial ( $1^{a}$ ed.). Edición: Paraninfo.

Villanueva, J. y De Toro, J. (2017). Marketing estratégico. España: EUNSA. 


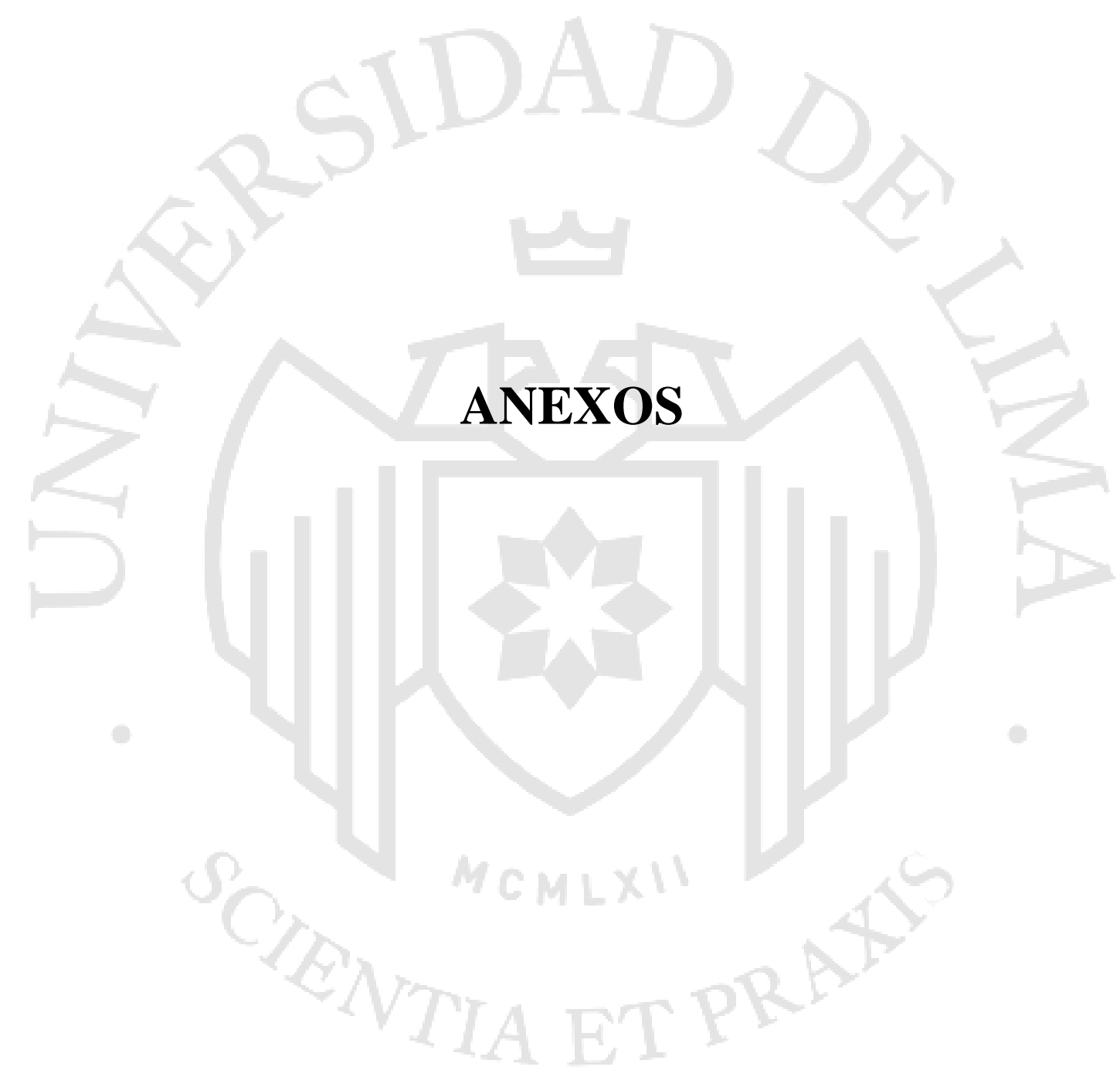




\section{Anexo 1: Modelo Canvas}

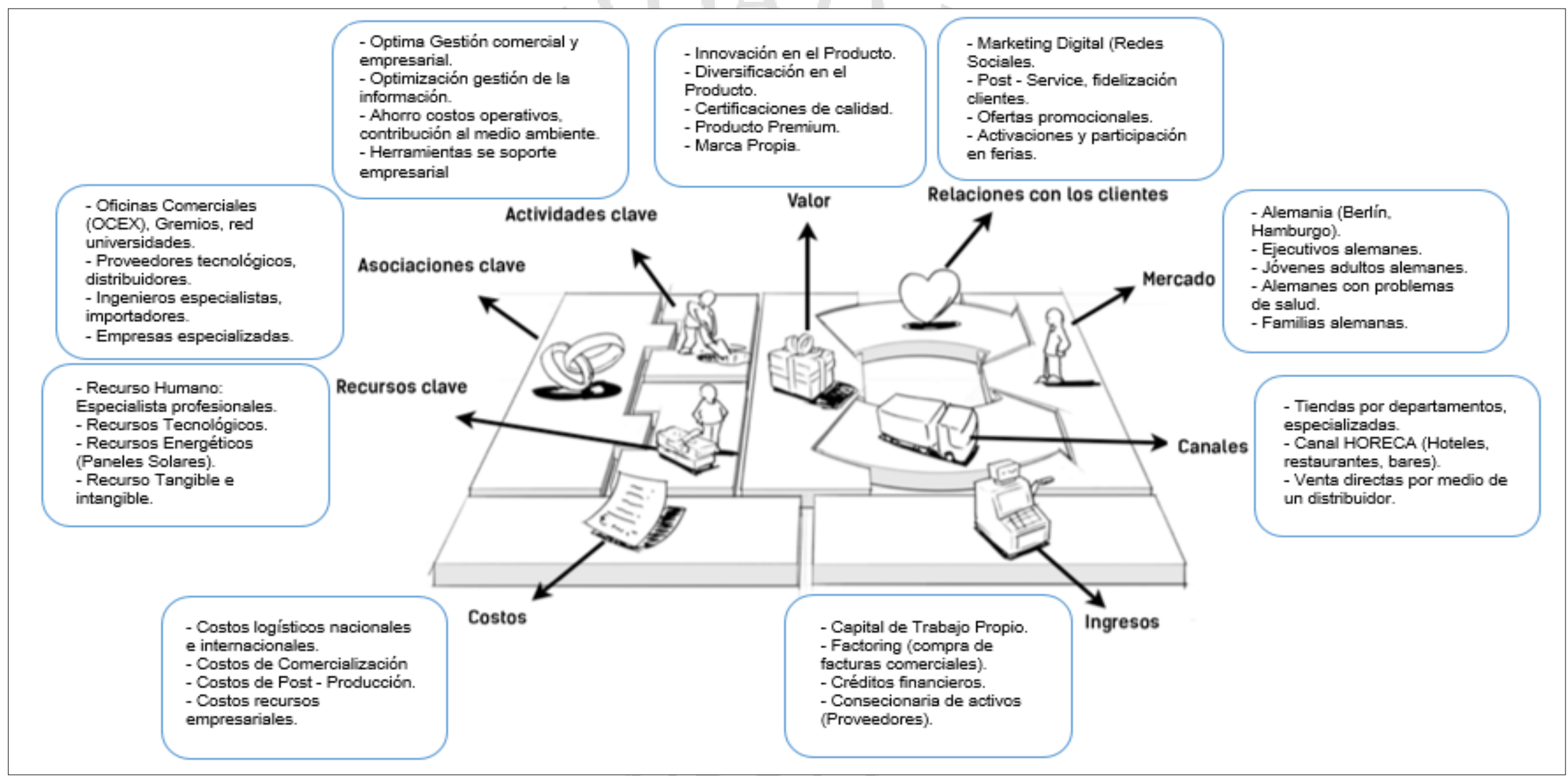

Elaboración propia 
Anexo 2: Matriz de Monitoreo de Actividades

\begin{tabular}{|c|c|c|c|c|c|}
\hline FACTOR & MEDIO/ACTIVIDAD & INDICADOR & $\begin{array}{l}\text { UNIDAD DE } \\
\text { MEDIDA }\end{array}$ & $\begin{array}{l}\text { MEDIO DE } \\
\text { VERIFICACIÓN }\end{array}$ & BENEFICIOS \\
\hline $\begin{array}{l}\text { Posicionar a la empresa } \\
\text { con una marca propia en } \\
\text { el mercado internacional }\end{array}$ & $\begin{array}{l}\text { - Definición e implementación de estrategia } \\
\text { de posicionamiento y diferenciación de } \\
\text { producto. }\end{array}$ & $\begin{array}{l}\text { \% de incremento de participación de la } \\
\text { empresa en el mercado Internacional } \\
2018 \text { - } 2019 \text {. }\end{array}$ & \begin{tabular}{|l|} 
Variación \\
Porcentual
\end{tabular} & $\begin{array}{l}\text { Estados Financieros } \\
2019\end{array}$ & $\begin{array}{l}\text {-Mayor participación en el mercado destino. } \\
\text { - Reconocimiento de nuestra marca a nivel mundial. } \\
\text { - Formar alianzas estraegicas a nivel mundial. } \\
\text { - Estrategias de branding y Publicidad Online. }\end{array}$ \\
\hline $\begin{array}{l}\text { Incrementar la Ventas } \\
\text { Internacionales }\end{array}$ & \begin{tabular}{|l|} 
- Elaboración e implementación del Plan de \\
Negocios de la empresa. \\
- Buscar nuevas oportunidades de mercado \\
destino para nuestro producto.
\end{tabular} & $\begin{array}{l}\text { - \# Planes de negocio desarrollados e } \\
\text { implementados } 2018 . \\
\text { - \# Nuevos mercados identificados } \\
\text { para la internacionalización. }\end{array}$ & $\begin{array}{l}\text { Número de } \\
\text { documentación } \\
\text { elaborada y } \\
\text { gestionada }\end{array}$ & $\begin{array}{l}\text { Documentación físico y } \\
\text { virtual }\end{array}$ & $\begin{array}{l}\text {-Mayor rentabilidad } \\
\text { - Crecimiento en el vaor de la empresa. } \\
\text { - Más oportunidades laborales para nuestros } \\
\text { stakeholders. }\end{array}$ \\
\hline $\begin{array}{l}\text { Mejorar la gestión integral } \\
\text { de la compañia }\end{array}$ & $\begin{array}{l}\text { - Implementación de un sistema de gestión } \\
\text { integrado (Software). }\end{array}$ & $\begin{array}{l}\text { - \# Software implementados en la } \\
\text { empresa en el año. } \\
\text { - Tiempo y orden por proceso. }\end{array}$ & $\begin{array}{l}\text { Los resultados } \\
\text { esperados por el } \\
\text { Software }\end{array}$ & $\begin{array}{l}\text { Sistema implementado } \\
\text { para gestiones de la } \\
\text { empresa }\end{array}$ & $\begin{array}{l}\text {-Mejor administración de la información. } \\
\text { - Tener la capacidad de tener información histórica, de } \\
\text { almacenarla y generar nueva información que permita } \\
\text { tomar buenas decisiones. }\end{array}$ \\
\hline $\begin{array}{l}\text { Desarrollando y } \\
\text { diversificando nuevos } \\
\text { productos }\end{array}$ & $\begin{array}{l}\text { - Benchmarking de producto y mercado. } \\
\text { - Brainstorming de Ideas, Design Thinking } \\
\text { Innovation. }\end{array}$ & $\begin{array}{l}\text { - \# Producto desarrollado. } \\
\text { - \# Innovaciones por producto. }\end{array}$ & $\begin{array}{l}\text { Portafolio de } \\
\text { productos } \\
\text { implementados }\end{array}$ & $\begin{array}{l}\text { Ficha y expediente } \\
\text { técnico }\end{array}$ & $\begin{array}{l}\text { - Disponer de una amplia cartera de productos. } \\
\text { - Innovación en nuestros productos. } \\
\text { - Competitividad en el mercado internacional. }\end{array}$ \\
\hline $\begin{array}{l}\text { Mejorar la eficiencia en la } \\
\text { Post producción }\end{array}$ & $\begin{array}{l}\text { - Obtención de certificación de calidad } \\
\text { (BPM, HACCP, ISO 9001). } \\
\text { - Obtención de registros y licencias. } \\
\text { - Capacitación al personal de producción. }\end{array}$ & $\begin{array}{l}\text { - \# Sistemas de calidad certificados. } \\
\text { - \% Productos con registros y } \\
\text { certificados. } \\
\text { - \# Empleados que mejoran sus } \\
\text { competencias. }\end{array}$ & \begin{tabular}{|l|} 
Optimización y \\
automización en los \\
procesos de post \\
producción
\end{tabular} & $\begin{array}{l}\text { - Certificados Obtenidos. } \\
\text { - Registros Obtenidos. } \\
\text { - Constancia de } \\
\text { capacitación entregadas. }\end{array}$ & $\begin{array}{l}\text { - Mejora de productividad. } \\
\text { - Optimización de costos de producción. } \\
\text { - Mejora del estudio del trabajo de nuestro equipo de } \\
\text { trabajo. }\end{array}$ \\
\hline $\begin{array}{l}\text { Implementar un programa } \\
\text { de Sostenibilidad Social, } \\
\text { Económico y Ambiental }\end{array}$ & $\begin{array}{l}\text { - Implementación de una iniciativa de } \\
\text { desarrollo de proveedores dentro del área } \\
\text { de influenza. }\end{array}$ & $\begin{array}{l}\text { - \# Proveedores beneficiados con la } \\
\text { iniciativa. }\end{array}$ & $\begin{array}{l}\text { Documento de } \\
\text { iniciativa }\end{array}$ & $\begin{array}{l}\text { - Registro de compras } \\
\text { realizadas. } \\
\text { - Registro de } \\
\text { capacitaciones. }\end{array}$ & $\begin{array}{l}\text { - Contribuir con el bienestar social del pais. } \\
\text { - Fidelización de proveedores. } \\
\text { - Generación de una red de contactos (Stakeholders). }\end{array}$ \\
\hline
\end{tabular}

Elaboración propia 


\section{Anexo 3: Plan de Responsabilidad Social}

El proyecto plantea la implementación de un plan de mejora en la calidad de los productos y/o servicios para cinco (05) empresas proveedores ; para ello se coordinará la definición de los proveedores que serán beneficiados con las actividades

del proyecto. Por consiguiente, se deberá realizar en una primera etapa un "Diagnóstico y la elaboración del Plan de

mejora" y definido las necesidades de mejora de los proveedores en esta primera etapa se procederá a desarrollar la

segunda etapa del proyecto, que consiste en "Implementación del Plan de mejora" para cada uno de los proveedores

participantes en el proyecto.

\begin{tabular}{|l|l}
\hline Entidad Articuladora & VINKA DEL PERÚ SAC \\
\hline Entidad Tractora & VINKA DEL PERÚ SAC \\
\hline
\end{tabular}

\section{Objetivo Central del Proyecto:}

Las empresas rurales o asociaciones regionales consoliden sus brechas productivas de calidad, de gestión y comerciales con la empresa compradora (Tractora), en un marco de negocios inclusivos.

\section{Beneficios Esperados:}

Mejora de la productividad y la calidad de los productos.

Más oportunidades de trabajo, mejora de calidad de vida y una buena remuneración.

Ampliar la visión de negocios y generar una red de contactos empresarial a nivel internacional.

\section{Etapas de Realización:}

1era Etapa: Elaboración del Diagnóstico y un Plan de Mejoras (5 Meses)

2da Etapa: Implementación del Plan de Mejoras. (18 Meses).

Indicadores:

\# Brechas encontradas / \# Brechas Resueltas

Tiempo Estimado Óptimo / Tiempo Estimado Real

Volumen Comprado Proveedores

\# Empleo creado Proveedores 


\section{Anexo 4: Canales de Distribución de Vinos en Alemania}

Channel Distribution for Wine in Germany

Off-trade Volume 2017 and Percentage Point Growth - 2012-2017

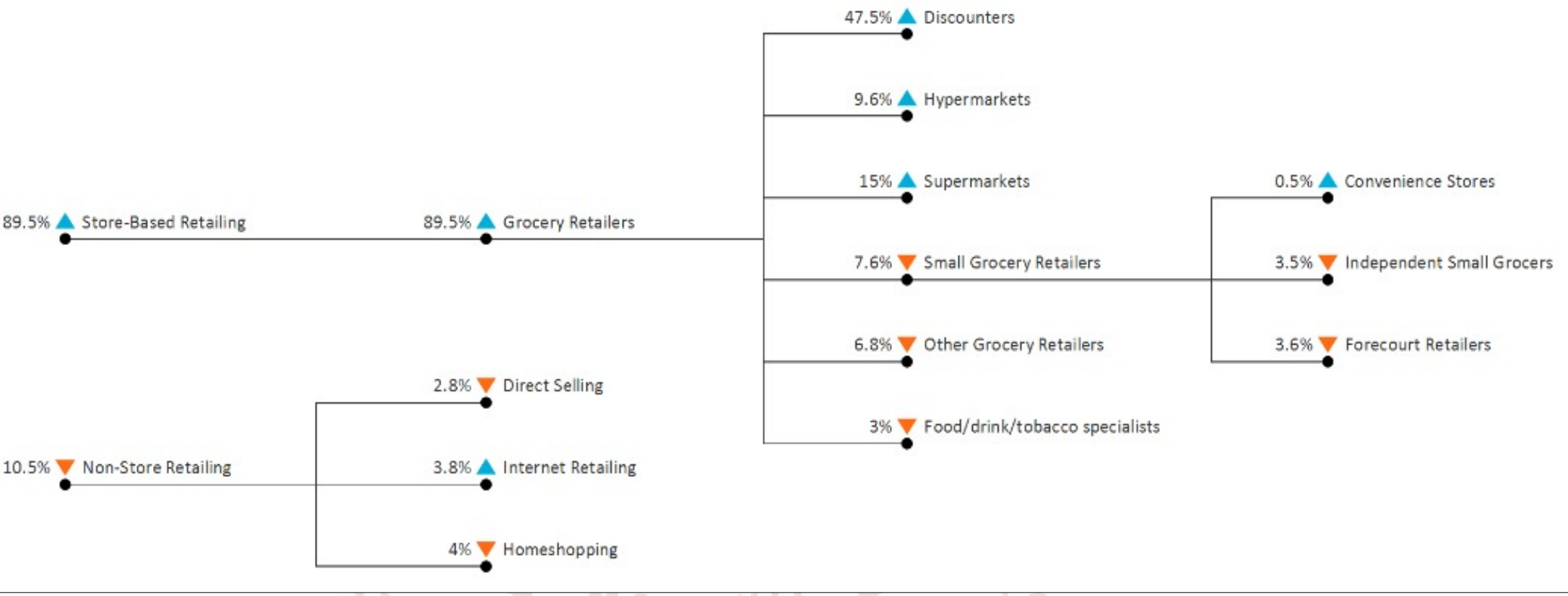

Fuente: Euromonitor (2017) 